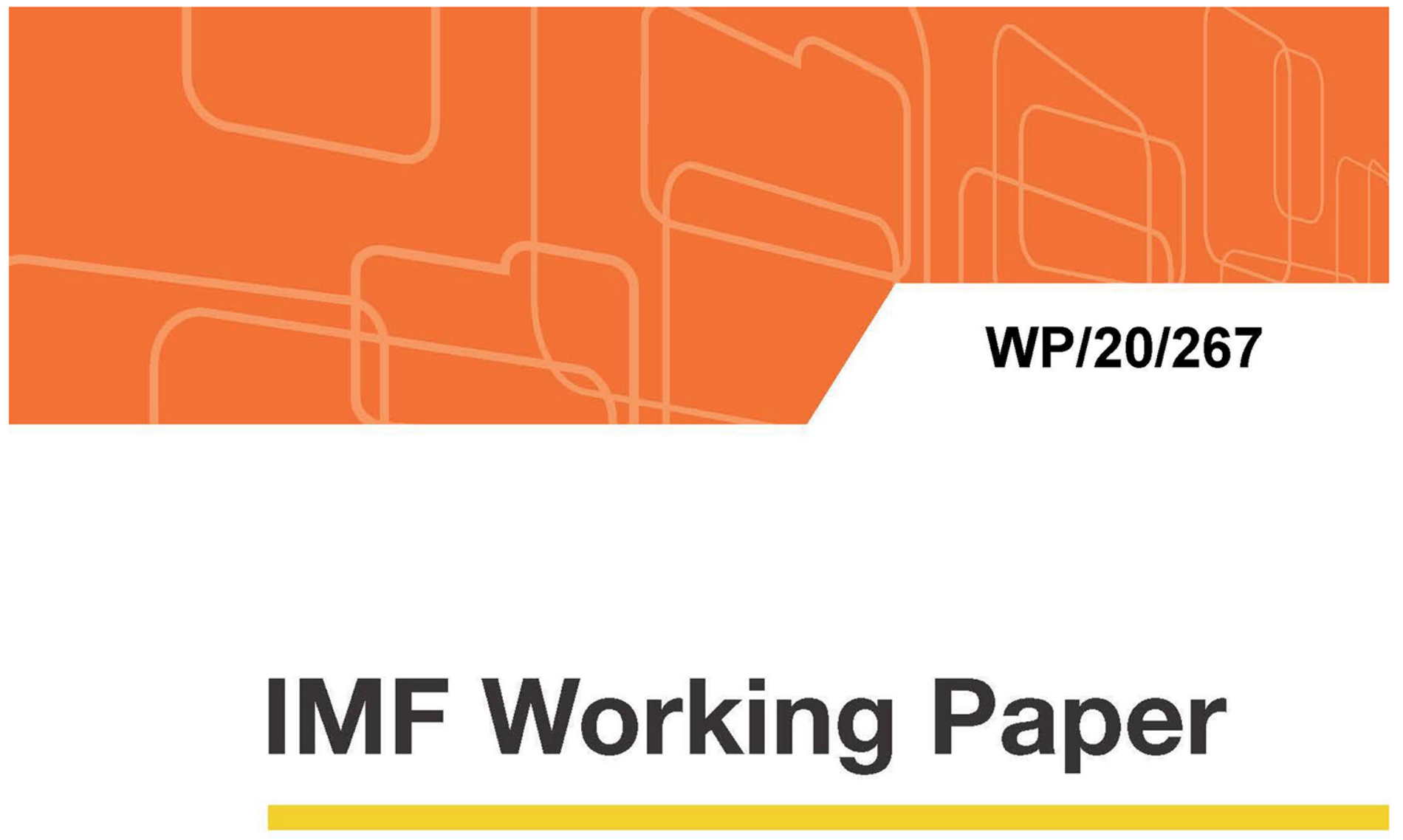

\title{
Crossing the Credit Channel: Credit Spreads and Firm Heterogeneity
}

by Gareth Anderson and Ambrogio Cesa-Bianchi

IMF Working Papers describe research in progress by the author(s) and are published to elicit comments and to encourage debate. The views expressed in IMF Working Papers are those of the author(s) and do not necessarily represent the views of the IMF, its Executive Board, or IMF management.

$$
\text { I N T E R N A T I O N A L M O N E T A R Y F U N D }
$$




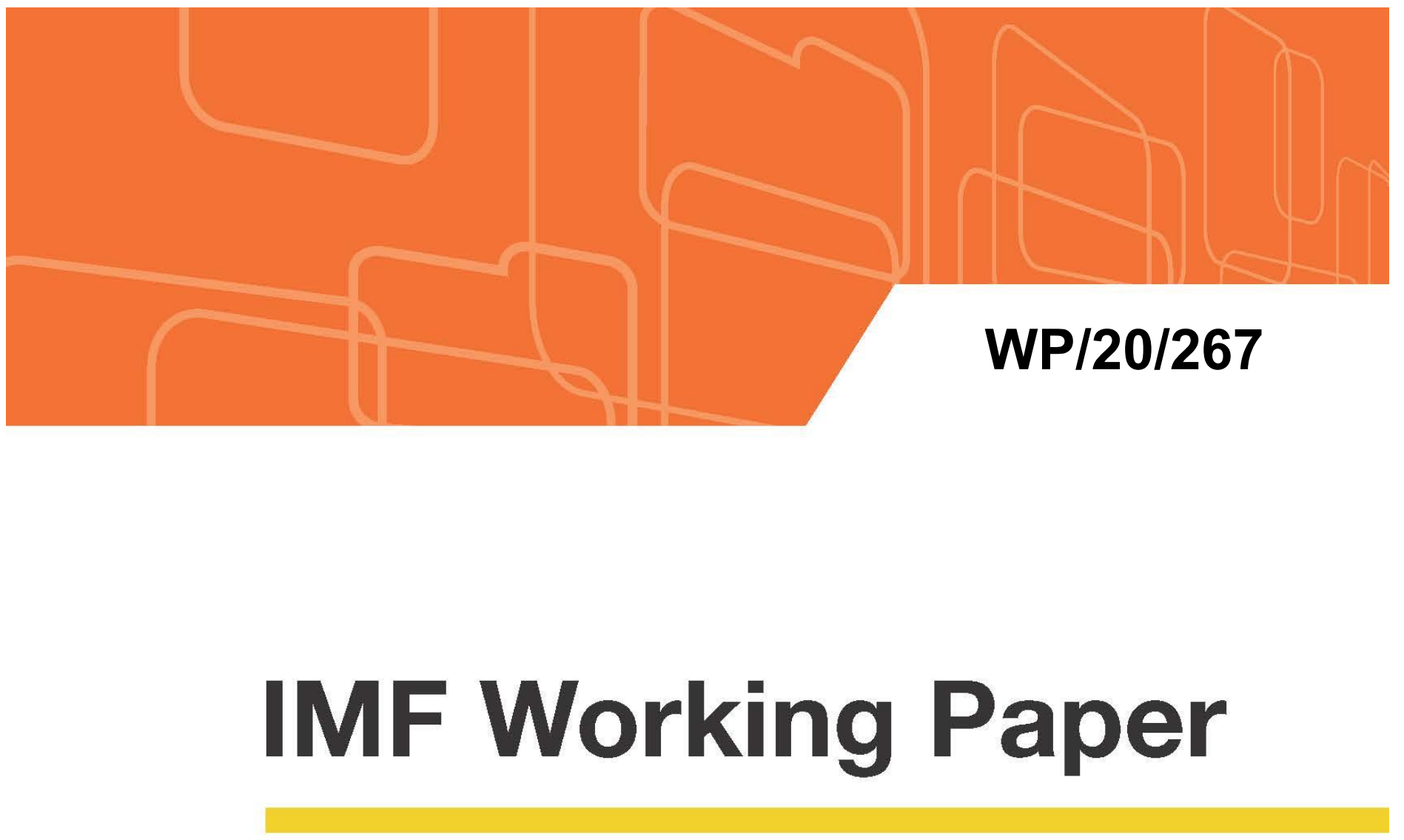

\section{Crossing the Credit Channel: Credit Spreads and Firm Heterogeneity}

by Gareth Anderson and Ambrogio Cesa-Bianchi

IMF Working Papers describe research in progress by the author(s) and are published to elicit comments and to encourage debate. The views expressed in IMF Working Papers are those of the author(s) and do not necessarily represent the views of the IMF, its Executive Board, or IMF management.

$$
\text { I N T ER N A T I O N A L M O N E T A R Y F U N D }
$$




\title{
IMF Working Paper
}

Middle East and Central Asia Department

\section{Crossing the Credit Channel: Credit Spreads and Firm Heterogeneity Prepared by Gareth Anderson and Ambrogio Cesa-Bianchi}

Authorized for distribution by Martin Cerisola

December 2020

\section{IMF Working Papers describe research in progress by the author(s) and are published to elicit comments and to encourage debate. The views expressed in IMF Working Papers are those of the author(s) and do not necessarily represent the views of the IMF, its Executive Board, or IMF management.}

\begin{abstract}
Credit spreads rise after a monetary policy tightening, yet spread reactions are heterogeneous across firms. Exploiting information from a panel of corporate bonds matched with balance sheet data for U.S. non-financial firms, we document that firms with high leverage experience a more pronounced increase in credit spreads than firms with low leverage. A large fraction of this increase is due to a component of credit spreads that is in excess of firms' expected default. Our results suggest that frictions in the financial intermediation sector play a crucial role in shaping the transmission mechanism of monetary policy.
\end{abstract}

JEL Classification Numbers: E44, E50

Keywords: monetary policy, heterogeneity, credit spreads, excess bond premium, credit channel, financial accelerator, event study

Authors' E-Mail Addresses: ganderson2@,imf.org; ambrogio.cesa-bianchi@bankofengland.co.uk 


\title{
Crossing the Credit Channel: Credit Spreads and Firm Heterogeneity ${ }^{\text {放 }}$
}

\author{
Gareth Anderson ${ }^{\dagger} \quad$ Ambrogio Cesa-Bianchi ${ }^{\ddagger}$
}

\begin{abstract}
Credit spreads rise after a monetary policy tightening, yet spread reactions are heterogeneous across firms. Exploiting information from a panel of corporate bonds matched with balance sheet data for US non-financial firms, we document that firms with high leverage experience a more pronounced increase in credit spreads than firms with low leverage. A large fraction of this increase is due to a component of credit spreads that is in excess of firms' expected default. Our results suggest that frictions in the financial intermediation sector play a crucial role in shaping the transmission mechanism of monetary policy.
\end{abstract}

Keywords: Monetary Policy, Heterogeneity, Credit Spreads, Excess Bond Premium, Credit Channel, Financial Accelerator, Event Study.

JEL Codes: E44, E50.

\footnotetext{
Treviously circulated as "Credit Spreads, Firm Heterogeneity, and Monetary Policy". We would like to thank for comments Andrea Ajello, Saleem Bahaj, Juliane Begenau (discussant), Giancarlo Corsetti, Andrea Ferrero, Nicola Gennaioli, Jordi Gali, Alessandro Gobbi (discussant), Rodrigo Guimaraes, Refet Gürkaynak, Priit Jeenas, Şebnem Kalemli-Özcan, Yueran Ma, Jochen Mankart, Paul Myerscough, Caterina Mendicino, Benjamin Moll, Tommaso Monacelli, Pablo Ottonello, Evi Pappa, Andrea Prestipino, Giorgio Primiceri, Omar Rachedi (discussant), Morten Ravn, Ricardo Reis, Hélène Rey, Dmitry Sergeyev, Paolo Surico, Andrea Tambalotti, Jan Vlieghe and seminar participants at Oxford University, LSE, Warwick University, Cass Business School, Nottingham University, Bank of England, Bundesbank, Lancaster University, and conference participants at the 13th Macro Finance Workshop (Northwestern), Oxford-FRBNY-BoE Conference on Monetary Economics (Oxford), ECB workshop on 'Monetary Policy, Macroprudential Policy and Financial Stability (ECB)', 2019 CFM London Macro Workshop (NIESR), 2018 BGSE Summer Forum (Asset Prices, Finance and Macro), Pavia Workshop on Macro with Heterogeneous Agents (Pavia), 6th Workshop in Macro Banking and Finance (Alghero), Conference on 'Advances in Applied Macro-Finance' (Bilgi), CEBRA 2020 Annual Meeting. The views expressed in this paper are those of the author(s) and do not necessarily represent the views of the Bank of England nor the views of the IMF, its Executive Board, or IMF management.

${ }^{\dagger} \mathrm{IMF}$ and University of Oxford. Email: ganderson2@imf .org.

${ }_{\ddagger}^{\ddagger}$ Bank of England, CEPR, and CFM. Email: ambrogio.cesa-bianchi@bankofengland.co.uk.
} 


\section{Introduction}

What do firm-level funding costs and firms' balance sheets tell us about the transmission mechanism of monetary policy? Combining a bond-level data set on credit spreads with firmlevel balance sheet information, we document that monetary policy has heterogeneous effects on firms, depending on their level of leverage. A surprise monetary policy tightening leads to an increase in credit spreads that is larger for firms with high leverage. A decomposition of credit spreads into an expected default component and a residual risk premium component shows that the latter accounts for most of the relative increase in spreads for highly leveraged firms.

To interpret our empirical results, we develop a theoretical framework that combines financial frictions on both firms (the borrowers) and financial intermediaries (the lenders). Borrowers are subject to asymmetric information and monitoring costs, as in the financial accelerator framework of Bernanke et al. (1999). Lenders are subject to a moral hazard problem as in Gertler and Karadi (2011) and Gertler and Kiyotaki (2010). In our framework, monetary policy affects credit spreads via its effect on the financial position of both firms and intermediaries. On the one hand, a monetary policy tightening leads to a reduction in a firm's net worth, which increases its default probability and, therefore, the credit spread charged on its external borrowing. On the other hand, a monetary policy tightening also leads to a reduction in financial intermediaries' net worth, which increases the credit spread on their lending, independently of changes in firms' creditworthiness.

The theoretical analysis highlights a simple equivalence result. A tightening in borrowers' balance sheet constraints has the same qualitative effect on firm investment and credit spreads as a tightening in lenders' balance sheet constraints. Whether it is transmitted via a reduction in the net worth of firms or intermediaries, monetary policy leads to an observationally equivalent contraction in the capital supply curve. Because of this equivalence, the interpretation of empirical results based on the response of firm-level outcomes to monetary policy changes is plagued by a complicated identification problem. Crucially, our empirical decomposition of credit spreads into expected default and risk premium components enables us to make some progress in highlighting the relative importance of these two mechanisms. In the data, high-leverage firms are more responsive to monetary policy changes even when keeping their 'distance to default' constant, showing that our findings are not solely driven by firms' credit risk. Our results therefore suggest that frictions in the financial intermediation sector can play a crucial role in shaping the transmission mechanism of monetary policy. 
The empirical approach we employ is inspired by recent studies that investigate the role of financial frictions in the transmission of monetary policy to firm investment. The vast majority of these studies estimate the response of firm-level quantities, such as investment or employment, to high-frequency surprises in federal funds futures around policy announcements by the Federal Reserve's Federal Open Market Committee (FOMC) (Gürkaynak et al., 2005). ${ }^{1}$ This paper's main innovation is to focus on credit spreads as an outcome variable. Credit spreads can be precisely measured at a much higher frequency than firm-level quantities, which are (at best) available at a quarterly frequency. As FOMC decisions happen at irregular times during the year, any empirical analysis that focuses on quantities requires aggregating interest rate surprises over quarters or years - therefore potentially giving rise to an aggregation bias. ${ }^{2}$ Moreover, the forward-looking nature of credit spreads makes them respond to news more quickly than quantities. The high-frequency nature of our analysis delivers a cleaner identification of the impact of monetary policy on firm-level outcomes, as well as a more precise estimation of its effects. Despite all these advantages, credit spreads have been widely overlooked in the literature.

In our empirical analysis, we proceed as follows. First, we construct a new bond-level data set of corporate bond spreads. Credit spreads are available at a daily frequency and are measured directly from the prices of senior unsecured corporate debt traded in the secondary market. Second, we construct a measure of exogenous monetary policy surprises exploiting high-frequency variation in the price of federal funds futures contracts around policy announcements, as in Jarociński and Karadi (2020). Third, we estimate the heterogeneous effect of monetary policy on credit spreads in a 1-week window around FOMC announcements using a panel event-study regression approach. For comparison with the existing literature we complement our event study analysis by also looking at the response of firm-level quantities (debt and investment) to monetary policy at a business cycle frequency, using a panel local projections approach. We finally employ Gilchrist and Zakrajsek (2012)'s approach to decompose the overall effect of monetary policy on credit spreads into a component capturing the transmission via firms' expected default and a residual component capturing the transmission via financial intermediaries' risk bearing capacity (the Excess Bond Premium in Gilchrist and Zakrajsek (2012)'s parlance).

\footnotetext{
${ }^{1}$ See, for example, Ottonello and Winberry (2020) and Cloyne et al. (2018)

${ }^{2}$ Recent studies have shown that this aggregation is far from innocuous: commonly used methods of aggregating shocks to match the frequency at which the variable of interest is observed can induce serial correlation in the series of aggregated shocks (Ramey, 2016) and yield inconsistent estimates of the aggregated impulse responses (Chudik and Georgiadis, 2019, Gazzani and Vicondoa, 2019).
} 
The analysis delivers the following empirical results. A monetary policy surprise that raises the policy rate by 25 basis points leads to an average increase in credit spreads of 28 basis points. This average effect is heterogeneous across firms and varies considerably with firm leverage. For example, the response of credit spreads for firms that lie below the median of the leverage distribution is around 21 basis points and is much smaller than the response of credit spreads for firms above the median, which is around 32 basis points. Our baseline results hold when controlling for other firm characteristics that are typically used to proxy for financial constraints, such as age, size, credit ratings, distance to default, and liquid assets. They are robust to alternative ways of computing the monetary policy surprises. And they are consistent with the findings from panel local projections on firm-level quantities at quarterly frequency, showing that a surprise monetary policy tightening leads to a persistent contraction in debt and investment that is larger for firms with high leverage.

Finally, armed with Gilchrist and Zakrajsek (2012)'s decomposition of credit spreads, we ask whether monetary policy transmits to credit costs via a change in a firm's default risk, a change in the EBP, or both. This is informative because the excess bond premium, which is purged of firm's default premia and orthogonal to firms' fundamentals, can be interpreted as a measure of firms' borrowing costs that is due to the risk bearing capacity of financial intermediaries. The results show that virtually all of the conditional response of credit spreads to monetary policy is accounted for by the EBP.

The rest of the paper is structured as follows: the remainder of this Section provides a brief review of the relevant literature; Section 2 describes the data used in the empirical analysis; Section 3 presents the main empirical results obtained from the high-frequency panel regressions, an extensive set of robustness tests, and the results obtained from the local projections at quarterly frequency; Section 4 provides an interpretation of the empirical results through the lens of our theoretical model; Section 5 provides further results using the decomposition of credit spreads into expected default and Excess Bond Premium components; Section 6 concludes. In the Appendix we describe the simple theoretical framework (Appendix A) that we use to interpret our results, the data sources (Appendix B), the construction of the monetary policy surprises (Appendix C), and an extensive set of additional results on the unconditional properties of the data (Appendix D), the calculation of the distance to default measure and the EBP (Appendix E), the high-frequency panel regressions (Appendix F), and the lower frequency local projections (Appendix G). 
Literature. Not surprisingly, there is a voluminous literature on the role of financial frictions for the transmission of monetary policy. ${ }^{3}$ As a review of the older literature is beyond the scope of this paper, we focus here on a few key recent studies.

The vast majority of recent papers focus on firm-level quantities at quarterly or annual frequency and have reached contrasting conclusions. Ottonello and Winberry (2020) use US firm-level data on fixed capital investment from Compustat and find that firms with high leverage and a low distance to default respond to a monetary policy tightening by reducing investment less than low-leverage firms. ${ }^{4}$ Using a representative sample of US manufacturing firms, Crouzet and Mehrotra (2020) show that small firms' higher volatility over the business cycle does not seem to be explained by financial factors, such as leverage or liquid asset holdings.

In contrast, with data from Compustat for US firms, Jeenas (2018) finds that firms with higher leverage and lower liquid asset holdings at the time of a contractionary monetary surprise tend to experience lower fixed capital expenditure, inventories and sales growth. Cloyne et al. (2018) use firm-level investment data - for both US firms (from Compustat) and UK firms (from Thomson Reuters' WorldScope) - and find that younger firms paying no dividends exhibit the largest and most significant change in capital expenditure in response to monetary policy surprises. Bahaj et al. (2018) use a detailed near-representative data set for UK firms and show that a firm's number of employees responds more strongly to monetary policy among young and highly leveraged firms. ${ }^{5}$ Using a large firm-bank level data set for European countries, Kalemli-Ozcan et al. (2018) show that firms with higher leverage reduce investment more and this effect strengthens when these firms are linked to weak banks. All these papers interpret their empirical findings as supportive of an important role played by financial frictions.

As in this paper, a smaller set of recent papers focus on firm-level outcomes that are observable at high frequency, namely share prices. Ippolito et al. (2018) show that the stock prices of firms with floating rate debt respond to monetary policy more when these firms are un-hedged against interest rate risk. Ozdagli (2018) shows that the stock prices of firms subject to greater information frictions have a weaker reaction to monetary policy.

\footnotetext{
${ }^{3}$ See, among many others, Bernanke and Blinder (1992), Bernanke and Gertler (1989), Bernanke and Gertler (1995), Kashyap et al. (1994), Gertler and Gilchrist (1994), Kashyap and Stein (1995), Kashyap and Stein (2000).

${ }^{4}$ Note that they consider a monetary policy easing throughout their paper, but since the model they use is linear, the sign of the estimates can be flipped to consider a monetary policy tightening, as in this paper.

${ }^{5}$ In contrast to the above-mentioned papers, Bahaj et al. (2018) focus on a specific type of balance sheet effect, namely the role of changes in housing values of firms' directors.
} 
Gurkaynak et al. (2019) show that the response of firm-level stock prices to monetary policy depends on the firm cash flow exposure. As we do, these three papers find an important role for financial frictions in explaining the firm-level response to monetary policy. Differently, Lakdawala and Moreland (2019) find that equity prices of high-leverage firms were less responsive to monetary policy shocks before the global financial crisis, but this result has reversed in the most recent sample. ${ }^{6}$

\section{Data}

We compile our bond-level data set by combining the following sources: intra-day surprises in interest rates and equity prices around FOMC announcements; daily bond-level information from ICE Bank of America Merrill Lynch (ICE BofAML) and Thomson Reuters Datastream; daily equity prices from the Center for Research in Security Prices (CRSP); and quarterly firm-level balance sheet data from Compustat. Below, we briefly describe each data source. Additional details on the sources and data treatment are provided in Appendix B.

Our final data set merges all bond- and firm-level information into an 'event study' data set around FOMC announcement days. Specifically, we collect all available bond data on a monetary policy announcement day $(t)$, and keep all bonds for which we can match equity price and balance sheet data. Our final data set covers 156 FOMC announcements over the 1999-2017 period, has information on 9, 413 bonds and 975 firms, and a total of 285,794 observations.

\subsection{Identification of Monetary Policy Surprises}

A key challenge in measuring changes in monetary policy is that most of the variation in the federal funds rate is driven by the Federal Reserve's endogenous response to aggregate economic conditions. To address this issue, the common practice in the recent literature is to use the change in the federal funds rate implied from a federal funds futures contract, computed using a narrow 30-minute window of time around a monetary policy announcement by the FOMC (see Kuttner, 2001, Gürkaynak et al., 2005). As futures contracts provide a measure of market participants' expectation for the evolution of interest rates, these 30-

\footnotetext{
${ }^{6}$ Our paper is also related to a recent literature arguing that firms' borrowing capacity is tightly linked to the firms' earnings flows, as current earnings are subject to scrutiny by lenders. Drechsel (2018) and Lian and Ma (2019) emphasize the role of debt-to-earnings or debt-to-EBITDA covenants, while Greenwald (2019) focuses on one additional property of debt covenants, namely interest coverage covenants.
} 
minute surprises can be thought of as a noisy proxy for an exogenous monetary policy shock. The identifying assumption is that, given the short time horizon over which they are measured, the interest rate surprises cannot be 'contaminated' by other non-monetary news.

But it is still possible that the unexpected component of policy decisions (as measured by the interest rate surprises) contains news about the determinants of monetary policy, therefore introducing a confounding factor. When information frictions between the central bank and financial market participants are present, interest rate surprises can also capture (i) a difference in expectations about the state of the economy (e.g. the size of the output gap) or (ii) a difference in the actual central bank reaction function relative to the expectation of market participants. ${ }^{7}$ To address this issue, in this paper we follow the methodology developed by Jarociński and Karadi (2020) to decompose monetary policy news from other contemporaneous non-monetary news embedded in the interest rate surprises.

\section{Figure 1 High Frequency Interest Rate Surprises Decomposition: MONETARY vs. NON-MONETARY SURPRISES}

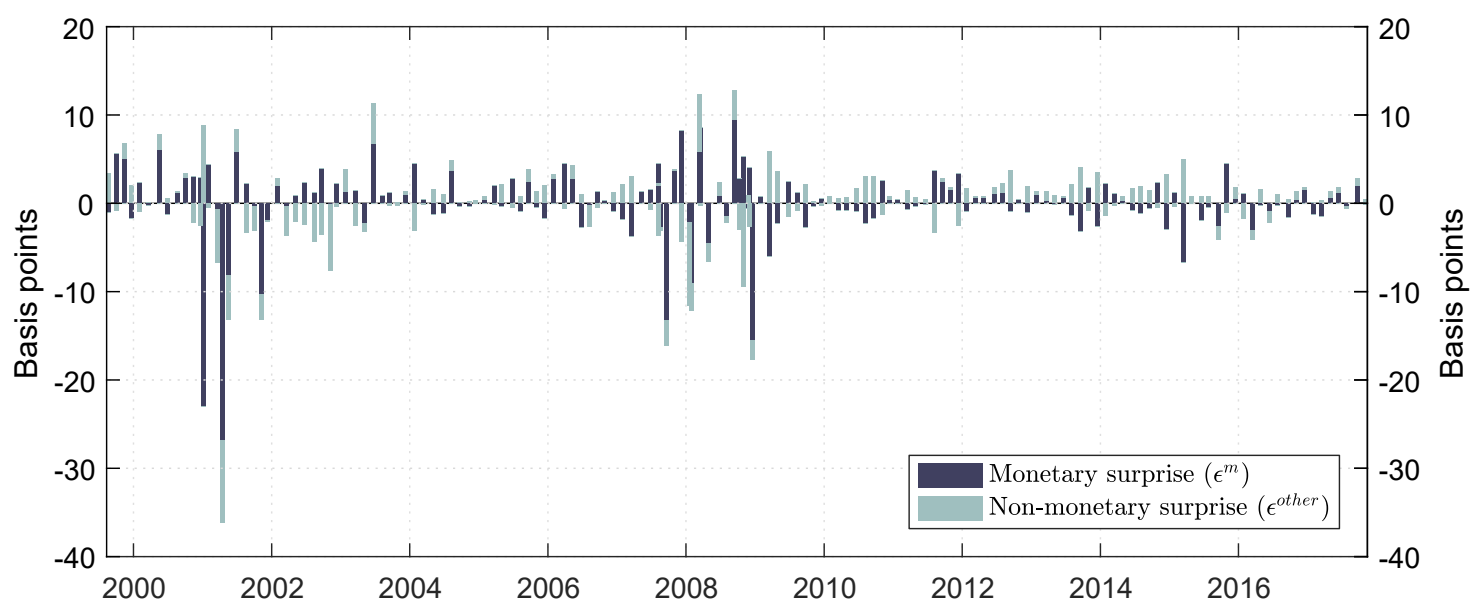

Note. This figure plots the monetary $\left(\epsilon^{m}\right.$, dark bars) and non-monetary ( $\epsilon^{\text {other }}$, light bars) components that drive the raw interest rate surprise $s_{t}^{F F 4}$. The decomposition is obtained with the methodology of Jarociński and Karadi (2020), using data on 156 FOMC announcements between August 1999 and November 2017.

The decomposition (reported in Figure 1) is achieved by a simple rotation of the co-

\footnotetext{
${ }^{7}$ See Melosi (2017) and Nakamura and Steinsson (2018) for examples where central bank announcements can simultaneously convey information about monetary policy and the central bank's assessment of the economic outlook. Recent studies have shown that such a 'Fed information component' can be sizable in highfrequency market-based surprises around policy announcements by the Federal Reserve. See Barakchian and Crowe (2013), Ramey (2016), Miranda-Agrippino and Ricco (2020), Jarociński and Karadi (2020), Lunsford (2018). Bauer and Swanson (2020) argue that the empirical evidence supporting this channel is not robust, and favour an alternative interpretation where market participants learn about the central bank's reaction function.
} 
variance matrix of high-frequency movements in interest rates and stock market prices in a narrow window around the policy announcement. The identifying restrictions are simple and intuitive: shocks that lead to a negative comovement of interest rates and equity prices are interpreted as driven by monetary news, while shocks that lead to a positive comovement of interest rates and equity prices are interpreted as driven by non-monetary news. ${ }^{8}$ As in Jarociński and Karadi (2020), we perform the decomposition using 30-minute surprises in the S\&P 500 stock market index $\left(s_{t}^{e q}\right)$ and the 3-month ahead federal funds futures (FF4) contract $\left(s_{t}^{F F 4}\right)$, from which we obtain the orthogonal monetary $\left(\epsilon^{m}\right)$ and non-monetary $\left(\epsilon^{\text {other }}\right)$ surprises plotted in Figure 1. In our sample, the monetary surprise explains 75 percent of the total variance of $s_{t}^{F F 4}$, while the remaining 25 percent is explained by the non-monetary surprise.

\subsection{Bond-level Credit Spreads}

We consider credit spreads constructed from daily data on the prices of senior unsecured corporate debt traded in the secondary market over the 1999-2017 period, issued by 975 US listed non-financial corporations. We collect the data from ICE Bank of America Merrill Lynch (ICE BofAML) Global Index System. Specifically we use the constituents of the Global Corporate Index (GOBC) and the Global High Yield Index (HW00). Using bond identification numbers (the ISIN code), we complement the ICE BofAML data with additional bond level data from Thomson Reuters Datastream, as detailed in the Appendix. ${ }^{9}$

The main variable of interest for our study is the Option Adjusted Spread (OAS), which we denote by $c s_{t}$. The OAS is defined as the number of basis points that the government spot curve is shifted in order to match the present value of discounted cash flows to the corporate bond's price. The OAS has two key features that make it a useful measure of credit spreads for this study. The first one is a maturity adjustment: spreads are computed relative to a risk-free security that replicates the cash-flows of the corporate debt instrument. As noted by Gilchrist et al. (2009), this adjustment is important, as a maturity mismatch between the risky bond and the risk-less bond can lead to a mechanical bias in the measurement of credit spreads and their response to shocks. The second one is an option adjustment. It is well known that the vast majority of corporate bonds issued by non-financial corporations

\footnotetext{
${ }^{8}$ Alternatively one could project the high frequency interest rate surprises on the difference between private forecast and Federal Reserve Greenbook forecast (Barakchian and Crowe (2013) and Gertler and Karadi (2015)) or Greenbook forecast revisions (Miranda-Agrippino and Ricco (2020)).

${ }^{9}$ This is the same source as the one used in the latest part of the data set of Gilchrist and Zakrajsek (2012). We outline in the appendix a list of differences between our data and theirs.
} 
embed a call option that allows the issuer to redeem the security prior to its maturity. If a bond is callable, policy-induced movements in Treasury yields will, by changing the value of the embedded call option, have an independent effect on the bond price, complicating the interpretation of the response of bond yields and the associated credit spreads (see Duffee, 1998). The OAS adjusts for this by removing the price of embedded options from the overall price of the bond.

Figure 2 The Cross-Section of Corporate Bond Spreads

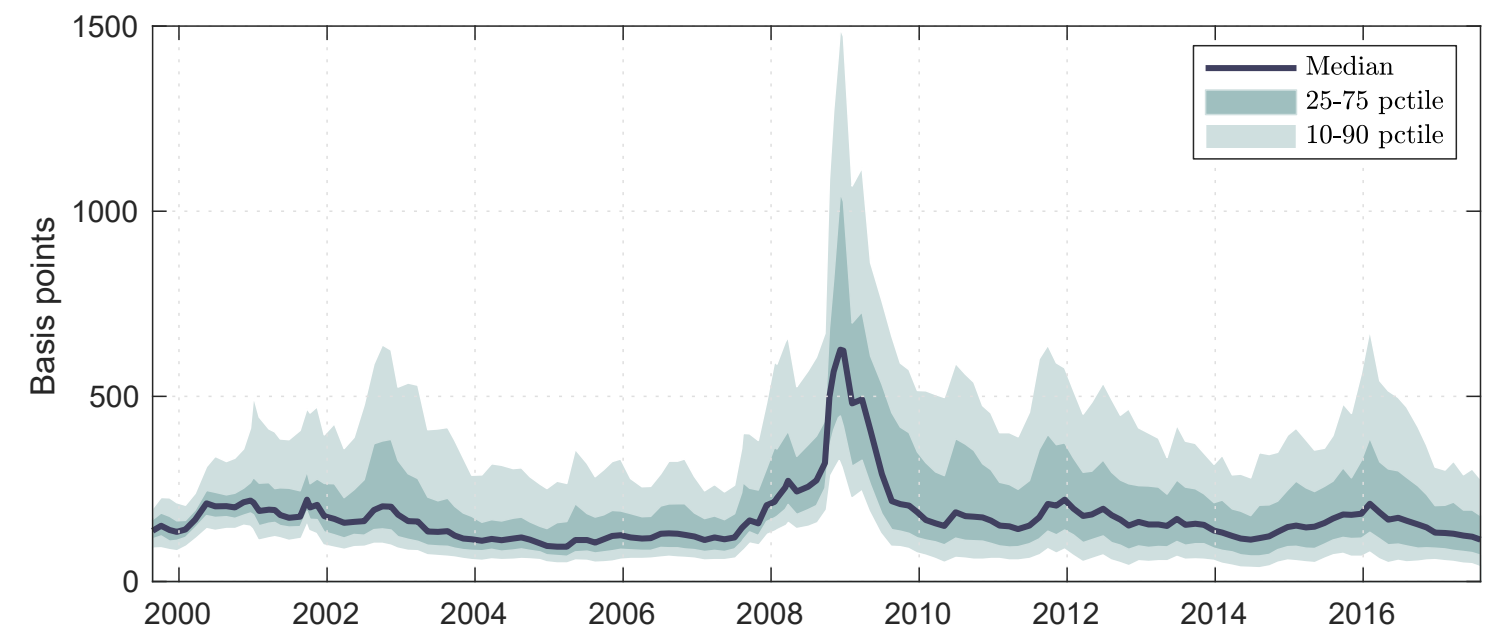

Note. The figure plots the panel of corporate bond spreads in our data set around FOMC dates. The dark solid line displays the cross-sectional median of credit spreads. The dark shaded areas display the 25-75 percentile range. The light shaded areas display the 10-90 percentile range. Sample period: August 1999 to November 2017.

The sample period we focus on runs from August 1999 to November 2017. The data set has information on an extensive share of the full universe of US corporate bonds. For example, the flow of new issuance in our data set in 2014 was 495 billion US dollars, which is about 70 percent of the total market issuance in that year. ${ }^{10}$ We clean the data by following standard data treatment as, for example, in Gilchrist and Zakrajsek (2012). Specifically, we drop bonds with an issued amount lower than 1 Million US dollars, if the maturity is smaller than 1 year or greater than 30 years, and if the spread is above 3,500 basis points. We focus on non-financial, senior, unsecured bonds issued in domestic currency. Figure 2 plots the median OAS in our data set for each date $t$, together with the $25-75$ and $10-90$ percentiles. The data displays significant variation both in the time series and in the crosssectional dimension, which is crucial in identifying the heterogeneous effects of monetary policy on firms' borrowing costs.

\footnotetext{
${ }^{10}$ Data from the Federal Reserve. See item New Security Issues (1.46), U.S. Corporations, non-financial.
} 


\subsection{Additional Firm-level Information}

As the bond-level data described above includes a firm identifier, it can be matched to other firm-level information. For listed firms within our bond panel we match daily equity data (share price and number of shares outstanding) from the Center for Research in Security Prices (CRSP); as well as quarterly balance sheet information (including total assets, total debt, sales, age) from Compustat. ${ }^{11}$

Table 1 Firm-Level Summary Statistics: High vs. Low Leverage

\begin{tabular}{lccccc}
\hline & \multicolumn{5}{c}{ Low Leverage (below median) } \\
\hline & Mean & SD & P25 & Median & P75 \\
\cline { 2 - 6 } Firm Total Assets $(\$ M)$ & 56,427 & 70,788 & 11,208 & 30,277 & 67,243 \\
Firm Age (years) & 38 & 14 & 26 & 42 & 50 \\
Firm Credit Rating & & & BBB2 & BBB1 & A2 \\
Firm Hadlock-Pierce Constraint & -4.2 & 0.4 & -4.5 & -4.4 & -4.0 \\
Bond Spread (basis points) & 177 & 159 & 88 & 136 & 207 \\
Bond Amount Issued (\$M) & 648 & 523 & 300 & 500 & 750 \\
Total Observations & 134,379 & & & & \\
& & & & & \\
& & High Leverage (above & median) & \\
& Mean & SD & P25 & Median & P75 \\
\cline { 2 - 6 } & 36,432 & 57,452 & 7,570 & 19,136 & 44,033 \\
Firm Total Assets (\$M) & 33 & 16 & 18 & 34 & 49 \\
Firm Age (years) & & & BB2 & BBB2 & BBB1 \\
Firm Credit Rating & -4.2 & 0.4 & -4.5 & -4.3 & -3.8 \\
Firm Hadlock-Pierce Constraint & 267 & 249 & 113 & 190 & 336 \\
Bond Spread (basis points) & 619 & 584 & 300 & 500 & 750 \\
Bond Amount Issued (\$M) & 131,176 & & & & \\
Total Observations & & & & & \\
\hline
\end{tabular}

Nоте. Summary statistics for firms below/above the median leverage in the sample. The sample period covers the period between August 1999 and November 2017. The sample consists of 975 firms and 9, 413 bonds. Hadlock-Pierce Constraint refers to the index developed by Hadlock and Pierce (2010).

\footnotetext{
${ }^{11}$ Our sample consists of relatively large firms with publicly-traded debt and equity. As large firms tend to be the most credit-worthy by traditional measures (see Farre-Mensa and Ljungqvist, 2016), previous empirical research in this area typically assumes that such firms have relatively unimpeded access to external financing. What is crucial for the question in this paper, however, is to be able to identify a group of firms that is relatively more constrained than other firms. The large degree of heterogeneity in our sample allows us to do so. If we were to consider smaller, bank dependent firms it is likely that the heterogeneity in financial constraints would be even stronger (Levin et al., 2004).
} 
As noted in Figure 2, the behavior of spreads is very heterogeneous in the cross-section. As a preliminary, unconditional exploration, we check whether this heterogeneity is linked to firms' characteristics and, in particular, to the leverage of the firm. We focus on leverage because it is the key state variable that affects the cost of external finance in models of financial frictions and is the variable which we use to interpret our findings in Appendix A. ${ }^{12}$

Table 1 reports the summary statistics for firms that have leverage below and above the median leverage ratio in our sample, respectively. In our data set, firms with high leverage also have high credit spreads, a fact that is in line with the predictions from our simple theoretical model. ${ }^{13}$ For example, the average credit spread among high-leverage firms is 267 basis points, compared to an average spread of 177 for low-leverage firms. Table 1 also shows that (i) high-leverage firms are smaller (as measured by total assets), younger, and have lower credit ratings; and (ii) that the relation between leverage and credit spreads is non-monotonic, as some firms in the high-leverage group have lower credit spreads than firms in the low-leverage group. For example, the $25^{\text {th }}$ percentile of spreads in the high-leverage group (at 113 basis points) is smaller than the $75^{\text {th }}$ percentile of spreads in the low-leverage group (at 207 basis points). These two facts show that heterogeneity is multi-dimensional and that there are potentially other relevant empirical proxies for financial constraints — such as age, size, liquid assets, etc., which are frequently considered in the literature. While in the following Sections we will focus on leverage as our main proxy for financial constraints, in robustness exercises we will also control for these alternative proxies.

\section{The Heterogeneous Effects of Monetary Policy on Credit Spreads}

In this Section we present our main empirical results. First, we estimate the heterogeneous effects of monetary policy on credit spreads using an event-study panel regression approach. Second, we report an extensive set of robustness tests, where we control for alternative prox-

\footnotetext{
${ }^{12}$ The relationship between leverage and financial constraints is, ex ante, not obvious. A firm that has no access to credit markets will have zero leverage, which implies that leverage can be higher for financially unconstrained firms. This type of relationship is unlikely in our data, which is composed by large firms that have relatively unimpeded access to external financing. As we explain below, the data support this conjecture.

${ }^{13}$ See Figure D.1 in the Appendix for additional evidence on the positive relation between leverage and credit spreads in our data. This positive relationship is consistent with a model where firms with high leverage are more financially constrained. If low-leverage firms were more financially constrained than high-leverage firms, we should observe a negative relation between credit spreads and leverage.
} 
ies of financial constraints and employ alternative measures of monetary surprises. Third, we estimate the dynamic effects of monetary policy on debt and investment, at quarterly frequency, with panel local projections.

\subsection{Event Study Firm-level Panel Regressions}

We consider the following event study specification:

$$
\Delta c s_{i j, t}=\alpha_{i}+\beta \epsilon_{t}^{m}+e_{i j, t}
$$

where $\Delta c s_{i j, t}$ is the change in spread of bond $i$ belonging to firm $j$ around an FOMC announcement day $t$; $\alpha_{i}$ is a bond fixed effect, which should account for unobserved heterogeneity resulting from time-invariant bond characteristics; and $\epsilon_{t}^{m}$ is our measure of monetary policy surprises on FOMC announcement days. The coefficient $\beta$ captures the average effect of monetary policy on firms' credit spreads. The size of the surprise is normalized so that it corresponds to a 25 basis point increase in the 1-year T-bill.

In our baseline specification we consider a 1-week change in the spread, from the day before the announcement to five working days after the announcement. We do this because corporate bond markets might take time to incorporate the effects of the monetary policy surprise. Corporate bonds, and particularly high yield bonds, tend to be less liquid than other assets, such as equities and treasuries. Therefore, a slightly longer window is warranted to allow them to react. This choice is somewhat conservative relative to comparable event studies in the literature. For example, Gertler and Karadi (2015) and Gilchrist et al. (2020) use a two-week window to analyze how corporate bond spreads respond to monetary policy surprises. ${ }^{14}$

Table 2 reports the estimation results. Standard errors, reported in parentheses, are clustered two-way at the firm and time (i.e. event) level. Column (1) of Table 2 shows that a 25 basis point surprise tightening leads to an increase in credit spreads of about 28 basis points. The estimated coefficient, which is significant at the 1 percent significance level, captures the average response of credit spreads in the cross-section of firms to monetary policy. It provides strong support to the notion that the cost of external finance increases by more than the risk free rate in response to a monetary tightening (as shown by Gertler and Karadi (2015) and Caldara and Herbst (2019) in VAR analysis). Interestingly, we get

\footnotetext{
${ }^{14}$ In contrast, papers focusing on Treasury bonds or equity (for example, Gürkaynak et al. (2005) or Ozdagli (2018)) typically use 1-day or 2-day windows.
} 
Table 2 Heterogeneous Response of Credit Spreads to Monetary Policy

\begin{tabular}{lccc}
\hline Dep. Variable: $\Delta c s_{i j}$ & $(1)$ & $(2)$ & $(3)$ \\
\hline & Baseline & $\begin{array}{c}\text { Low/High } \\
\text { Leverage }\end{array}$ & $\begin{array}{c}\text { Leverage } \\
\text { Interaction }\end{array}$ \\
\hline MP surp. $\left(\epsilon^{m}\right)$ & $27.68^{* *}$ & & $26.84^{* *}$ \\
& $(10.62)$ & & $(10.56)$ \\
MP surp. $\times$ Low Lev. $\left(\epsilon^{m} \times \ell_{j}^{\text {Low }}\right)$ & & $21.15^{* * *}$ & \\
& & $(7.35)$ & \\
MP surp. $\times$ High Lev. $\left(\epsilon^{m} \times \ell_{j}^{\text {High }}\right)$ & & $31.54^{* *}$ & $11.09^{*}$ \\
& & $(13.68)$ & $(6.61)$ \\
MP surp. $\times$ Lev. $\left(\epsilon^{m} \times L_{j}\right)$ & & & Yes \\
& Yes & Yes & No \\
Double clustering & No & No & 0.031 \\
Time-sector FE & 0.034 & 0.032 & 279,974 \\
R-squared & 285,794 & 279,974 & \\
Observations & & & \\
\hline
\end{tabular}

Noтe. Results from estimating specifications (1), (2), and (3), where $\epsilon_{t}^{m}$ is the monetary policy surprise; $\Delta c s_{i j, t}$ is the change in spreads of bond $i$ belonging to firm $j$ between the day before the FOMC announcement and five days after the announcement; $\alpha_{i}$ is a bond fixed-effect; $\ell_{j, t-1}^{H i g h}=1$ when the leverage of firm $j$ lies above the median of the leverage distribution (and zero otherwise), while $\ell_{j, t-1}^{L o w}=1$ when the leverage of firm $j$ lies below the median of the leverage distribution (and zero otherwise); $L_{j}$ is the standardized leverage of firm $j$. Standard errors (reported in parentheses) are clustered two-way, at the firm level and time level. Credit spreads are measured in basis points and the size of the surprise is normalized so that it corresponds to a 25 basis point increase in the 1-year T-bill. The asterisks denote statistical significance $(* * *$ for $p<0.01, * *$ for $p<0.05, *$ for $p<0.1$ ).

a similar coefficient when we only exploit the time series variation in our data, by taking a cross-sectional average of credit spreads for each FOMC meeting and estimating a simple time series OLS regression, which provides evidence that our results are not driven by outliers. ${ }^{15}$ Finally, note that the magnitude of the response is in line with the aggregate VAR results in Gertler and Karadi (2015), despite the different sample period and methodology. In contrast to our approach, Gertler and Karadi look at the response of the EBP to the raw monetary surprises $s_{t}^{F F 4}$. They find that the EBP increases by about 13 basis points in response to a monetary surprise that raises the 1-year rate by 25 basis points. We show in Appendix that we get a similar coefficient when estimating (1) using the raw interest rate surprises and decomposing credit spreads into an expected default component and the EBP.

We now explore the cross-sectional dimension of our data set in greater detail. In particu-

\footnotetext{
${ }^{15}$ Results from this simple time series specification are reported in Table F.7 in the Appendix.
} 
lar, we ask: does monetary policy transmit in a heterogeneous fashion across firms, depending on their balance sheet characteristics? We focus on leverage as our main measure of firms' balance sheet positions. We make this choice because in many models of financial frictions (including the one we derive in Appendix A) leverage is tightly linked to the cost of external finance and firms' borrowing/investment decisions. We are not implying that leverage is the only relevant dimension. In robustness analysis, we condition on alternative proxies that are typically used in the literature (e.g. age, size, liquid assets) and we find essentially the same results. ${ }^{16}$

With a slight abuse of notation, we denote by $L_{j, t-1}$ the leverage of firm $j$ in the quarter preceding the monetary policy announcement at time $t$. Leverage is defined as the ratio of total debt over total assets. We start with a simple specification where we split our sample of bond observations into two groups, based on where each firm lies in the leverage distribution. Specifically, we define two dummy variables: $\ell_{j, t-1}^{H i g h}$, which equals 1 when the leverage of firm $j$ lies above the median of the leverage distribution in the quarter preceding the monetary policy surprise (and zero otherwise), and $\ell_{j, t-1}^{L o w}$, which equals 1 when the leverage of firm $j$ lies below the median of the leverage distribution (and zero otherwise). We then consider how the response of spreads to monetary policy surprises varies across the two groups by estimating the following specification:

$$
\Delta c s_{i j, t}=\alpha_{i}+\beta_{1}\left(\epsilon_{t}^{m} \ell_{j, t-1}^{L o w}\right)+\beta_{2}\left(\epsilon_{t}^{m} \ell_{j, t-1}^{H i g h}\right)+\gamma \ell_{j, t-1}^{L o w}+\delta \ell_{j, t-1}^{H i g h}+e_{i j, t} .
$$

Coefficients $\beta_{1}$ and $\beta_{2}$ capture the impact of monetary policy on credit spreads for low- and high-leverage firms, respectively. The results are reported in column (2) of Table 2. They show that the response of credit spreads for low-leverage firms is smaller than the average effect, at around 21 basis points. The response of credit spreads for firms in the high-leverage group is much larger, at around 32 basis points.

Next, we consider the continuous measure of leverage and estimate a specification where we interact the monetary policy surprise with firms' leverage in the quarter that precedes the monetary policy surprise:

$$
\Delta c s_{i j, t}=\alpha_{i}+\beta \epsilon_{t}^{m}+\gamma\left(\epsilon_{t}^{m} L_{j, t-1}\right)+\delta L_{j, t-1}+e_{i j, t} .
$$

\footnotetext{
${ }^{16}$ Depending on which sub-sample of the overall universe of firms is considered, however, there might be other firm characteristics that better capture financial constraints - e.g. age (as in Cloyne et al., 2018, Bahaj et al., 2018) or liquid assets (as in Jeenas, 2018).
} 
We standardize $L_{j, t-1}$ over the sample so that the coefficient $\gamma$ captures the marginal impact of $\epsilon_{t}^{m}$ on $\Delta c s_{i j, t}$ for a firm whose leverage is 1 standard deviation above the average leverage in the sample. Results from this specification are reported in column (3) of Table 2. They show that firms with higher-than-average leverage experience a larger-than-average increase in credit spreads. The effect is statistically significant and economically sizeable. A firm whose leverage ratio is 1 standard deviation above the average, experiences a credit spread increase that is around 11 basis points larger than for the average firm.

How do our results compare to those in the existing literature? Cloyne et al. (2018) show that younger, non-dividend paying firms experience a larger increase in average interest payments relative to older dividend paying firms. In contrast, Ottonello and Winberry (2020) show that average interest payments increase by less for high-leverage firms relative to lowleverage firms following a monetary policy tightening. ${ }^{17}$ While our evidence aligns better with the findings in Cloyne et al. (2018), both approaches have the drawback of measuring firm-level borrowing costs with interest payments, as reported in the firm's balance sheet (xint in Compustat).

Relying on balance sheet data has three notable drawbacks. First, interest expenses reflect past lending decisions and are therefore a 'backward' measure of borrowing costs, which can diverge substantially from the marginal cost on new borrowing (i.e. what theory has predictions about). Second, changes in interest expenses will partly reflect movements in risk-free interest rates, while economic theory has predictions on the cost of borrowing net of the risk free interest rate. Third, interest expenses ignore the widely heterogeneous maturity of debt across firms. Focusing on credit spreads allows us to make some progress in addressing these issues. While still an imperfect proxy, the yield implied by the price of traded corporate bonds is conceptually closer to the marginal cost of new borrowing than the backward-looking interest expense measure used in other studies. Furthermore, by calculating the spread (through the subtraction of a same-maturity risk free interest rate) we are able to compare the cost of borrowing net of movements in risk free rates and across different maturities.

In the following subsections, we consider an extensive set of additional empirical exercises showing the robustness of our main results.

\footnotetext{
${ }^{17}$ Note that they consider a monetary policy easing, but since the model they employ is linear, the sign of the estimates can be flipped to consider a monetary policy tightening, as in this paper.
} 


\subsection{Robustness of the Baseline Results}

Additional controls Ozdagli and Weber (2017) document substantial heterogeneity in the effects of monetary policy across industrial sectors. This raises the question of whether our baseline results are simply driven by a systematic correlation between leverage and industrial sectors. To address this concern we add to our specification time-sector fixed effects, namely:

$$
\Delta c s_{i j, t}=\alpha_{i}+\beta_{s c t, t}+\gamma\left(\epsilon_{t}^{m} \ell_{j, t-1}^{H i g h}\right)+\delta \ell_{j, t-1}^{H i g h}+e_{i j, t},
$$

where $\beta_{s c t, t}$ is a dummy variable taking value of 1 for all firms belonging to the same sector (sct) in a given time period $t .{ }^{18}$ Note that, since the linear effect of $\epsilon_{t}^{m}$ is absorbed by the time-sector fixed effect, the term $\gamma$ captures the response of high-leverage firms relative to low-leverage firms. ${ }^{19}$

The results from this specification are reported in Table 3, column (1). The estimated $\gamma$ coefficient is still positive and highly statistically significant. In column (2) of Table 3 we report the results obtained from a specification that is identical to (4) but where we control for additional firm-specific covariates, namely firm (log) size, time since IPO (in years), the firm credit rating, and sales growth. The estimated coefficient is virtually identical to the one in column (1). Ottonello and Winberry (2020) show that using within-firm variation in leverage (i.e. $L_{j, t-1}-\mathbb{E}_{j}\left[L_{j, t-1}\right]$ ), rather than the level of a firm's leverage as in our baseline, can make a substantial difference for the estimated sensitivity of a firm's investment to monetary policy. The intuition is that the baseline results in Table 2 may be driven by permanent differences in firm leverage. In column (3) we report the results obtained from a specification that is identical to (4) but where the high-leverage dummy is based on withinfirm variation in leverage $\left(L_{j, t-1}-\mathbb{E}_{j}\left[L_{j, t-1}\right]\right)$, which we denote by $\mathcal{L}_{j, t-1}$. The estimated coefficient is smaller than in column (1) but is still positive and statistically significant. In column (4) we report the results from an instrumental variable (IV) specification, where we use our monetary policy surprises as an instrument for the change in the 1-year government bond yield around FOMC announcements. Again, the results are largely unchanged. Finally, we run our time-sector fixed effects specification (4) on a sample that excludes the global financial crisis and the subsequent period, i.e. that excludes all observations after December

\footnotetext{
${ }^{18}$ We use the finest available sector classification provided by BofAML, which includes information on 59 sectors. See Appendix B for more details.

${ }^{19}$ In Appendix F we report the results from this specification (and all other specifications described in this Section) using the continuous leverage interaction $\left(L_{j, t-1}\right)$ rather than the high leverage dummy $\left(\ell_{j, t-1}^{H i g h}\right)$, namely $\Delta c s_{i j, t}=\alpha_{i}+\beta_{s c t, t}+\gamma\left(\epsilon_{t}^{m} L_{j, t-1}\right)+\delta L_{j, t-1}+e_{i j, t}$. Our key findings are unchanged.
} 
Table 3 Heterogeneous Response of Credit Spreads: Robustness

\begin{tabular}{|c|c|c|c|c|c|}
\hline Dep. Variable: $\Delta c s_{i j}$ & (1) & (2) & (3) & (4) & (5) \\
\hline & $\begin{array}{c}\text { Time- } \\
\text { sector } \\
\text { FE }\end{array}$ & Controls & $\begin{array}{l}\text { Within } \\
\text { Leverage }\end{array}$ & IV & Pre-crisis \\
\hline MP surp. $\times$ High Lev. $\left(\epsilon^{m} \times \ell_{j}^{\text {High }}\right)$ & $\begin{array}{c}18.85^{* *} \\
(9.26)\end{array}$ & $\begin{array}{c}19.12^{* *} \\
(9.54)\end{array}$ & & & $\begin{array}{c}18.64^{* *} \\
(7.23)\end{array}$ \\
\hline MP surp. $\times$ High Lev. $\left(\epsilon^{m} \times \tilde{\ell}_{j}^{H i g h}\right)$ & & & $\begin{array}{l}13.35^{*} \\
(7.64)\end{array}$ & & \\
\hline 1yr Rate x High Lev. $\left(\epsilon^{m} \times \ell_{j}^{H i g h}\right)$ & & & & $\begin{array}{c}18.05^{* * *} \\
(1.40)\end{array}$ & \\
\hline Double clustering & Yes & Yes & Yes & Yes & Yes \\
\hline Time-sector FE & Yes & Yes & Yes & Yes & Yes \\
\hline R-squared & 0.308 & 0.303 & 0.308 & -0.014 & 0.341 \\
\hline Observations & 279,603 & 267,306 & 279,603 & 279,603 & 52,056 \\
\hline
\end{tabular}

Note. Results from estimating specification (4), namely $\Delta c s_{i j, t}=\alpha_{i}+\beta_{s c t, t}+\gamma\left(\epsilon_{t}^{m} \ell_{j, t-1}^{H i g h}\right)+\delta \ell_{j, t-1}^{H i g h}+e_{i j, t}$ and its variants described in the text, where $\epsilon_{t}^{m}$ is the monetary policy surprise; $\Delta c s_{i t}$ is the change in spreads between the day before the FOMC announcement and five days after the announcement; $\ell_{j, t-1}^{H i g h}=1$ when the leverage of firm $j$ lies above the median of the leverage distribution (and zero otherwise); $\alpha_{i}$ is a bond fixed-effect; $\beta_{s c t, t}$ is a time-sector fixed effect; $\tilde{\ell}_{j, t}^{H i g h}=1$ when within-firm leverage of firm $j$ lies above the median of the leverage distribution (and zero otherwise); 1yr Rate is the interest rate on the 1-year T-bill. Standard errors (reported in parentheses) are clustered two-way, at the firm level and time level. Additional controls include firm (log) size, sales growth, credit rating, and time since IPO. Credit spreads are measured in basis points and the size of the surprise is normalized so that it corresponds to a 25 basis points increase in the 1-year T-bill. The asterisks denote statistical significance $\left(* * *\right.$ for $p<0.01,{ }^{* *}$ for $p<0.05$, ${ }^{*}$ for $p<0.1$ ).

2007. The results are reported in column (5). A comparison with the results in column (1) shows that the sensitivity of credit spreads to monetary policy surprises has not changed since the pre-crisis period.

Double-sorting with additional firm characteristics While the results in Table 3 show the robustness of our findings to a comprehensive set of alternative specifications, one additional concern is that leverage might be correlated with other firm characteristics. Indeed, the stylized facts in Table 1 show that, in our sample, firms with high leverage tend to be smaller, younger, and have lower credit ratings. It could therefore be the case that our regressions are capturing the heterogeneous effects of these other characteristics, rather than leverage.

To address this concern, we run a series of 'double-interaction' regressions. That is, we 
estimate the following specification:

$$
\Delta c s_{i j, t}=\alpha_{i}+\beta_{s c t, t}+\gamma\left(\epsilon_{t}^{m} \ell_{j, t-1}^{H i g h}\right)+\delta\left(\epsilon_{t}^{m} x_{j, t-1}^{H i g h}\right)+\Gamma W_{j, t-1}+e_{i j, t},
$$

where $x_{j, t-1}^{H i g h}$ is a dummy variable that is defined in an identical way to $\ell_{j, t-1}^{\text {High }}$ but is based on other firm characteristics (such as age, size, credit rating, etc.); and $W_{j, t-1}$ includes both $\ell_{j, t-1}^{H i g h}$ and $x_{j, t-1}^{H i g h}$. The results are reported in Table 4.

The $\gamma$ coefficient now has a slightly different interpretation. Consider the case of $x_{j, t-1}^{H i g h}$ being firms' size. Then $\gamma$ captures the relative impact of monetary policy on high-leverage firms controlling for the interaction of monetary policy with firm size. Effectively, we are double sorting firms by their position in the leverage distribution and in the size distribution. As in previous specifications, in this Section we also include time-sector fixed effects.

For comparison with our baseline, column (1) of Table 4 reports the results from specification (4), i.e. the specification including time-sector fixed effects and a single interaction based on firm leverage. Columns (2) to (8) report the results from specification (5), where $x_{j, t-1}^{H i g h}$ is based on firm-level proxies for firms' financial constraints typically used in the literature. In particular, we consider firm (log) size, sales growth, credit ratings, time since IPO, a measure of the firm's distance to default (calculated using the Merton-KMV framework, detailed in Appendix E), the ratio between total debt and EBITDA, and the measure of a firm's liquid assets used in Jeenas (2018), respectively.

First, note that the estimated $\gamma$ coefficient - which captures the relative response of firms with leverage above the median of the leverage distribution - is very similar (and, in fact, not statistically different) in all columns. ${ }^{20}$ This result suggests that leverage is not simply capturing the effect of other firm-level characteristics. Second, the interaction coefficients based on the other firm characteristics generally have the expected sign but are often not statistically significant. This does not mean, however, that when considered alone they do not matter. In Appendix $\mathrm{F}$ we show that, when considered alone, they generally are statistically significant and with the expected sign (see Table F.5). For example, we find that older firms are less responsive to monetary policy shocks, as in Cloyne et al. (2018) and Bahaj et al. (2018). We also find that firms with high liquid assets are less responsive to monetary policy shocks, as in Jeenas (2018). In contrast to the results in Ottonello and Winberry (2020), however, we find that the credit spreads of firms with higher distance to

\footnotetext{
${ }^{20}$ This is also true when estimating 'double-interaction' regressions using the continuous leverage interaction $L_{j, t-1}$ instead of the high leverage dummy $\ell_{j, t-1}^{H i g h}$. See Table F.3 in the Appendix.
} 
Table 4 Heterogeneous Response of Credit Spreads: Double Sorting

\begin{tabular}{|c|c|c|c|c|c|c|c|c|}
\hline Dep. Variable: $\Delta c s_{i j}$ & $(1)$ & $(2)$ & $(3)$ & $(4)$ & $(5)$ & $(6)$ & (7) & (8) \\
\hline & Baseline & Size & $\begin{array}{l}\text { Sales } \\
\text { Growth }\end{array}$ & $\begin{array}{l}\text { Credit } \\
\text { Rating }\end{array}$ & $\begin{array}{l}\text { Time } \\
\text { IPO }\end{array}$ & $\mathrm{DD}$ & $\begin{array}{l}\text { Debt- } \\
\text { Ebitda }\end{array}$ & $\begin{array}{l}\text { Liquid } \\
\text { Assets }\end{array}$ \\
\hline MP surp. $\times$ High Lev. $\left(\epsilon^{m} \times \ell_{j}^{H i g h}\right)$ & $\begin{array}{c}18.85^{* *} \\
(9.26)\end{array}$ & $\begin{array}{c}18.78^{* *} \\
(9.22)\end{array}$ & $\begin{array}{c}19.53^{* *} \\
(9.45)\end{array}$ & $\begin{array}{c}16.42^{* *} \\
(8.23)\end{array}$ & $\begin{array}{c}18.69^{* *} \\
(9.09)\end{array}$ & $\begin{array}{c}18.77^{* *} \\
(8.95)\end{array}$ & $\begin{array}{c}17.16^{*} \\
(8.78)\end{array}$ & $\begin{array}{c}19.13^{* *} \\
(9.47)\end{array}$ \\
\hline MP surp. $\times$ Size $\left(\epsilon^{m} \times x_{j}^{H i g h}\right)$ & & $\begin{array}{l}-0.25 \\
(7.39)\end{array}$ & & & & & & \\
\hline MP surp. $\times$ Sales growth $\left(\epsilon^{m} \times x_{j}^{H i g h}\right)$ & & & $\begin{array}{l}-5.07 \\
(5.10)\end{array}$ & & & & & \\
\hline MP surp. $\times$ Credit rating $\left(\epsilon^{m} \times x_{j}^{H i g h}\right)$ & & & & $\begin{array}{l}-12.30 \\
(8.06)\end{array}$ & & & & \\
\hline MP surp. $\times$ Time IPO $\left(\epsilon^{m} \times x_{j}^{H i g h}\right)$ & & & & & $\begin{array}{l}-2.36 \\
(5.09)\end{array}$ & & & \\
\hline MP surp. $\times \mathrm{DD}\left(\epsilon^{m} \times x_{j}^{H i g h}\right)$ & & & & & & $\begin{array}{l}-3.14 \\
(8.35)\end{array}$ & & \\
\hline MP surp. $\times$ Debt-Ebitda $\left(\epsilon^{m} \times x_{j}^{H i g h}\right)$ & & & & & & & $\begin{array}{c}14.94^{* *} \\
(7.13)\end{array}$ & \\
\hline MP surp. $\times$ Liquid Assets $\left(\epsilon^{m} \times x_{j}^{H i g h}\right)$ & & & & & & & & $\begin{array}{c}2.92 \\
(4.09)\end{array}$ \\
\hline Double clustering & Yes & Yes & Yes & Yes & Yes & Yes & Yes & Yes \\
\hline Time-sector FE & Yes & Yes & Yes & Yes & Yes & Yes & Yes & Yes \\
\hline R-squared & 0.308 & 0.309 & 0.309 & 0.310 & 0.308 & 0.310 & 0.311 & 0.308 \\
\hline Observations & 279,603 & 279,603 & 279,075 & 277,288 & 279,603 & 277,281 & 251,257 & 279,597 \\
\hline
\end{tabular}

NoтE. Results from estimating specification (5), namely $\Delta c s_{i j, t}=\alpha_{i}+\beta_{s c t, t}+\gamma\left(\epsilon_{t}^{m} \ell_{j, t-1}^{H i g h}\right)+\delta\left(\epsilon_{t}^{m} x_{j, t-1}^{H i g h}\right)+\Gamma W_{j, t-1}+e_{i j, t}$, where $\epsilon_{t}^{m}$ is the monetary policy surprise; $\Delta c s_{i t}$ is the change in spreads between the day before the FOMC announcement and five days after the announcement; $\alpha_{i}$ is a bond fixed-effect; $\beta_{s c t, t}$ is a time-sector fixed effect; $\ell_{j, t-1}^{H i g h}=1$ when firm $j$ leverage lies above the median of the leverage distribution (and zero otherwise); $x_{j, t-1}^{H i g h}=1$ when a given characteristic $(X)$ of firm $j$, namely size, sales growth, credit rating, time since IPO, distance to default (DD), debt-to-EBITDA ratio, and liquid assets lies above the median of its distribution (and zero otherwise). $\Gamma W_{j, t-1}$ includes both $\ell_{j, t-1}^{H i g h}$ and $x_{j, t-1}^{H i g h}$. Standard errors (reported in parentheses) are clustered two-way, at the firm level and time level. Credit spreads are measured in basis points and the size of the surprise is normalized so that it corresponds to a 25 basis points increase in the 1 -year T-bill. 
default respond by less to monetary policy surprises.

Alternative interest rate surprises. Our results are robust to using the raw highfrequency interest rate surprises $\left(s_{t}^{F F 4}\right)$ instead of our preferred measure of monetary surprises $\left(\epsilon_{t}^{m}\right)$, based on Jarociński and Karadi (2020)'s approach. Column (1) of Table 5 reports the coefficient estimates from specification (4), where we include time-sector fixed effects and we interact the raw interest rate surprises $s_{t}^{F F 4}$ with the high-leverage dummy. The interaction coefficient (measuring the relative response of high-leverage firms relative to low-leverage firms) is still positive and significant. The coefficient, however, halves in size and is less statistically significant than in our baseline estimate, which we report here in column (2) for ease of comparison.

\section{Table 5 Heterogeneous Response of Credit Spreads: Monetary Vs. Non-Monetary Surprises}

\begin{tabular}{lccc}
\hline Dep. Variable: $\Delta c s_{i j}$ & $(1)$ & $(2)$ & $(3)$ \\
\hline Indep. Variable: & $\begin{array}{c}\text { Interest rate surp. } \\
\left(s^{F F 4}\right)\end{array}$ & $\begin{array}{c}\text { Monetary surp. } \\
\left(\epsilon^{m}\right)\end{array}$ & $\begin{array}{c}\text { Non-monetary } \\
\text { surp. }\left(\epsilon^{\text {other }}\right)\end{array}$ \\
\hline MP surp. $\times$ Lev. $\left(\epsilon \times \ell_{j}^{\text {High }}\right)$ & $8.95^{*}$ & $18.85^{* *}$ & -10.94 \\
& $(5.34)$ & $(9.26)$ & $(11.27)$ \\
\hline Double clustering & Yes & Yes & Yes \\
Time-sector FE & Yes & Yes & Yes \\
R-squared & 0.373 & 0.308 & 0.300 \\
Observations & 279,603 & 279,603 & 279,603 \\
\hline
\end{tabular}

Note. Results from estimating specification (4), namely $\Delta c s_{i j, t}=\alpha_{i}+\beta_{s c t, t}+\gamma\left(\epsilon_{t} \ell_{j, t-1}^{H i g h}\right)+\delta \ell_{j, t-1}^{H i g h}+e_{i j, t}$, with different high frequency surprises $(\epsilon)$. In column (1) the independent variable is the raw FF4 surprise $\left(s_{t}^{F F 4}\right)$; in column (2) is our baseline monetary surprise $\left(\epsilon_{t}^{m}\right)$; and in column (3) is the non-monetary surprise $\left(\epsilon_{t}^{\text {other }}\right)$; $\Delta c s_{i t}$ is the change in spreads between the day before the FOMC announcement and five days after the announcement; $\ell_{j, t-1}^{H i g h}=1$ when the leverage of firm $j$ lies above the median of the leverage distribution (and zero otherwise); $\alpha_{i}$ is a bond fixed-effect; $\beta_{s c t, t}$ is a time-sector fixed effect. Standard errors (reported in parentheses) are clustered two-way, at the firm level and time level. Credit spreads are measured in basis points and the size of the surprise is normalized so that it corresponds to a 25 basis points increase in the 1 -year T-bill. The asterisks denote statistical significance $(* * *$ for $p<0.01, * *$ for $p<0.05$, * for $p<0.1)$.

This pattern is consistent with $s_{t}^{F F 4}$ potentially being driven by a linear combination of true monetary policy shocks (of which $\epsilon_{t}^{m}$ is a noisy proxy) and a component working in opposite direction, which could reflect a Fed information effect or market participants learning about the Fed's reaction function (as discussed in Section 2.1). Consistent with this view, column (3) of Table 5 shows that an increase in interest rates that is driven by 
the non-monetary surprises $\left(\epsilon_{t}^{\text {other }}\right)$ induces high-leverage firms to respond by less than lowleverage firms (even though the effect is not statistically significant). ${ }^{21}$ In sum, the results from this robustness exercise show how the non-monetary news embedded in raw interest rate surprises can lead to a large downward bias in the estimated effect of monetary policy on credit spreads, both in the time series and in the cross-section.

\subsection{Firm-level Panel Local Projections}

The focus of the analysis so far has been on the high-frequency response of credit spreads. In our view, the high-frequency approach naturally leads to a more credible identification of the impact of monetary policy on firm-level outcomes, as well as a more precise estimation of its effects. However, the impact of monetary policy on credit spreads documented so far could be driven by transitory adjustments in prices. It might also be the case that our measured policy surprises are short-lived disturbances to market interest rates with no persistent effects on firm-level outcomes. With this in mind, we extend the daily event-study regressions of the previous Section to a business cycle frequency analysis.

For the firms in our data set, we collect quarterly data on total debt and investment from Compustat and we aggregate monetary policy surprises at a quarterly frequency over the period 1990Q1 to 2017Q4 (details reported in Appendix B). With this data set, we use a panel local projection approach, as in Jorda (2005), to examine the heterogeneous effects of monetary policy on firm-level debt and investment. Specifically, we estimate the following specification:

$$
y_{j, \tau+h}-y_{j, \tau-1}=\alpha_{j}^{h}+\beta_{s c t, \tau}+\gamma^{h} \epsilon_{\tau}^{m} \ell_{j, \tau-1}^{H i g h}+\sum_{p=1}^{P} \Gamma_{p} W_{j, \tau-p}+e_{j, \tau+h},
$$

where $y_{j, \tau}$ is debt or investment of firm $j$ in quarter $\tau ; \beta_{s c t, \tau}$ is a quarter-sector fixed effect; $\ell_{j, \tau-1}^{H i g h}$ is a dummy variable that equals 1 when the leverage of firm $j$ in $\tau-1$ lies above the median of the leverage distribution (and zero otherwise); and $\gamma^{h}$ is the coefficient of interest that measures the effect of $\epsilon_{\tau}^{m}$ on $y_{\tau+h}$ for high-leverage firms relative to low-leverage firms; $h$ denotes the horizon, with $h=0,1,2, \ldots, H$; and $W_{j, \tau}$ is a vector of (lagged) firm-level controls, including size, real sales growth, and leverage.

The resulting relative impulse responses for total debt and investment, captured by the

\footnotetext{
${ }^{21}$ The results based on specification (1), not reported here for brevity and relegated to Table F.8 in Appendix F, show that average credit spreads fall in response to an increase in $\epsilon_{t}^{\text {other }}$.
} 
Figure 3 Heterogeneous Responses of Debt and Investment

(A) Total debt

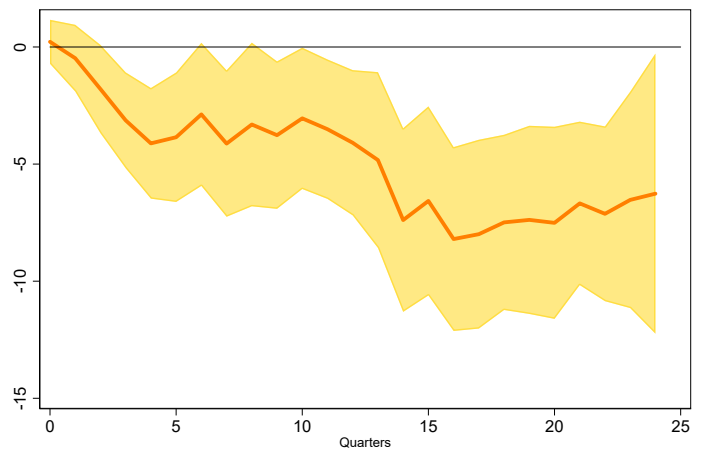

(B) Investment

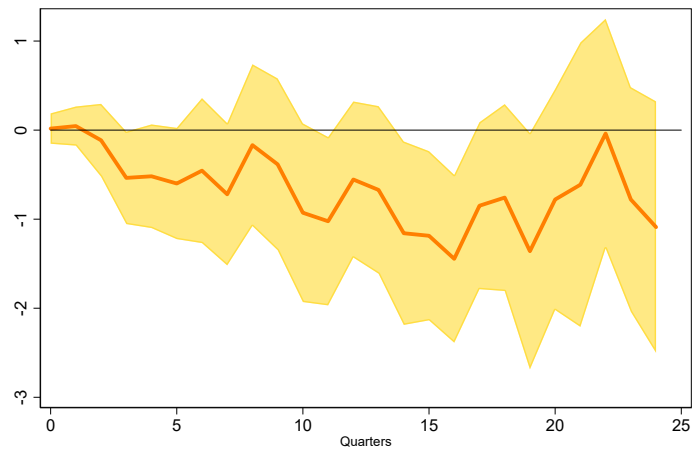

Note. Relative impulse response of total debt and investment. The impulse responses $\left(\gamma^{h}\right)$ are estimated with the local projection specification in (6), namely $y_{j, \tau+h}-y_{j, \tau-1}=\alpha_{j}^{h}+\beta_{s c t, \tau}+\gamma^{h} \epsilon_{\tau}^{m} \ell_{j, \tau-1}^{H i g h}+\sum_{p=1}^{P} \Gamma_{p} W_{j, \tau-p}+e_{j, \tau+h}$, where $h=0,1,2, \ldots, 24 ; j ; \epsilon_{\tau}^{m}$ is the monetary policy surprise; $\alpha_{i}$ is a bond fixed-effect; $\beta_{s c t, \tau}$ is a quarter-sector fixed effect; $\ell_{j, \tau-1}^{H i g h}=1$ when firm $j$ leverage lies above the median of the leverage distribution (and zero otherwise); and $W_{j, \tau}$ is a vector of (lagged) firm-level controls, including size, real sales growth, and leverage. The shaded areas display 90 percent confidence intervals based on two-way clustered (quarter and firm) standard errors.

coefficient $\gamma^{h}$, are reported in Figure 3, in Panel (A) and Panel (B), respectively. Panel (A) shows that the relative response of total debt for high-leverage firms becomes negative and statistically significant shortly after the shock hits. That is: firms with high leverage decrease their stock of debt by more than firms with low leverage. Panel (B) shows that a similar picture emerges for firm-level investment. The differential impulse response is zero on impact, and becomes negative in the quarters following the shock, with a profile that resembles closely the one of total debt - even though the effects are less precisely estimated and the relative response only becomes statistically significant around three years after the shock. Note that the results are virtually unchanged (if anything, they become slightly stronger) if we estimate specification (6) on pre-crisis data as in Jeenas (2018), Ottonello and Winberry (2020), and Cloyne et al. (2018); as well as if we compute our high-leverage dummy based on within-firm variation in leverage, namely $L_{j, \tau-1}-E_{j}\left[L_{j, \tau-1}\right]$, as in Ottonello and Winberry (2020) (results reported in Appendix G).

In sum, the results in this Section show that the patterns uncovered with the highfrequency event study regressions also hold at business cycle frequency, with high-leverage firms being more responsive than low leverage firms to monetary policy changes. 


\section{Interpretation}

To interpret our empirical results, we develop a simple theoretical framework that combines financial frictions on both firms (the borrowers) and financial intermediaries (the lenders). Borrowers are subject to asymmetric information and monitoring costs, as in the financial accelerator framework of Bernanke et al. (1999). Lenders are subject to a moral hazard problem in the spirit of Gertler and Kiyotaki (2010) and Gertler and Karadi (2011).

In our framework, monetary policy affects credit spreads via its effect on the financial position of both firms and intermediaries. On the one hand, a monetary policy tightening leads to a reduction in a firm's net worth, which increases its default probability and, therefore, the credit spread charged on its external borrowing. On the other hand, a monetary policy tightening also leads to a reduction in financial intermediaries' net worth, which increases the credit spread on their lending, independently of changes in a firm's creditworthiness. Whether it is via a reduction in firms' or intermediaries' net worth, monetary policy leads to an observationally equivalent contraction in the capital supply curve faced by firms. In this Section, we focus on the main implications of the model for credit spreads in response to a monetary policy tightening, with the full model derivation presented in Appendix A.

Basic mechanism. Because of asymmetric information and monitoring costs, a firm with limited net worth that needs to borrow to finance capital expenditures faces an upward sloping marginal cost of investment, namely the non-flat part of the upward sloping curve in panel (A) of Figure 4. The demand for capital is downward sloping due to decreasing returns to capital. The equilibrium level of the external finance premium (i.e. the cost of external finance relative to the risk free rate) is given by the intersection between the capital supply and the capital demand curves, depicted by $\mathcal{A}$ in panel (A) of Figure 4.

Absent any offsetting channels, a monetary policy tightening leads to an inward shift of the capital demand curve (yellow dashed line in panel (B) of Figure 4), so that the equilibrium moves from $\mathcal{A}$ to $\mathcal{B}$. Lower capital demand decreases the firm's borrowing. Leverage falls, and so does the firm's default probability, leading to a fall in credit spreads. Note that this is in stark contrast with what we observe in our data, where credit spreads, on average, increase in response to a monetary policy tightening (see column (1) of Table 2). But if the shock reduces the net worth of financially constrained agents (i.e. either the firm or financial intermediaries), it also induces an inward shift of the capital supply curve (the dashed blue line in panel (C) of Figure 4).

In theory, the response of the external finance premium to the monetary policy tighten- 
Figure 4 A Monetary Policy Tightening
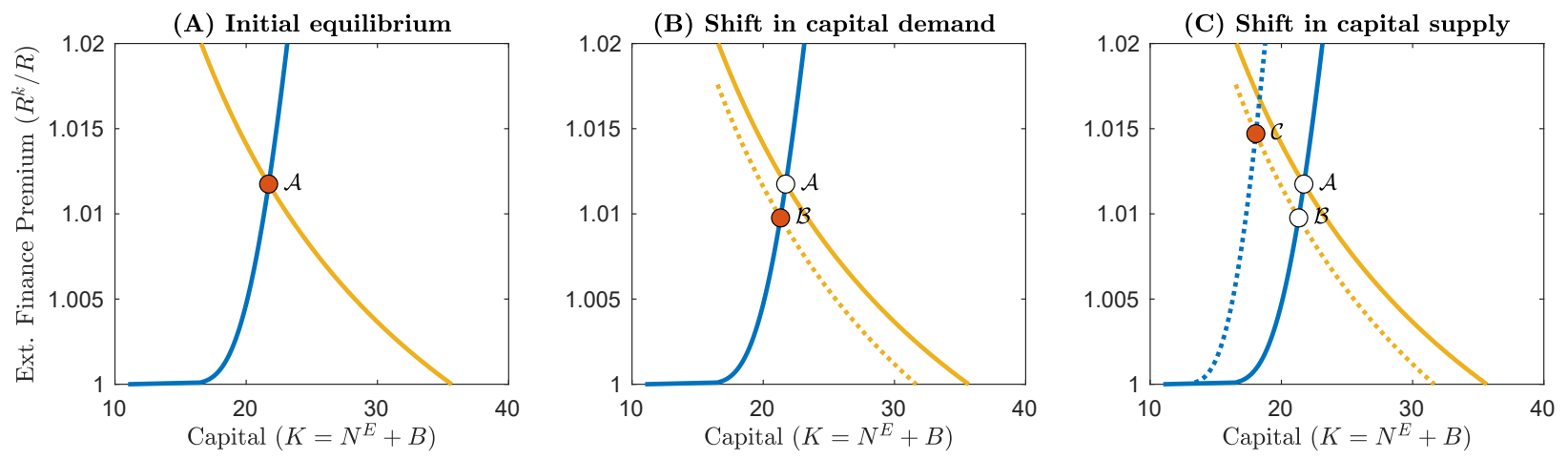

Note. Equilibrium in the capital market and effects of a monetary policy tightening. On the horizontal axis is entrepreneurial capital $K=N^{E}+B$, where $N^{E}$ is entrepreneurial net worth and $B$ is entrepreneurial borrowing; and on the vertical axis is the external finance premium $R^{K} / R$. Panel (A) depicts the initial equilibrium. Panel (B) depicts the shift in the capital demand curve induced by the monetary policy tightening. Panel $(\mathrm{C})$ depicts the shift in the capital supply curve due to a tightening in financial constraints, assuming that monetary policy reduces entrepreneurial net worth $\left(N^{E}\right)$ and/or financial intermediaries' net worth $\left(N^{F I}\right)$. The details of the model are reported in Appendix A.

ing can be either positive or negative depending on the magnitude of the shift in the capital supply curve, which in turns depends on the sensitivity of firms' and/or financial intermediaries' net worth to the shock. Consistent with our empirical findings, in panel (C) of Figure 4 we assumed that the inward shift in the capital supply curve is large enough to induce an increase in the external finance premium, moving the equilibrium from $\mathcal{B}$ to $\mathcal{C}$. An average increase in credit spreads is therefore consistent with a strong role for financial frictions. ${ }^{22}$ However, it is silent about the relative role of firms versus financial intermediaries as the source of financial frictions.

Heterogeneity. The sensitivity of credit spreads for firms that are relatively more financially constrained is also ex ante ambiguous. ${ }^{23}$ Consider two firms with different levels of net worth, and otherwise identical. In our model, the low net worth firm (firm $i$ ), which is more financially constrained and faces (in equilibrium) a steeper marginal cost of investment, has a higher leverage and a higher credit spread than the firm with high net worth (firm $j$ ), as

\footnotetext{
${ }^{22}$ Note that the average response of firm-level quantities is not informative about the role of financial frictions, as the shift in the capital demand and the capital supply curves both imply a reduction in borrowing and investment.

${ }^{23}$ In a much richer heterogeneous firm New Keynesian model with default risk, Ottonello and Winberry (2020) show that, theoretically, the investment of firms with high default risk can be more or less responsive to monetary policy, depending on how large is the inward movement of the capital supply curves relative to the shift in the capital demand curve.
} 
shown in panel $(\mathrm{A})$ of Figure $5 .^{24}$

Figure 5 A Monetary Policy Tightening: Heterogeneity
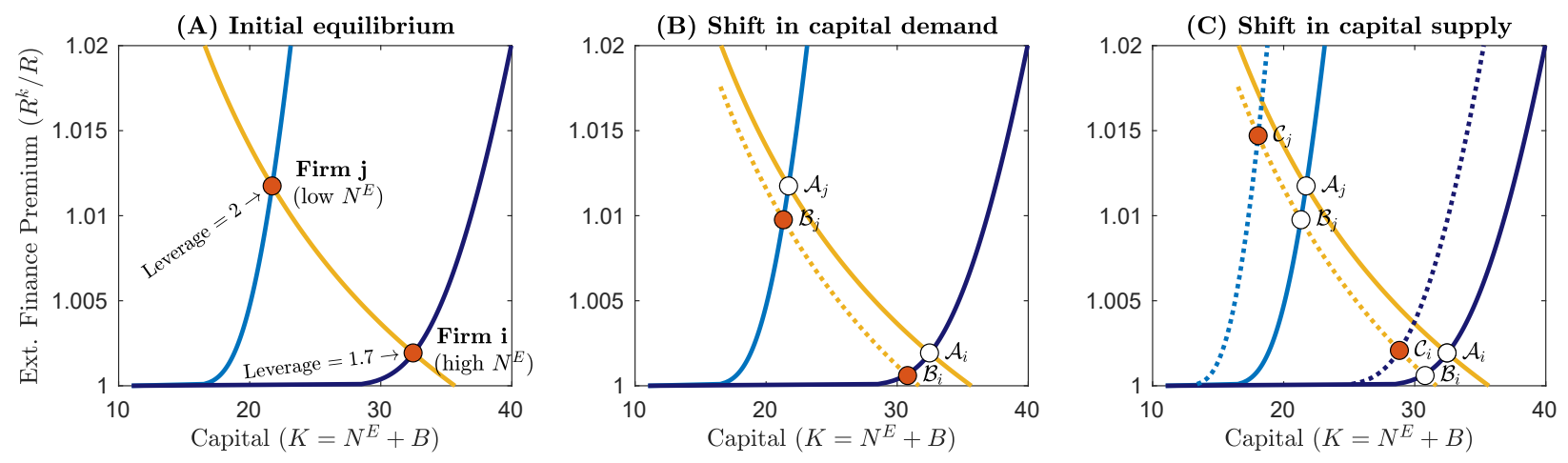

Note. Equilibrium in the capital market and effects of a monetary policy tightening for two firms with heterogeneous levels of net worth. Firm $j$ has low net worth, while firm $i$ has high net worth. On the horizontal axis is entrepreneurial capital $K=N^{E}+B$, where $N^{E}$ is entrepreneurial net worth and $B$ is entrepreneurial borrowing; and on the vertical axis is the external finance premium $R^{K} / R$. Panel (A) depicts the initial equilibrium. Panel (B) depicts the shift in the capital demand curve induced by the monetary policy tightening. Panel (C) depicts the shift in the capital supply curves due to a tightening in financial constraints, assuming that monetary policy reduces entrepreneurial net worth $\left(N^{E}\right)$ and/or financial intermediaries' net worth $\left(N^{F I}\right)$. The details of the model are reported in Appendix A.

In response to a monetary policy tightening, and absent a shift in the capital supply curves, the capital demand curve shifts inward (dashed yellow line in panel (B) of Figure 5) and the equilibria move from $\mathcal{A}$ to $\mathcal{B}$. As a result, the low-leverage firm (firm $i$ ) experiences a fall in credit spreads that is smaller than the high-leverage firm (firm $j$ ). Not only credit spreads fall for both firms, but also the relative response of the high-leverage firm is negative, strongly in contrast with our event study results (see column (2) and (3) of Table 2). Note that the equilibria $\mathcal{B}_{i}$ and $\mathcal{B}_{j}$ are also inconsistent with the findings from the panel local projections, which show that high-leverage firms decrease debt and investment by more than low-leverage firms.

If the shock, however, also leads to an inward shift in the capital supply curves (via a tightening of financial constraints of either firms or intermediaries) these results can revert. If the shift is large enough, credit spreads might increase, and might do so more for the high-leverage firm; and debt and investment might fall more for the high-leverage firm. The magnitude of the shift (both in absolute but also in relative terms) depends crucially on the

\footnotetext{
${ }^{24}$ Note that this positive relation between leverage and credit spreads is in line with what we observe unconditionally in our data set, where firms with high leverage tend to have high credit spreads and low ratings. See Figure D.1 in Appendix.
} 
strength of the financial frictions. In panel (C) of Figure 5 we assumed that the equilibria move from $\mathcal{B}$ to $\mathcal{C}$, consistent with our findings from both the event-study and the projections.

In sum, our empirical results are consistent with an inward shift of the capital supply curves that is large enough to make credit spreads increase by more and debt/investment to fall by more for high-leverage firms. If interpreted through the lens of our theoretical framework, this evidence points to a relevant role for financial constraints in the transmission of monetary policy. The cross-sectional response of credit spreads and debt/investment, however, is silent about the relative role of firms versus financial intermediaries as the source of financial frictions. Shedding light on the separate role that frictions on firms and on financial intermediaries play is a challenging task, as it involves a complicated identification problem. In the next Section, we consider an empirical decomposition of credit spreads that allows us to make some progress in disentangling these two channels.

\section{Inspecting the Mechanism: Expected Default and the Excess Bond Premium}

Motivated by the discussion in the previous Section, we now consider an empirical decomposition of credit spreads that allows us to sharpen our understanding of how monetary policy transmits to credit costs.

In our theoretical framework, asymmetric information and monitoring costs on the firm's side imply a tight relationship between firms' leverage, default probability, and credit spreads. By decreasing firms' net worth, a monetary policy tightening increases firms' leverage and default probability, leading to higher credit spreads. But credit spreads would increase even keeping firms' net worth constant, as monetary policy decreases financial intermediaries' net worth. As a result, empirically identifying the separate role that firms and financial intermediaries have in driving our results involves a complicated identification problem.

To make some progress in this direction, we merge our data set with additional information on firms' balance sheets and stock prices and employ Gilchrist and Zakrajsek (2012)'s

framework to decompose credit spreads into two orthogonal components: (i) a component capturing fluctuations in firms' expected default risk and (ii) a residual component that captures fluctuations in credit spreads above and beyond the compensation that investors require for expected defaults (i.e., the Excess Bond Premium (EBP)). In our model, a fall in intermediaries' net worth does not directly affect firms' leverage (and hence their default 
probability), but implies a higher credit spread for any given level of leverage. ${ }^{25}$ By focusing on the component of spreads which is not associated with firms' default risk, the EBP can give us a sense of the role that financial intermediaries play in the transmission of monetary policy. $^{26}$

To obtain the decomposition of credit spreads, we proceed as follows. We regress corporate bond spreads on a firm-specific estimate of the distance to default, calculated using the Merton-KMV framework, and on a vector of bond-specific controls. The fitted value from this regression $\left(\hat{c} s_{i j, t}\right)$ isolates the variation in credit spreads due to fluctuations in the creditworthiness of firms. Note that the regression has an $R^{2}$ of about $75 \%$, and therefore does a good job at capturing credit spreads variation. ${ }^{27}$ The residual $\left(\hat{\nu}_{i j, t}\right)$ reflects the variation in credit spreads that is in excess of firms' expected default risk.

Armed with this decomposition, we estimate how the two components of credit spreads respond to monetary policy surprises. We start by estimating the simple baseline specification (1) that captures the average effect of monetary policy on $\hat{c s} s_{i j, t}$ and $\hat{\nu}_{i j, t}$. For comparison, column (1) of Table 6 also reports the estimated response of overall credit spreads $\left(c s_{i j, t}\right)$ to monetary policy - which is therefore identical to our baseline estimate reported in Table 2. Columns (2) and (3), which decompose the average effect in column (1) into an expected default component and an excess bond premium component, show that virtually all of the effect of monetary policy on credit spreads is due to the excess bond premium. The coefficient on $\hat{\nu}_{i j, t}$, at 25 basis points, is highly statistically significant and about eight times larger than the coefficient on $\hat{c} s_{i j, t}$, which instead is not statistically different from zero.

While the fitted spreads $\hat{c} s_{i j, t}$ can explain almost 75 percent of the variation in overall credit spreads, the excess bond premium $\hat{\nu}_{i j, t}$ inherits much of the volatility of credit spreads (see Figure E.1 in the Appendix). Therefore, the result in Table 6 could simply reflect the higher variance of $\hat{\nu}_{i j, t}$ relative to $\hat{c s}_{i j, t}$. To check whether this is the case, we re-estimate specification (1) after standardizing both series, which we label $\widetilde{\Delta \hat{c} s}_{i j, t}$ and $\widetilde{\Delta \hat{\nu}}_{i j, t}$. The results (reported in Table F.6 in the Appendix) show that the response of $\widetilde{\Delta \hat{\nu}}_{i j, t}$ is still significantly larger than $\widetilde{\Delta \hat{c} s}_{i j, t}$. This implies that the larger coefficient in Table 6 is not only due to the higher variance of $\hat{\nu}_{i j, t}$ (relative to $\hat{c s}_{i j, t}$ ), but also to a stronger transmission via the EBP.

\footnotetext{
${ }^{25}$ This is true in the short-run, as firms' net worth is not affected on impact by the fall in intermediaries' net worth and capital is fixed. After the shock hits, firms find optimal to adjust their leverage taking into account the new capital supply schedule. See Appendix A for details.

${ }^{26}$ Gilchrist and Zakrajsek (2012) show empirically that the excess bond premium is tightly linked to the financial position of US broker dealers, who are large and active players in corporate bond markets.

${ }^{27}$ In Appendix E we report all the details of this procedure and a comparison of our results with the decomposition of Gilchrist and Zakrajsek (2012).
} 
Table 6 Expected Default and Excess Bond Premium

\begin{tabular}{lccc}
\hline & $(1)$ & $(2)$ & $(3)$ \\
\hline Dep. Variable: & Spread $(\Delta c s)$ & $\begin{array}{c}\text { Default Risk } \\
(\Delta \hat{c s})\end{array}$ & $\begin{array}{c}\text { Exc. Bond } \\
\text { Premium }(\Delta \hat{\nu})\end{array}$ \\
\hline MP surp. $\left(\epsilon^{m}\right)$ & $27.68^{* *}$ & 2.98 & $24.70^{* *}$ \\
& $(10.62)$ & $(1.81)$ & $(10.30)$ \\
\hline Double clustering & Yes & Yes & Yes \\
Time-sector FE & No & No & No \\
R-squared & 0.034 & 0.030 & 0.033 \\
Observations & 285,794 & 285,794 & 285,794 \\
\hline
\end{tabular}

Nоте. Results from estimating specification (1), namely $y_{i j, t}=\alpha_{i}+\beta \epsilon_{t}^{m}+e_{i j, t}$, where $y_{i t}=$ $\left(\Delta c s_{i j, t}, \Delta \hat{c} s_{i j, t}, \Delta \hat{\nu}_{i j, t}\right) ; \epsilon_{t}^{m}$ is the monetary policy surprise, $\Delta c s_{i j, t}, \Delta \hat{c s}_{i j, t}$, and $\Delta \hat{\nu}_{i j, t}$ are the change in spreads, fitted spreads and the excess bond premium between the day before the FOMC announcement and five days after the announcement, respectively; $\alpha_{i}$ is a bond fixed-effect. Standard errors (reported in parentheses) are clustered two-way, at the firm level and time level. Credit spreads are measured in basis points and the size of the surprise is normalized so that it corresponds to a 25 basis points increase in the 1 -year T-bill. The asterisks denote statistical significance (*** for $p<0.01$, ** for $p<0.05, *$ for $p<0.1)$.

We next turn to the cross-sectional response of the fitted spread and the excess bond premium components to monetary policy. We estimate a specification with time-sector fixed effects, as in equation (4). The estimated $\gamma$ coefficient captures the impact of monetary policy on the credit spread of high-leverage firms relative to low-leverage firms. The estimated coefficients on $c s_{i j, t}, \hat{c s_{i j, t}}$, and $\hat{\nu}_{i j, t}$ are reported in Table 7, in columns (1), (2), and (3), respectively. The results show that the excess bond premium accounts for virtually all of the relative response of credit spreads to a monetary policy surprise. The expected default component also has a positive coefficient even though it is quantitatively small and statistically insignificant.

In sum, the results in this Section show that a large proportion of the overall movement in credit spreads is accounted for by a component that is orthogonal to firms' default risk. In our theoretical framework, this component can be interpreted as a measure of firms' borrowing costs that is due to frictions in the financial intermediation sector. Hence, our results provide supportive evidence that frictions in the financial intermediation sector play a crucial role in shaping the transmission mechanism of monetary policy. 
Table 7 Expected Default and Excess Bond Premium: Heterogeneity

\begin{tabular}{lccc}
\hline & $(1)$ & $(2)$ & $(3)$ \\
\hline Dep. Variable: & Spread $(\Delta c s)$ & $\begin{array}{c}\text { Default Risk } \\
(\Delta \hat{c} s)\end{array}$ & $\begin{array}{c}\text { Exc. Bond } \\
\text { Premium }(\Delta \hat{\nu})\end{array}$ \\
\hline MP surp. $\times$ Lev. $\left(\epsilon^{m} \times \ell_{j}^{H i g h}\right)$ & $18.85^{* *}$ & 0.30 & $18.56^{* *}$ \\
& $(9.26)$ & $(0.58)$ & $(9.33)$ \\
\hline Double clustering & Yes & Yes & Yes \\
Time-sector FE & Yes & Yes & Yes \\
R-squared & 0.308 & 0.373 & 0.300 \\
Observations & 279,603 & 279,603 & 279,603 \\
\hline
\end{tabular}

Note. Results from estimating specification (4), namely $y_{i t}=\alpha_{i}+\beta_{s c t, t}+\gamma\left(\epsilon_{t}^{m} \ell_{j, t-1}^{H i g h}\right)+\delta \ell_{j, t-1}^{H i g h}+e_{i j, t}$, where $y_{i t}=\left(\Delta c s_{i j, t}, \Delta \hat{c s}_{i j, t}, \Delta \hat{\nu}_{i j, t}\right) ; \epsilon_{t}^{m}$ is the monetary policy surprise; $\Delta c s_{i j, t}, \Delta \hat{c s} \hat{i j, t}_{i}$, and $\Delta \hat{\nu}_{i j, t}$ are the change in spreads, fitted spreads and the excess bond premium between the day before the FOMC announcement and five days after the announcement, respectively; $\ell_{j, t-1}^{H i g h}=1$ when firm $j$ leverage lies above the median of the leverage distribution (and zero otherwise); $\alpha_{i}$ is a bond fixed-effect; $\beta_{s c t, t}$ is a time-sector fixed effect. Standard errors (reported in parentheses) are clustered two-way, at the firm level and time level. Credit spreads are measured in basis points and the size of the surprise is normalized so that it corresponds to a 25 basis points increase in the 1-year T-bill. The asterisks denote statistical significance (*** for $p<0.01,{ }^{* *}$ for $p<0.05,{ }^{*}$ for $p<0.1$ ).

\section{Conclusion}

Understanding how monetary policy transmits to firms' borrowing and investment decisions is of crucial importance to policy makers. The increased availability of granular firm-level information has led researchers to look at the cross-sectional response of debt and investment to empirically test competing theoretical mechanisms. This paper contributes to an ongoing debate on the role of financial frictions for the transmission mechanism of monetary policy by adding a dimension that has been overlooked in previous work.

We consider the firm-level response of the cost of external finance - in addition to the firmlevel response of debt and investment - to monetary policy. The joint response of prices and quantities is crucial in determining the relative magnitude of shifts in the capital demand and capital supply curves. Moreover, credit spreads react to monetary policy at a much higher frequency than debt or investment, allowing for a more precise identification of both monetary policy surprises and their effects.

Following a monetary policy tightening, high-leverage firms experience a more pronounced increase in borrowing costs and a sharper contraction in debt and investment than 
low-leverage firms. When decomposing the total effect of monetary policy on credit spreads into a component capturing a firm's default risk and a component capturing the compensation required by investors in excess of default risk, virtually all of the conditional response of credit spreads to monetary policy is accounted for by the latter. Our results suggest that frictions in the financial intermediation sector can play a crucial role in shaping the transmission mechanism of monetary policy. 


\section{Appendix}

\section{A Theoretical Framework}

In this Section we develop a simple theoretical framework that provides one way of interpreting our empirical results. Our framework combines financial frictions on both entrepreneurs who run firms (the borrowers) and financial intermediaries (the lenders). Borrowers are subject to asymmetric information and monitoring costs, as in the financial accelerator framework of Bernanke et al. (1999). Lenders are subject to a moral hazard problem in the spirit of Gertler and Kiyotaki (2010) and Gertler and Karadi (2011). In our framework, monetary policy affects credit spreads via its effect on the financial position of both firms and intermediaries.

\section{A.1 The model}

We consider three sets of agents: (1) risk neutral entrepreneurs who run firms and require funding for risky projects; (2) competitive risk neutral mutual funds who sell securities $S$ to financial intermediaries and use the proceeds to buy goods which are lent to entrepreneurs; and (3) financial intermediaries that raise deposits from households and buy securities from mutual funds. Each financial intermediary is endowed with $N^{F I}$ goods. We will refer to this as the net worth of the financial intermediary. The financial intermediary combines net worth and deposits $D$ from households to purchase securities $S$ from the mutual fund. Entrepreneurs have heterogeneous levels of net worth, $N^{E}$. In what follows, we will consider the interaction between an entrepreneur, a competitive mutual fund, and a financial intermediary. This entrepreneur has access to a project with expected gross return $\mathbb{E}[\omega] R^{k}$, where $\omega \sim \log \mathcal{N}\left(1, \sigma^{2}\right)$ is an idiosyncratic surprise that is private information to the entrepreneur; and $R^{k}$ is the aggregate return to capital, which is taken as given by the entrepreneur. As net worth is limited, the entrepreneur has to finance capital expenditures $(K)$ with a mix of net worth $\left(N^{E}\right)$ and debt $(B)$. The balance sheets of entrepreneurs, mutual funds, and financial intermediaries are:

\begin{tabular}{c|c}
\hline \multicolumn{2}{c}{ Entrepreneur } \\
\hline Assets & Liabilities \\
\hline Capital, $K$ & Loans, $B$ \\
& Net worth, $N^{E}$ \\
\hline
\end{tabular}

\begin{tabular}{c|c}
\hline \multicolumn{2}{c}{ Mutual Fund } \\
\hline Assets & Liabilities \\
\hline Loans, $B$ & Securities, $S$ \\
& \\
\hline
\end{tabular}

\begin{tabular}{c|c}
\hline \multicolumn{2}{c}{ Financial Intermediary } \\
\hline Assets & Liabilities \\
\hline Securities, $S$ & Deposits, $D$ \\
& Net worth, $N^{F I}$ \\
\hline
\end{tabular}

Entrepreneurs. Entrepreneurial debt is supplied by a risk neutral mutual fund at lending rate, $R^{L}$ (more on this below). The entrepreneur has limited liability: if revenues cannot 
cover debt repayments (i.e., for bad realizations of $\omega$ ), the entrepreneur goes bankrupt and loses everything.

The competitive risk neutral mutual fund operates under the participation constraint that the expected return on lending equals the gross funding cost, namely the return on securities sold to the financial intermediary, $R^{S}$. The mutual fund therefore offers a menu of loan contracts $\left(R^{L}, B\right)$. In case of bankruptcy, the mutual fund must pay a monitoring cost, $\mu$, to observe entrepreneur returns and seize them. The expected return on lending is given by the weighted average of two terms: (1) the return on loans $\left(R^{L} B\right)$, weighted by the share non-defaulting entrepreneurs; and (2) whatever is left in the firm (net of monitoring costs, $\left((1-\mu) \omega_{i} R^{K}\left(N^{E}+B\right)\right)$, weighted by the share of defaulting entrepreneurs. The gross funding cost is the interest rate on securities. So, the zero profit condition is:

$$
[1-F(\bar{\omega})] \cdot R^{L} B+(1-\mu) \int_{0}^{\bar{\omega}} \omega R^{K}\left(N^{E}+B\right) d F(\omega)=B R^{S}
$$

where $\bar{\omega}$ is the threshold level of the idiosyncratic shock below which the entrepreneurs chooses to default, namely the level of $\omega$ such that $R^{K} \bar{\omega}\left(N^{E}+B\right)=R^{L} B$; and $F$ is the lognormal cumulative distribution function with support $(0, \infty)$. Using Bernanke et al. (1999) notation, the zero profit condition (A.1) can be re-written as:

$$
(\Gamma(\bar{\omega})-\mu G(\bar{\omega})) R^{K}\left(N^{E}+B\right)=B R^{S}
$$

where $G(\bar{\omega})=\int_{\bar{\omega}}^{\infty} \omega d F(\omega)$ and $\Gamma(\bar{\omega})=G(\bar{\omega})+\bar{\omega}(1-F(\bar{\omega}))$. Entrepreneurs maximize profits subject to the zero profit condition (A.2):

$$
\begin{aligned}
& \left.\max _{\bar{\omega}, L}\{(1-\Gamma(\bar{\omega})) L)\right\} \\
& \text { s.t. } \quad L=\frac{1}{1-\frac{R^{K}}{R^{S}}[\Gamma(\bar{\omega})-\mu G(\bar{\omega})]},
\end{aligned}
$$

where both profits and the zero profit condition have been written in terms of leverage $L=\left(B+N^{E}\right) / N^{E}$. The constraint can be substituted directly into the profit function, and one can solve for $\bar{\omega}$ :

$$
\frac{1-F(\bar{\omega})}{[1-\Gamma(\bar{\omega})]}=\frac{\frac{R^{K}}{R^{S}}\left(1-F(\bar{\omega})-\mu \bar{\omega} F^{\prime}(\bar{\omega})\right)}{\left.1-\frac{R^{K}}{R^{S}}[\Gamma(\bar{\omega})-\mu G(\bar{\omega})]\right)}
$$

This equation determines the cutoff productivity level $\bar{\omega}$ as a function of $R^{S}$ and $R^{K}$, which are taken as given by the entrepreneur. The leverage of the entrepreneur (and, therefore, the borrowed amount $B$ ) can be obtained from the zero profit condition (A.4). So equations (A.4) and (A.5) can be combined to plot a capital/capital supply curve in the 
$\left\{K, \frac{R^{K}}{R^{S}}\right\}$ space. $^{28}$

Financial intermediaries. The financial intermediary takes the return to deposits $R$ and the return to securities $R^{S}$ as given, and chooses the amount of deposits to accept from depositors to maximize:

$$
\pi=\max _{D}\left(R^{S} S-R D\right)
$$

We follow Gertler and Karadi (2011) and Gertler and Kiyotaki (2010) in assuming that the financial intermediary can default after receiving the payment $R^{S} S$ from the mutual fund and abscond with a fraction $\theta$ of total assets. The financial intermediary, therefore, maximizes (A.6) subject to a no default constraint:

$$
R^{S}\left(N^{F I}+D\right)-R D \geq \theta R^{S}\left(N^{F I}+D\right)
$$

The problem of the financial intermediary can be solved by setting up a Lagrangean:

$$
\mathcal{L}=R^{S}\left(N^{F I}+D\right)-R D+\lambda\left[R^{S}(N+D)-R D-\theta R^{S}(N+D)\right]
$$

which gives the following first order condition:

$$
R^{S}=\frac{1+\lambda}{1+\lambda(1-\theta)} R \text {. }
$$

When the moral hazard problem is sufficiently large, the constraint binds $(\lambda>0)$, so a spread opens up between the return to securities $\left(R^{S}\right)$ and the return to deposits $(R)$. If instead the moral hazard problem is not severe enough (or absent all together), $R^{S}=R$ and the zero profit condition (A.5) collapses to the baseline formulation in Bernanke et al. (1999).

Finally note that equations (A.4)-(A.5)-(A.9) can be combined to plot a capital supply curve in the $\left\{K, \frac{R^{K}}{R}\right\}$ space.

Capital demand. The equilibrium in the market for external financing is determined by the point where the demand for capital intersects the supply of funds (A.4)-(A.5)-(A.9). To derive a capital demand schedule we note that, in general equilibrium (and after aggregate and idiosyncratic shocks are realized), final good firms rent capital from entrepreneurs in a competitive rental market at rental rate $\left(z_{t}\right)$, and entrepreneurs sell undepreciated capital $\omega K(1-\delta)$ after goods production. As the rental rate of capital at equilibrium matches the

\footnotetext{
${ }^{28}$ Since in our simple framework net worth is given, the capital market is equivalent to the credit market (where remember that $K=N^{E}+B$ ). We therefore refer to capital and credit market interchangeably.
} 
marginal product of capital, the aggregate gross return on capital has to satisfy:

$$
R^{k}=z_{t}+(1-\delta)
$$

Finally, to plot the capital demand schedule in the same space as the capital supply schedule (A.4)-(A.5)-(A.9), we rescale (A.10) by the risk free rate, $R$. So, the capital demand schedule can be expressed as:

$$
\frac{R^{k}}{R}=\frac{1}{R}\left(\alpha K_{t}^{\alpha-1}+(1-\delta)\right)
$$

where we assumed a fixed labor supply for simplicity ( so that $z_{t}=\alpha K_{t}^{\alpha-1}$ ). Note that the capital demand schedule is downward sloping because of decreasing returns to capital.

\section{A.2 Equilibrium and curve shifting}

We first describe the equilibrium and monetary policy transmission for the simple case of a single entrepreneur with a given level of net worth. We then describe the case of multiple entrepreneurs with heterogeneous net worth.

Basic mechanism. Start from the equilibrium depicted by $\mathcal{A}$ in Figure A.1. This is at the intersection between the capital supply curve (given by the combination of (A.4)-(A.5)-(A.9)) and the capital demand curve (A.11).

\section{Figure A.1 A Monetary Policy Tightening}
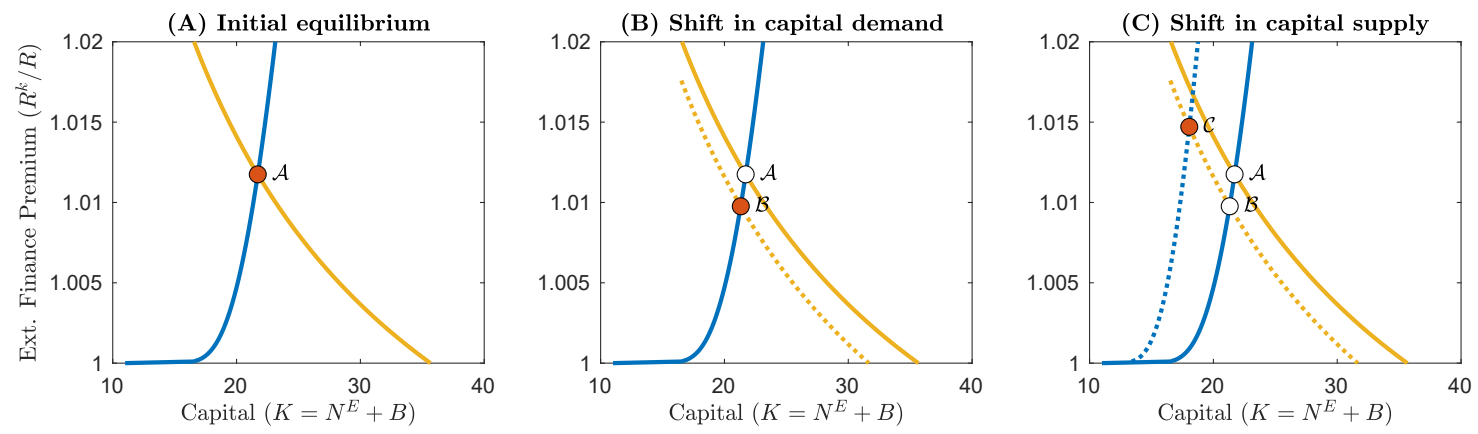

Note. Equilibrium in the credit market and effects of a monetary policy tightening. On the horizontal axis is entrepreneurial capital $K=N^{E}+B$, where $N^{E}$ is entrepreneurial net worth and $B$ is entrepreneurial borrowing; and on the vertical axis is the external finance premium $R^{K} / R$. Panel (A) depicts the initial equilibrium. Panel (B) depicts the shift in the credit demand curve induced by the monetary policy tightening. Panel $(\mathrm{C})$ depicts the shift in the capital supply curve due to a tightening in financial constraints, assuming that monetary policy reduces entrepreneurial net worth $\left(N^{E}\right)$ and/or financial intermediaries' net worth $\left(N^{F I}\right)$.

By reducing the demand for capital, a monetary policy tightening shifts the capital 
demand curve inward (yellow dashed line in panel (A) of Figure A.1). Abstracting for the moment from the effect of monetary policy on the net worth of entrepreneurs and/or intermediaries, the increase in $R$, leads to an increase in $R^{S}$ and therefore reduces $\frac{R^{K}}{R^{S}}$. According to (A.4)-(A.5)-(A.9), the new level of $\frac{R^{K}}{R^{S}}$ is consistent with a lower level of $\bar{\omega}$ and leverage. The monetary policy tightening can therefore be depicted in the $\left\{K, \frac{R^{K}}{R}\right\}$ space as a movement along the supply curve, moving the equilibrium from $\mathcal{A}$ to $\mathcal{B}$ (panel (B) of Figure A.1). As a result the external finance premium falls. Note that this is in stark contrast with our empirical findings, which show that credit spreads increase when monetary policy tightens (see Table 2, column (1)).

Assume now that the monetary policy tightening reduces the net worth of entrepreneurs and of financial intermediaries. We start by considering the partial equilibrium effect of a reduction in entrepreneurial net worth as a result of the monetary policy shock, keeping financial intermediaries' net worth fixed. Because of the fall in entrepreneurial net worth, when the shock hits, entrepreneurial leverage and the probability of default increase. For each level of total capital, entrepreneurial leverage and the probability of default are higher, and as a result the external finance premium, $\frac{R^{K}}{R}$, is also higher. This can be depicted in the $\left\{K, \frac{R^{K}}{R}\right\}$ space as an inward shift of the supply curve, moving the equilibrium from $\mathcal{B}$ to $\mathcal{C}$ in panel (C) of Figure A.1 (dashed blue line). This is the financial accelerator mechanism described in Bernanke et al. (1999). We assume that the fall in entrepreneurial net worth is large enough so that the external finance premium increases in equilibrium (see point $\mathcal{C}$ ). Note, however, that the response of the external finance premium to the monetary policy shock is ex ante ambiguous, and can be positive or negative depending on the strength of the financial friction. Our results in column (1) of Table 2 are consistent with the assumption here that the shift in the supply curve is sufficiently large so that the external finance premium increases.

Consider now the partial equilibrium effect of a reduction in financial intermediaries' net worth, keeping entrepreneurial net worth fixed. As net worth falls, financial intermediaries' incentive compatibility constraint becomes more binding, leading to an increase in the Lagrange multiplier $\lambda$. According to (A.9), a larger spread between $R^{S}$ and $R$ opens up. At the time of the shock, entrepreneurial leverage and the associated probability of default are unchanged. But the gross funding cost of the mutual fund has increased. As a result, to satisfy (A.4), the external finance premium, $\frac{R^{K}}{R}$, is higher for any given level of capital. Like in the case of a fall in entrepreneurial net worth, a fall in financial intermediaries' net worth can therefore be depicted in the $\left\{K, R^{K} / R\right\}$ space as an inward shift of the supply curve, moving the equilibrium from $\mathcal{B}$ to $\mathcal{C}$ (panel (C) of Figure A.1).

It is therefore clear that the same qualitative shift of the capital supply curve can be 
obtained with a tightening of financial constraints for either entrepreneurs or financial intermediaries. A fall in entrepreneurial net worth leads to a shift in the capital supply curve by tightening the mutual fund's zero profit condition (A.4). A fall in intermediaries net worth leads to a shift in the capital supply curve by tightening the intermediaries' incentive compatibility constraint (A.9), which in turn tightens the mutual fund's zero profit condition.

Our empirical results, presented in Section 5, provide suggestive evidence that the frictions associated with financial intermediaries are quantitatively important for the transmission of monetary policy. Specifically, Table 6 shows that virtually all of the response of credit spreads to monetary policy surprises is due to a component of credit spreads that is independent of firms default probability, the excess bond premium. As explained above, in our theoretical framework a fall in financial intermediaries' net worth results in a jump in the external finance premium, even when keeping entrepreneurial net worth and default probability initially fixed. In contrast, shocks to entrepreneurs' net worth (which equally result in an increase in the external finance premium in our theoretical model) also increase the entrepreneurs' default probability, as they directly increase entrepreneurs' leverage. Our finding that a large proportion of the overall movement in credit spreads is accounted for by changes in excess bond premia therefore provides supportive evidence that frictions associated with financial intermediation (rather than just those associated with entrepreneurs) play a key role in the transmission of monetary policy shock.

Heterogeneity. The model also has implications for the heterogeneous response of firms to monetary policy. Panel (A) of Figure A.2 shows the initial equilibrium for two firms that only differ in their level of net worth. Firm $j$ has low net worth, while firm $i$ has high net worth. The Figure shows that the low net worth entrepreneur is more financially constrained (i.e., in equilibrium, lies on a steeper portion of the supply schedule) and has a higher leverage and external finance premium.

Similar to the case of the single-entrepreneur analyzed above, the sensitivity of credit spreads for firms that are relatively more financially constrained is ex ante ambiguous. Ottonello and Winberry (2020) show that, theoretically, the investment of firms with high default risk can be more or less responsive to monetary policy, depending on how large the inward movement of the capital supply curve is relative to the shift in the demand curve.

A similar logic applies to credit spreads. When monetary policy tightens, and absent a shift in the capital supply curves, the less constrained (high net worth) firm experiences a smaller fall in credit spreads, as depicted by the movement from $\mathcal{A}$ to $\mathcal{B}$ in panel (B) of Figure 5. This means that the relative response of firms with high leverage would be negative, in contrast with our empirical results (see, for example, column (2) and (3) of Table 2). But, 
Figure A.2 A Monetary Policy Tightening: Heterogeneity
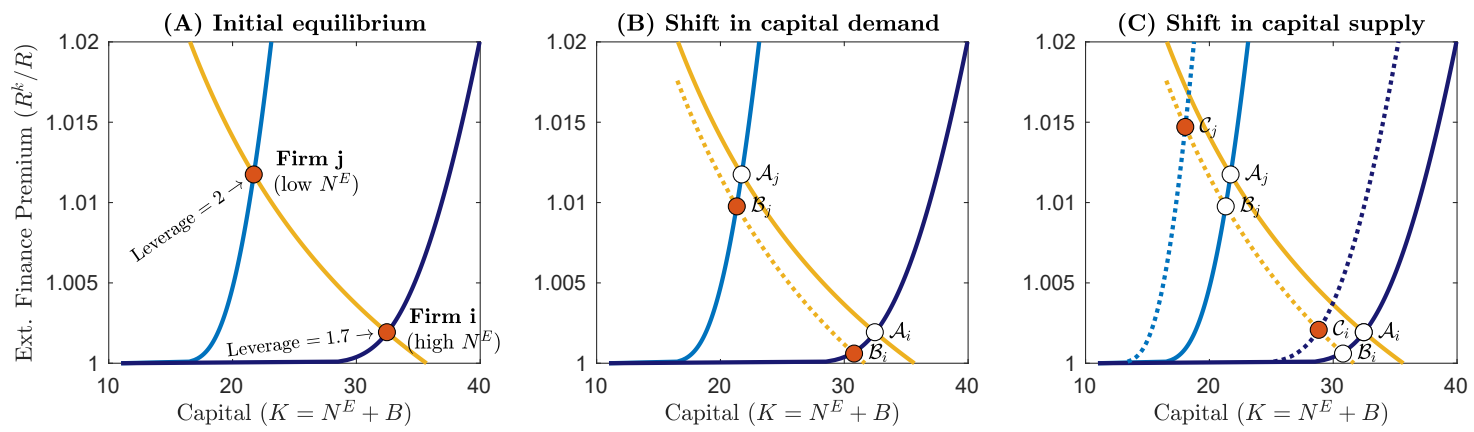

Note. Equilibrium in the credit market and effects of a monetary policy tightening for two firms with heterogeneous levels of net worth. Firm $j$ has low net worth, while firm $i$ has high net worth. On the horizontal axis is entrepreneurial capital $K=N^{E}+B$, where $N^{E}$ is entrepreneurial net worth and $B$ is entrepreneurial borrowing; and on the vertical axis is the external finance premium $R^{K} / R$. Panel (A) depicts the initial equilibrium. Panel (B) depicts the shift in the credit demand curve induced by the monetary policy tightening. Panel $(\mathrm{C})$ depicts the shift in the capital supply curves due to a tightening in financial constraints, assuming that monetary policy reduces entrepreneurial net worth $\left(N^{E}\right)$ and/or financial intermediaries' net worth $\left(N^{F I}\right)$.

if the shock also leads to an inward shift in the capital supply curves (via a tightening of financial constraints of either firms or intermediaries) this result can reverse. If the shift is large enough, credit spreads might increase, and might do so more for the high-leverage firm. The magnitude of the shift (both in absolute but also in relative terms) depends crucially on the strength of the financial frictions. In panel (C) of Figure 5 we assumed that the equilibrium moves from $\mathcal{B}$ to $\mathcal{C}$, consistent with our results in column (2) and (3) of Table 2 , which show that firms with higher-than-average leverage experience a larger-than-average increase in credit spreads in response to a monetary policy tightening. But the assumption is also consistent with the local projection results on firm-level quantities in Section 3.3, which show that in response to a monetary policy tightening, firm-level debt and investment of high-leverage firms decreases by more than low-leverage firms.

In sum, our empirical results are consistent with an inward shift in the capital supply curves that is large enough to make credit spreads increase by more and debt/investment decrease by more for high-leverage firms in response to a monetary policy tightening. If interpreted through the lens of our theoretical framework, this evidence points to a relevant role for financial constraints in the transmission of monetary policy. These results, however, are silent about the relative importance of financial constraints at the firm versus the intermediary level. This is true irrespective of whether we consider the response of credit spreads or debt/investment. 
Our decomposition of credit spreads into an expected default component and an excess bond premium component again helps to shed some light on these two separate mechanisms. Our empirical results in Table 7 show that the excess bond premia of high-leverage firms are, on average, more responsive to monetary policy than low leverage firms. The large and heterogeneous response of excess bond premia to monetary policy surprises suggests a role for a mechanism which is not directly related to changes in firms' default risk. As explained above, in our theoretical framework such a mechanism is provided by a fall in financial intermediaries' net worth.

When intermediaries' net worth falls, the external finance premium increases even when keeping entrepreneurial net worth and default probability initially fixed. Our empirical evidence is therefore consistent with a shift in the capital supply curves that is induced by a decline in financial intermediaries' net worth, and that is large enough to make the spreads of high-leverage firms to increase by more than low-leverage firms

One final consideration is in order here. Focusing on credit spreads rather than borrowing or investment provides more clear-cut, testable implications. As discussed above, in response to a contractionary monetary policy shock, the capital demand curve shifts inward along a firm's marginal cost of investment curve. As a result both borrowing and credit spreads fall. Balance sheet effects (on either firms or intermediaries) imply an inward shift of the marginal cost curve, which decreases borrowing further, but increases credit spreads. For both channels, a contractionary shock implies a fall in credit quantities, and so empirical investigations of the strength of the financial accelerator mechanism which focus on quantities need to test for a differential sensitivity of constrained and unconstrained firms to monetary policy. In contrast, credit spreads move in different directions depending on the strength of the financial accelerator mechanism. If the shift of the marginal cost curve dominates over the shift along the marginal cost curve, spreads increase. The opposite is true (i.e. credit spreads fall) if the the shift along the marginal cost curve dominates. Focusing on credit spreads therefore gives an additional dimension over which the predictions of theory can be tested, as we have predictions on both (1) the sign of the overall response of credit spreads, and on (2) the magnitude of the relative response of credit spreads in the cross-sectional dimension.

\section{B Data}

Corporate bond data. Corporate Bond data for the United States are sourced from the Intercontinental Exchange-Bank of America Merrill Lynch (ICE-BofAML) Global Index 
System. We focus on bonds in the Global Corporate Index (GOBC) and the Global High Yield Index (HWO0) over the period 1999-2017.

To measure corporate bond spreads, we use the Merrill Lynch "option adjusted spread" (OAS) on each bond. For bonds without embedded options, the spread reflects the number of basis points that the fair value government spot curve must be shifted so that the present discounted value of cash flows matches the price of the bond. For bonds with embedded options, ICE-BofAML use a log normal short interest rate model to calculate the present value of the bond's cash flows. The OAS is then calculated as the number of basis points that the short interest rate tree must be shifted so that the present discounted value of cash flows matches the price of the bond. ${ }^{29}$

As well as the OAS, we obtain a number of other bond characteristics from the ICEBofAML Global Index System. Specifically, we obtain data on each bond's age, market value, effective duration, coupon rate, as well as the industry of the issuer. We also use the bond-specific ISIN codes in the data set to obtain additional characteristics on the bonds from Thomson Reuters Datastream. Specifically we merge in information on the seniority of each bond, whether the bond is callable, the issue date of the bond, the redemption date of the bond and the ISO country code of the bond. We also use the Thomson Reuters Datastream to obtain information on the coupon rate and amount issued when it is missing from the ICE BofAML data.

Event study data set. In the event study data set the time dimension denotes FOMC meetings. In Table B.1 we summarize the characteristics of our US corporate bond sample which covers 156 FOMC meetings between August 1999 and November 2017. Our sample consists of 975 firms and 9, 413 bonds. In any given month, each firm has on average around 4 bonds outstanding, although the distribution is positively skewed, with some firms having many bonds outstanding in any given month. The average amount issued is $\$ 640$ million and the maximum amount issued is $\$ 15 \mathrm{bn}$. We consider both high yield and investment grade bonds. The median credit rating is BBB2. Around 60 percent of the bond observations in our sample are callable bonds.

Figure B.1 plots the average credit spread on outstanding bonds in our sample over the period 1999-2017. For comparison, we also plot the average credit spread calculated by Gilchrist and Zakrajsek (2012) (GZ). Our average credit spread closely tracks that of GZ other than for the period 2000-2003, for which the GZ average spread is more elevated. There are a number of reasons for the possible discrepancy between our measure and that of GZ. Firstly, the coverage of bonds in our data set differs from that of GZ. GZ use both

\footnotetext{
${ }^{29}$ For further details, see ICE Bond Index Methodologies (2017).
} 
Table B.1 Bond Data Set: Summary Statistics

\begin{tabular}{lccccc}
\hline & Mean & Std. Dev. & Min & Median & Max \\
\hline No. of Bonds per Firm/Month & 4.4 & 5.4 & 1.0 & 2.0 & 59.0 \\
Effective Yield (\%) & 4.8 & 2.8 & 0.1 & 4.5 & 38.2 \\
Spread (\%) & 2.3 & 2.4 & 0.1 & 1.6 & 35.0 \\
Coupon (\%) & 5.7 & 1.9 & 0.4 & 5.9 & 15.0 \\
Amount Issued (\$M) & 640 & 563 & 25 & 500 & 15,000 \\
Maturity at Issue (Years) & 14.8 & 9.6 & 1.5 & 10.0 & 50.0 \\
Time to Maturity (Years) & 10.7 & 8.6 & 1.0 & 7.4 & 30.0 \\
Effective Duration & 6.8 & 4.1 & 0.0 & 5.8 & 19.9 \\
Credit Rating (Composite) & - & - & $\mathrm{D}$ & $\mathrm{BBB2}$ & $\mathrm{AAA}$ \\
Callable (\% of Observations) & 63.0 & - & - & - & - \\
\hline
\end{tabular}

NoтE. Summary statistics for all bonds in our data set. The sample period covers 156 FOMC meetings between August 1999 and November 2017. The sample consists of 975 firms and 9,413 bonds..

Lehman/Warga and Merrill Lynch databases. The proportion of high yield bonds in our data set is relatively small at the beginning of our sample. If high yield bonds are more prominent in the GZ data set in these years, it may explain the elevated spreads. Secondly, the calculation of spreads is different in GZ. They construct a synthetic risk-free security with the same cash-flows as the corresponding corporate bond and then calculate the spread as the difference between the yield of the corporate bond and the yield of the synthetic security. No adjustment is made at this stage for callable bonds. In contrast, our spread measure is the "option-adjusted spread" calculated by ICE-BofAML.

Share price data. Market capitalization data is required for each firm in order to compute its distance to default using the Merton-KMV approach. For the United States, we use the Center for Research in Security Prices to obtain the daily share price and number of shares outstanding for the listed US firms within our bond price data set.

Balance sheet data for calculation of the excess bond premium. We also require balance sheet information on firm debt in order to compute the distance to default using the Merton-KMV model. The model requires daily data on current liabilities and long-term debt. For listed US firms in our bond price data set, we obtain quarterly balance sheet data from Compustat. We linearly interpolate between balance sheet observations to obtain a daily series for current liabilities and long-term debt.

Monetary policy surprises. We obtain intra-daily data on Federal funds futures contracts, eurodollar futures contracts, and S\&P500 returns from Reuters. More details on the surprises 
Figure B.1 Credit Spreads: Comparison with GZ

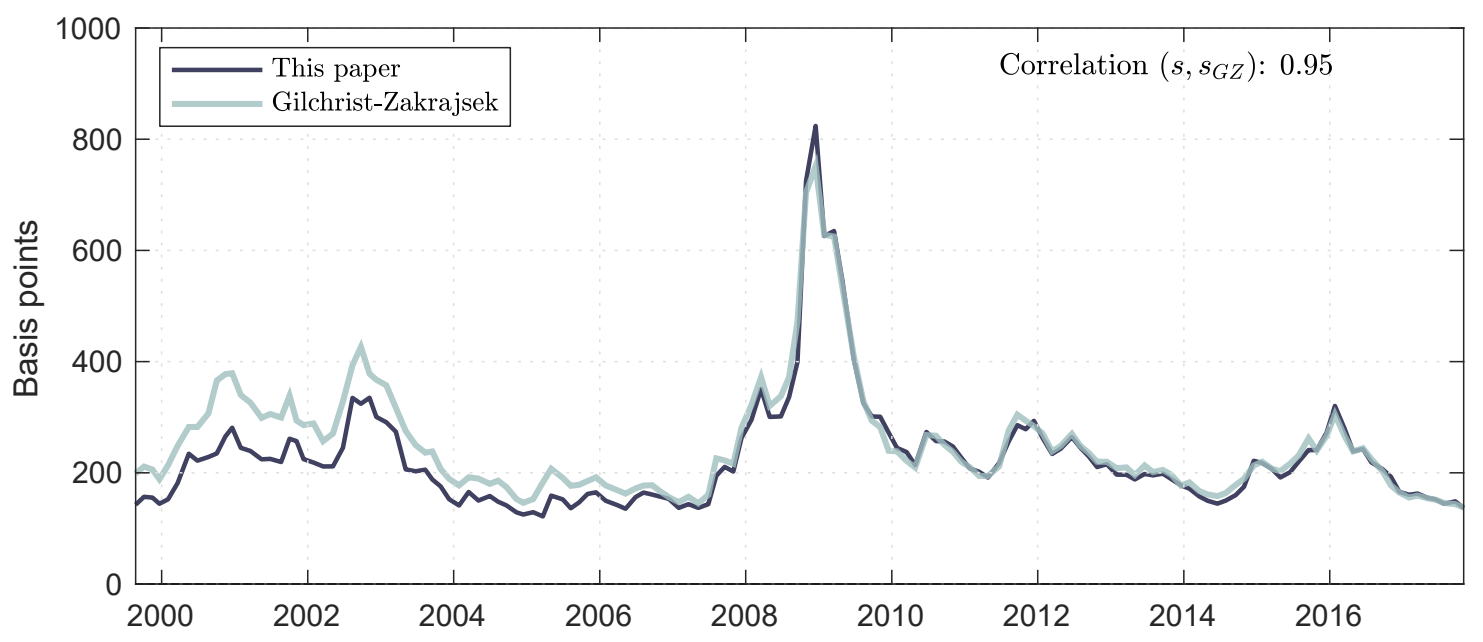

Note. The Figure plots the series of credit spreads used in this paper (solid dark line) and compares it with the series of credit spreads used in Gilchrist and Zakrajsek (2012) (thick light line).

are reported in Section C.

Investment. We closely follow the steps in Ottonello and Winberry (2020). In short, we compute investment as the log difference of a measure of the firm capital stock, namely $\Delta \log \left(k_{j, t+1}\right)$, where $k_{j, t+1}$ denotes the capital stock of firm $j$ at the end of period $t$. This is done by cumulating the changes of net plant, property, and equipment (ppentq, item 42) to the first available observations of gross plant, property, and equipment (ppegtq, item 118). We closely following the cleaning steps used in Ottonello and Winberry (2020). For more details, see their empirical Appendix.

Total debt. Total debt is the sum of Compustat items dlcq and dlttq (i.e. items 45 and $71)$.

Other Compustat variables. All other variables from Compustat used in our empirical analysis closely follow the definitions of the empirical Appendix of Ottonello and Winberry (2020).

Sectors in ICE BofAML data set. We use the finest available sector classification provided by ICE BofAML (level 4), which includes information on 59 sectors (reported in Table B.2). 
Table B.2 Sectors in BofAML Data Set

\begin{tabular}{ll}
\hline Sector name & Sector name \\
\hline Aerospace/Defense & Air Transportation \\
Personal \& Household Products & Environmental \\
Diversified Capital Goods & Oil Field Equipment \& Services \\
Support-Services & Auto Parts \& Equipment \\
Packaging & Tobacco \\
Electric-Generation & Discount Stores \\
Electric-Integrated & Integrated Energy \\
Machinery & Trucking \& Delivery \\
Electric-Distr/Trans & Real Estate Dev \& Mgt \\
Gas Distribution & Printing \& Publishing \\
Steel Producers/Products & Non-Electric Utilities \\
REITs & Gaming \\
Media Content & Energy - Exploration \& Production \\
Media - Diversified & Tech Hardware \& Equipment \\
Telecom - Wireline Integrated \& Services & Food - Wholesale \\
Telecom - Wireless & Oil Refining \& Marketing \\
Cable \& Satellite TV & Metals/Mining Excluding Steel \\
Building \& Construction & Beverage \\
Pharmaceuticals & Forestry/Paper \\
Medical Products & Restaurants \\
Health Facilities & Rail \\
Software/Services & Recreation \& Travel \\
Theaters \& Entertainment & Hotels \\
Specialty Retail & Advertising \\
Electronics & Auto Loans \\
Managed Care & Department Stores \\
Chemicals & Telecom - Satellite \\
Food \& Drug Retailers & Automakers \\
Health Services & Transport Infrastructure/Services \\
Building Materials & \\
\hline & \\
\hline & \\
\hline
\end{tabular}

\section{Monetary Policy surprises}

To construct the monetary policy surprises we closely follow the methodology detailed in Jarociński and Karadi (2020). Specifically, we identify monetary policy surprises by decomposing 30-minute surprises in the S\&P 500 stock market index $\left(s_{t}^{e q}\right)$ and the 3-month federal funds futures contract $\left(s_{t}^{F F 4}\right)$ using a sign restriction procedure. Specifically, we rotate the covariance matrix of $s=\left(s_{t}^{F F 4}, s_{t}^{e q}\right)$ with an orthonormal matrix and keep the draws that satisfy the following sign restrictions. 
Table C.1 IdentificAtion of $\epsilon^{m}$ : Sign Restrictions

\begin{tabular}{lcc}
\hline & $\begin{array}{c}\text { Monetary } \\
\text { shock }\left(\epsilon^{m}\right)\end{array}$ & $\begin{array}{c}\text { Non-monetary } \\
\text { shock }\left(\epsilon^{\text {other }}\right)\end{array}$ \\
\cline { 2 - 3 } Equity surprise $\left(s_{t}^{e q}\right)$ & - & + \\
Interest rate surprise $\left(s_{t}^{F F 4}\right)$ & + & + \\
\hline
\end{tabular}

Note. Signs imposed to decompose the high frequency surprise $s_{t}^{F F 4}$ into its monetary $\left(\epsilon^{m}\right)$ and non-monetary $\left(\epsilon^{\text {other }}\right)$ components.

Figure C.1 displays the behavior of $s_{t}^{F F 4}$ over time, while Figure 1 in the main text displays the underlying orthogonal monetary $\left(\epsilon^{m}\right)$ and non-monetary $\left(\epsilon^{\text {other }}\right)$ surprises that drive $s_{t}^{F F 4}$. The monetary surprise explains 75 percent of the total variance of $s_{t}^{F F 4}$.

Figure C.1 High Frequency Interest Rate Surprises

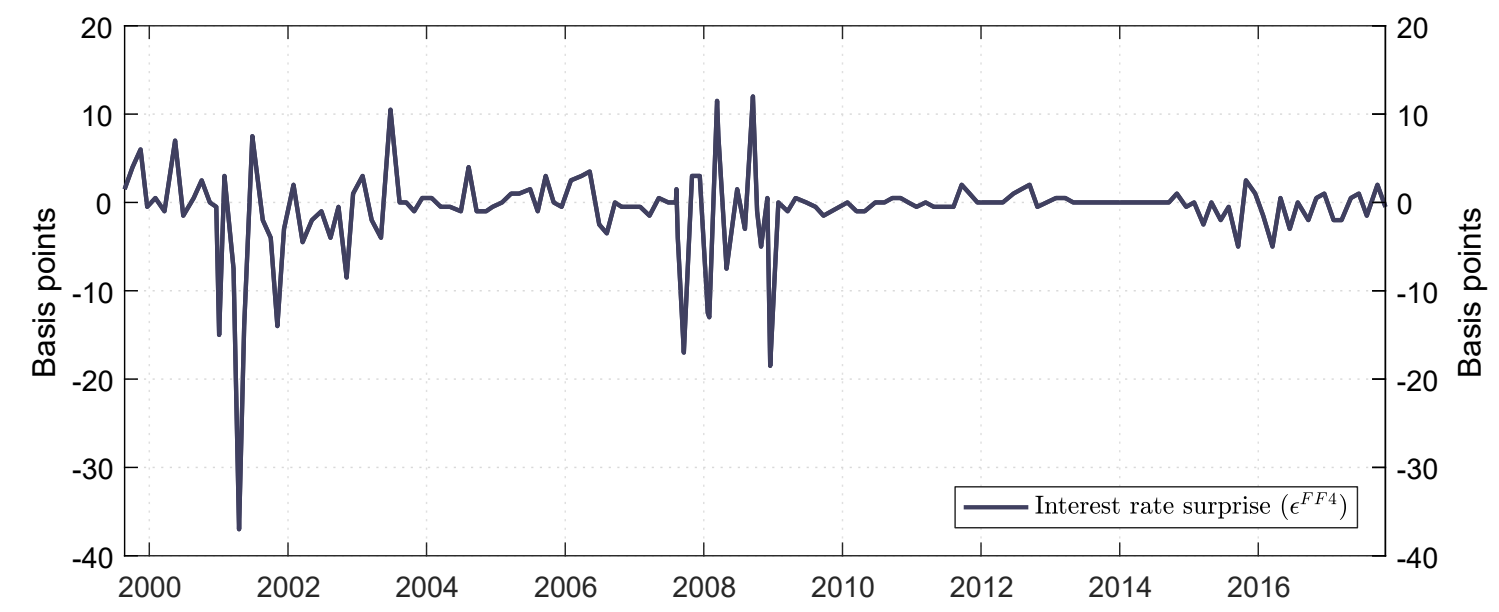

Note. This figure plots the raw 30-minute surprise in the 3-month ahead federal funds futures (FF4) contract $\left(s_{t}^{F F 4}\right)$ for each FOMC meeting in our sample.

We also obtain a very similar series of monetary surprises $\left(\epsilon^{m}\right)$ when, instead of using $s_{t}^{F F 4}$, we use a 'synthetic' interest rate obtained by extracting a principal component from a panel of (standardized) interest rates on different futures contracts $\left(s_{t}^{p c a}\right)$, namely federal funds futures (FF1 to FF6, i.e. the current-month contract rate and the contract rates for each of the next five months) and eurodollar futures (ED1 to ED8, i.e. the current quarter contract rate and the contract rates for each of the next seven quarters). This shows that the Jarociński and Karadi (2020) monetary policy surprise (i) is not affected by the noise that is inherent in a single futures contract and (ii) is robust to using information from interest rates at longer tenors - an advantageous feature given that a large part of our sample covers 
the zero lower bound. ${ }^{30}$

Figure C.2 plots the panel of (standardized) interest rates on different futures contracts, namely all the FF contracts and all the ED contracts. Not surprisingly, the Figure shows a high degree of comovement across futures contracts. However, the chart also reveals some differences, especially over the zero lower bound period.

Figure C.2 High Frequency Interest Rate Surprises: All Contracts

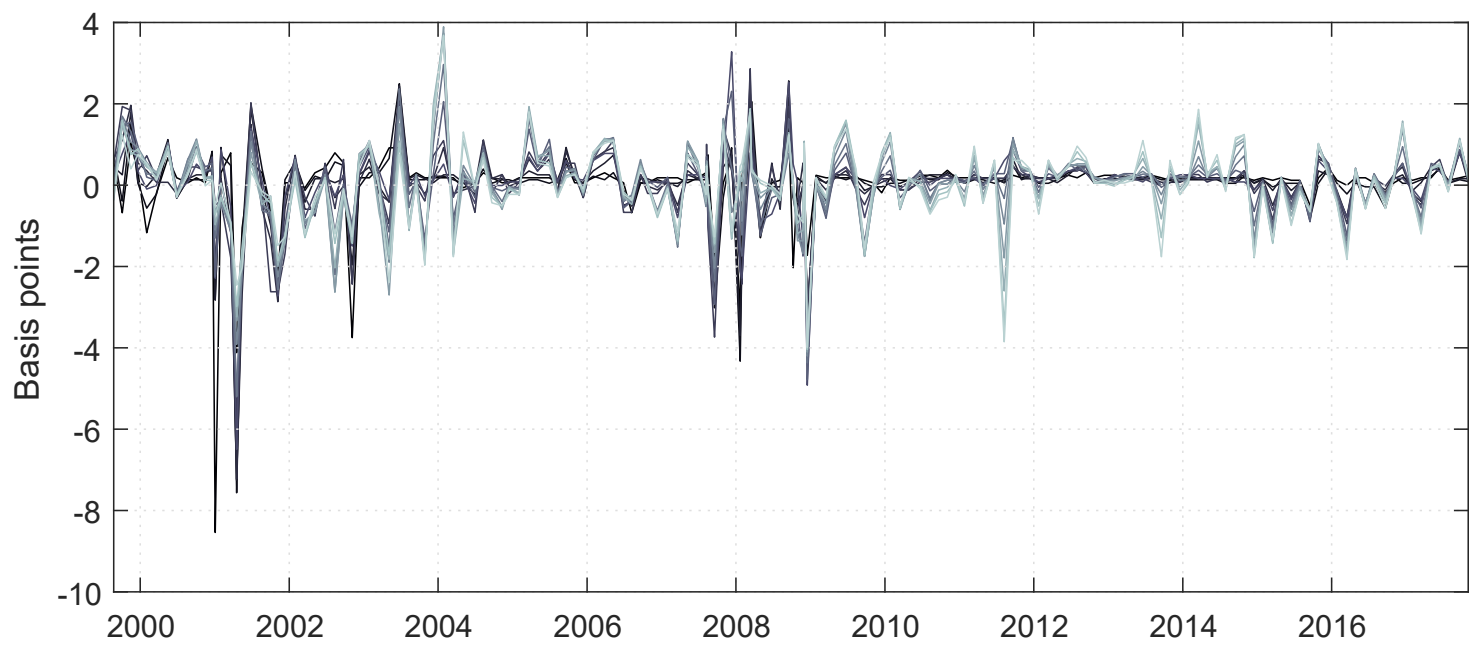

Note. Panel of interest rate surprises based on federal funds futures (FF1 to FF6) and eurodollar Futures (ED1 to ED8).

Figure C.3 reports a comparison between $s_{t}^{p c a}$ (the synthetic interest rate surprise, obtained by taking a principal component of the series in Figure C.2) and $s_{t}^{F F 4}$ (the more commonly used surprises in the 3-month federal funds futures). The correlation between $s_{t}^{p c a}$ and $s_{t}^{F F 4}$ is of 0.92 . This difference is mainly due to the zero lower bound period, where the synthetic series of interest rate surprises display more variation than the FF4 surprises.

We than apply the Jarociński and Karadi (2020) methodology using $s_{t}^{p c a}$ as the series of interest rate surprises. Figure C.4 reports a comparison between our baseline monetary policy surprises $\left(\epsilon^{m}\right)$, obtained using $s_{t}^{F F 4}$, and those obtained with $s_{t}^{p c a}$, which we label here $\epsilon_{t}^{m, p c a}$. The two series of monetary surprises are highly correlated, at 0.97 .

Finally, Table C.2 reports the summary statistics of the FF4 surprises $\left(s_{t}^{F F 4}\right)$, the Jarociński and Karadi (2020) monetary policy surprises $\left(\epsilon_{t}^{m}\right.$, i.e. our baseline measure of monetary surprises), and the monetary surprises based on $s_{t}^{p c a}\left(\epsilon_{t}^{m, p c a}\right)$.

\footnotetext{
${ }^{30}$ For example, Gürkaynak et al. (2005) argue that eurodollar futures were more liquid over our sample period than Fed Funds futures for maturities longer than two quarters. See also Swanson (2017).
} 
Figure C.3 High Frequency Surprises: $s_{t}^{F F 4}$ versus $s_{t}^{i}$

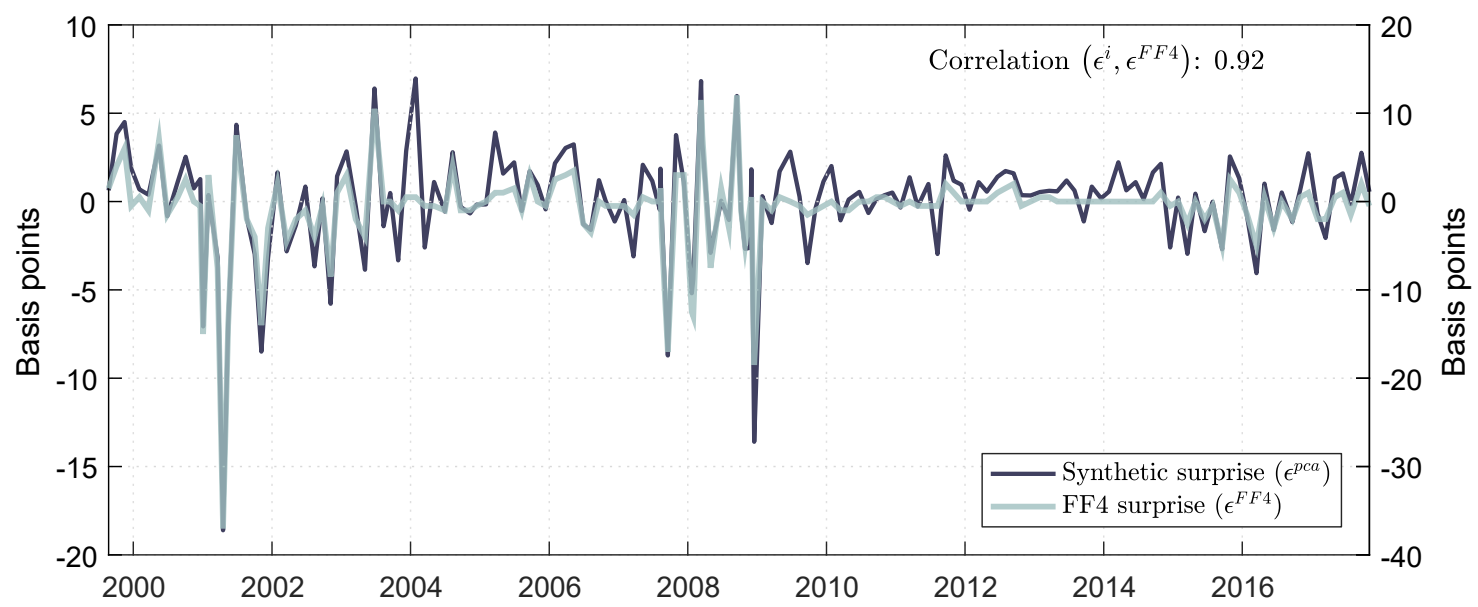

Note. The light line is the raw surprise in the 3-month ahead federal funds futures (FF4) contract $\left(s_{t}^{F F 4}\right.$. The dark line is a synthetic surprise obtained by extracting a principal component from a panel of (standardized) interest rates on different futures contracts, namely Federal Funds futures (FF1 to FF6) and eurodollar futures (ED1 to ED8). The principal component is computed over the longest available sample common to the interest rates futures series, which spans all FOMC meetings held between 1994 and 2017. The Figure plots the resulting principal component over the sample used in our empirical analysis, namely July 1997 to November 2017.

Figure C.4 High Frequency Monetary Shocks: $s_{t}^{F F 4}$ versus $s_{t}^{i}$

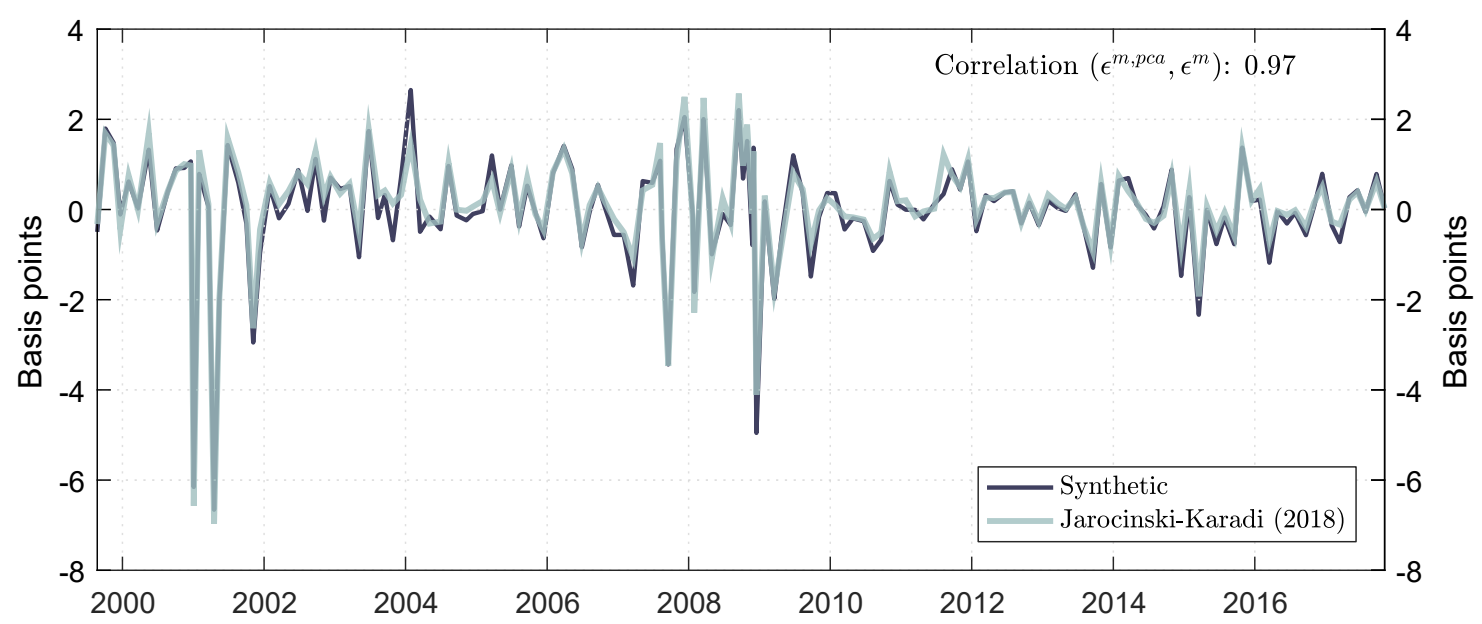

Note. The light line is our baseline monetary surprise $\left(\epsilon^{m}\right)$, obtained by applying the Jarociński and Karadi (2020) methodology using on $\left(s_{t}^{F F 4}, s_{t}^{e q}\right)$. The dark line is the monetary surprise obtained by applying the same methodology on $\left(s_{t}^{p c a}, s_{t}^{e q}\right)$, which we label here $\epsilon_{t}^{m, p c a}$. The two series of monetary surprises are highly correlated, at 0.97 . 
Table C.2 Interest Rate Surprises And Monetary Policy Shocks: Summary Statistics

\begin{tabular}{lccc}
\hline & $s_{t}^{F F 4}$ & $\epsilon_{t}^{m}$ & $\epsilon_{t}^{m, p c a}$ \\
\hline Average & -0.84 & 0.09 & -0.01 \\
St. Deviation & 5.08 & 1.21 & 1.23 \\
Skewness & -3.00 & -2.69 & -2.28 \\
Share of tightenings & $33 \%$ & $60 \%$ & $52 \%$ \\
Share of zeros & $22 \%$ & $0 \%$ & $0 \%$ \\
Share of loosenings & $45 \%$ & $40 \%$ & $48 \%$ \\
\hline
\end{tabular}

Note. Summary statistics of raw interest rate surprises, and the monetary policy surprises obtained with the methodology of Jarociński and Karadi (2020) based on $s_{t}^{F F 4}$ and $s_{t}^{p c a}$. 


\section{Leverage, Credit spreads, \& Credit ratings}

In our data the correlation between credit spreads and leverage is positive. Panel (A) of Figure D.1 reports a scatter plot of (average) firm level leverage on the horizontal axis against the (average) firm level credit spread. The (positive and significant) reduced form correlation between these two variables is in line with the predictions from the simple model outlined in Section A, where firm heterogeneity is driven by differences in net worth.

The positive correlation between leverage and credit spreads is also supportive of the fact that heterogeneity is not driven by monitoring costs $\mu$ or idiosyncratic variance $\sigma$. To see that, first note that, according to the theoretical model in Section A, for given net worth, a higher $\mu$ or a higher $\sigma$ would imply a higher credit spread and a lower leverage. If we assume that all the heterogeneity in the data is driven by differences in the monitoring cost or in the variance of the idiosyncratic surprises, we should observe a negative unconditional relation between credit spreads and leverage, which is clearly not the case in our sample.

The right panel of Figure D.1 makes a similar point to panel (A), showing that the correlation between leverage and credit ratings (where a high credit rating corresponds to a high number) is negative and highly statistically significant, i.e. firms with low leverage tend to have high credit ratings.

Figure D.1 Leverage, Credit spreads, \& Credit Ratings
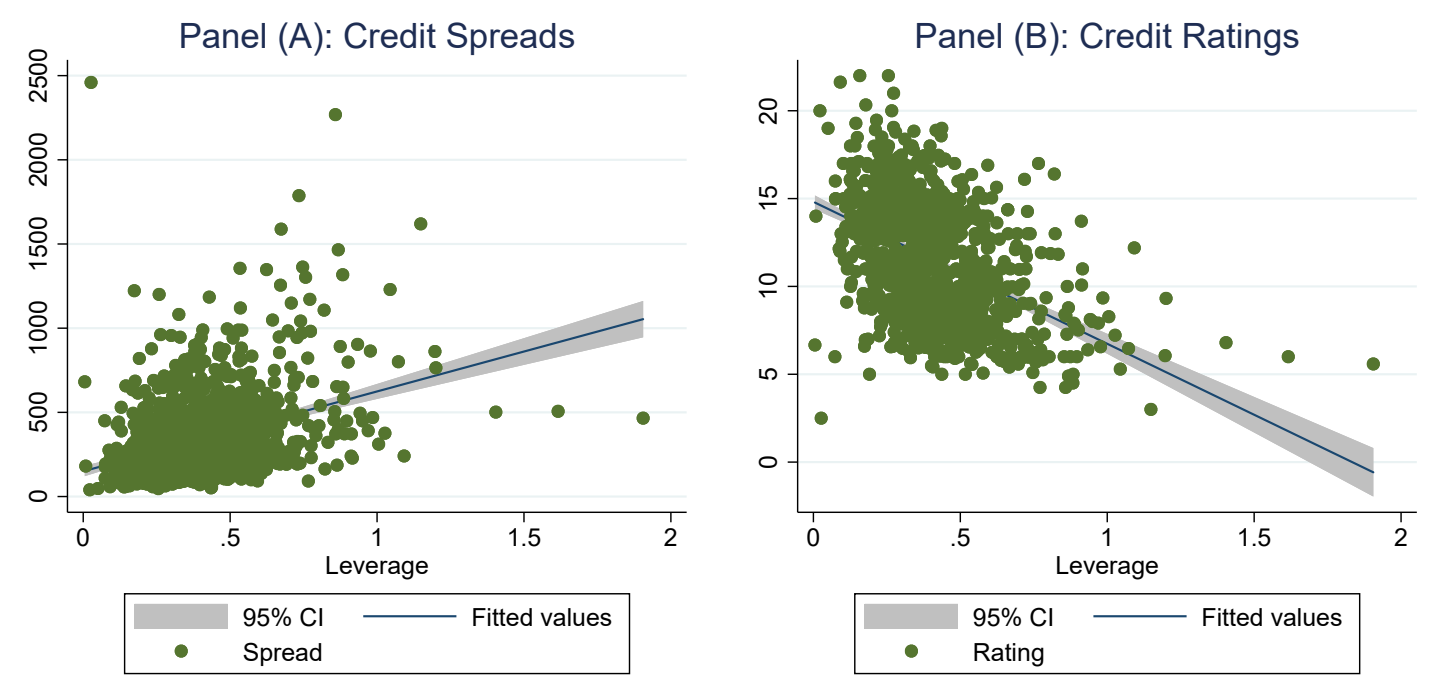

Note. The Figure reports a scatter plot of (average) firm level leverage on the horizontal axis against the (average) firm level credit spread (panel (A)) or the average firm-level credit rating (panel (B), where a high rating corresponds a high number). 


\section{E Merton-KMV Model \& Decomposing Credit Spreads}

In the paper we decompose credit spreads into two orthogonal components: a component capturing fluctuations in firms' expected defaults and a residual component capturing fluctuations of credit spreads in excess of firms' default compensation. In this Section we explain the procedure we used to obtain this decomposition, which closely follows Gilchrist and Zakrajsek (2012).

Specifically, we use the Merton-KMV framework to estimate the market value of firms in our data set and to calculate their distance to default. We follow the "iterative procedure" described in detail in Bharath and Shumway (2008). We assume that total firm value, $V$, follows a geometric Brownian motion:

$$
d V=\mu V d t+\sigma_{V} V d W
$$

where $\mu$ is the return on $V, \sigma_{V}$ is the volatility of $V$ and $d W$ is a standard Wiener process. Assuming that firm debt can be represented by a discount bond which matures at time $T$, the firm's equity value is given by the Black-Scholes-Merton equation:

$$
E=V \mathcal{N}\left(d_{1}\right)-e^{-r T} F \mathcal{N}\left(d_{2}\right)
$$

where $E$ is the market value of equity, $F$ is the face value of debt, $r$ is the risk-free rate and $\mathcal{N}($.$) is the cumulative standard normal distribution function. d_{1}$ and $d_{2}$ are given by:

$$
\begin{gathered}
d_{1}=\frac{\ln (V / F)+\left(r+0.5 \sigma_{V}^{2}\right) T}{\sigma_{V} \sqrt{T}} \\
d_{2}=d_{1}-\sigma_{V}
\end{gathered}
$$

The standard Merton model supplements (E.2) with a second equation obtained from Ito's Lemma, giving two equations in two unknowns ( $V$ and $\left.\sigma_{V}\right)$ which can be solved simultaneously. But as discussed in Bharath and Shumway (2008), the volatility of market leverage means that simultaneously solving the two equations rarely provides meaningful results. Instead we use the "iterative procedure". We begin by guessing the value of asset volatility, given by $\sigma_{V}=\sigma_{E}[E /(E+F)]$, where $\sigma_{E}$ is the volatility of the market value of equity. Using this guess, we use (E.2) to solve for the market value of the firm, $V$, for each day in the previous year. Using these estimates of the market value, we update our guess of $\sigma_{V}$ by calculating the volatility of returns over the previous year. We continue this process until our guess of $\sigma_{V}$ converges. Once the process has converged, we calculate the annual return 
on assets, $\mu$, using our estimates of the market value of the firm. The distance to default for the firm is given by:

$$
D D=\frac{\ln (V / F)+\left(\mu-0.5 \sigma_{V}^{2}\right) T}{\sigma_{V} \sqrt{T}}
$$

In estimating the distance to default for each firm, we follow the literature in considering a one year horizon for debt maturity $(T=1)$. We assume the face value of debt, $F$, is given by a firm's short-term debt plus half of its long-term debt. The volatility of equity, $\sigma_{E}$, is estimated using daily returns over the previous year.

Armed with a measure of firms' distance to default, we then use GZ's empirical corporate bond pricing framework to decompose credit spreads into two orthogonal components: a component capturing fluctuations in firms' expected default risk, and a residual component associated with the price of default risk (i.e., the excess bond premium, EBP, in GZ's parlance). Using our firm-specific measure of distance to default, we regress the (log) spread of bond $i$ for firm $j$ on the distance to default of firm $j$ and a vector of bond-specific controls:

$$
\ln \left(c s_{i j, t}\right)=\lambda D D_{j, t}+\gamma X_{i j, t}+e_{i j, t}
$$

where $c s_{i j, t}$ is the credit spread for firm $j$ on bond $i$ at time $t, D D_{j, t}$ is the firm-specific distance to default and $X_{i j, t}$ is a vector of bond-specific controls. The residuals obtained from estimating E.6 form our estimate of the bond-specific EBP. ${ }^{31}$

For comparability with GZ, we focus on senior unsecured bonds issued by domestic companies in the domestic currency. We exclude from our sample observations for which the spread is greater than 3500 basis points or below 5 basis points, bonds which have less than one year or more than thirty years to maturity and bonds which have a face value of less than $\$ 150$ million. Our vector of controls $X_{i j, t}$ includes the face value of the bond, its duration, the coupon rate, and the age of the bond. Similar to GZ, we also consider a correction for the bonds that are callable. ${ }^{32}$

In Table E.1 we present the results from the regression of corporate bond spreads on the distance to default and a number of bond controls (shown in equation (E.6)), which we use to decompose spreads into a component associated with the probability of default and the 'excess bond premium'.

Figure E.1 plots the decomposition of average spreads into the average fitted component

\footnotetext{
${ }^{31}$ Gilchrist and Zakrajsek (2012) define the excess bond premium at the aggregate level as the mean of the bond-specific excess bond premia.

${ }^{32}$ Gilchrist and Zakrajsek (2012) interact a dummy indicator of whether the bond is callable with the controls and the three 'yield curve factors' representing the level, slope and curvature of the yield curve. In contrast, we rely on an option adjustment that is calculated by our data provider.
} 


\section{Table E.1 Credit Spreads Decomposition:}

\section{OLS REGRESSION}

\begin{tabular}{lc}
\hline & $(\log )$ Spread $\left(\ln \left(c s_{i j, t}\right)\right)$ \\
\hline Distance to default & $-0.0550^{* * *}$ \\
& $(0.0002)$ \\
$\log ($ Age $)$ & $0.0089^{* * *}$ \\
& $(0.0004)$ \\
$\log ($ Issuance $)$ & $-0.0190^{* * *}$ \\
& $(0.0008)$ \\
$\log ($ Duration $)$ & $0.2758^{* * *}$ \\
& $(0.0008)$ \\
$\log ($ Coupon $)$ & $0.4137^{* * *}$ \\
& $(0.0014)$ \\
R-squared & 0.7491 \\
Observations & 897,892 \\
\hline Note. This Table reports the OLS estimation of Gilchrist and Zakrajsek (2012)'s regres- \\
sion. Corporate bond spreads are regressed on our proxy for the distance to default and a \\
number of bond controls, namely age, issuance, duration, and coupon, as well as industry \\
and rating fixed effects. The results from this regression allow us to decompose spreads \\
into a component associated with the probability of default (the fitted value) and the \\
excess bond premium (the residual). The asterisks denote statistical significance (*** for \\
$p<0.01, * *$ for $p<0.05, *$ for $p<0.1)$.
\end{tabular}

and the average excess bond premium using the regression results reported in Table E.1. In the five years prior to the financial crisis, the average excess bond premium was low (and largely negative). The average excess bond premium increased sharply during the financial crisis in 2008, peaking at 420 basis points in December 2008. Since the financial crisis, the average excess bond premium has fallen back, although remains at a slightly more elevated level than prior to the crisis.

Our average excess bond premium follows a similar profile to the excess bond premium calculated by GZ. The correlation over the whole sample period, from August 1999 to November 2017, is 0.77. Similar to the profiles of average spreads, shown in Figure E.2, the GZ excess bond premium is elevated relative to our measure for the period 2000-2003. Comparing our measure to the GZ excess bond premium over the period January 2003-November 2017 , the correlation coefficient is 0.96 .

Note that, in any case, some differences in the profile of the EBP are to be expected. Our sample period is different from the original sample used by GZ and they obtain credit spreads 
Figure E.1 Credit Spreads Decomposition:

Expected Default and the Excess Bond Premium

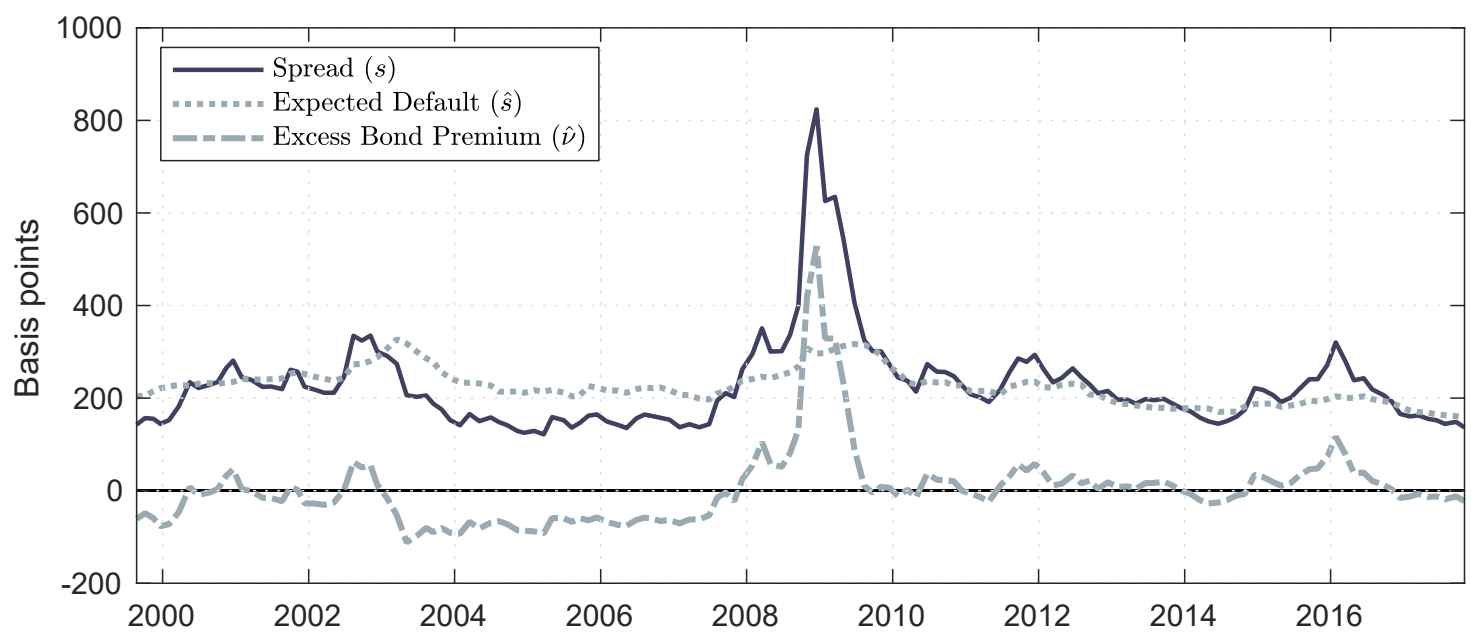

Note. The Figure plots the decomposition of average credit spreads into the average fitted component and the average excess bond premium, computed according the regression results reported in Table E.1.

Figure E.2 Excess Bond PRemium: Comparison with GZ

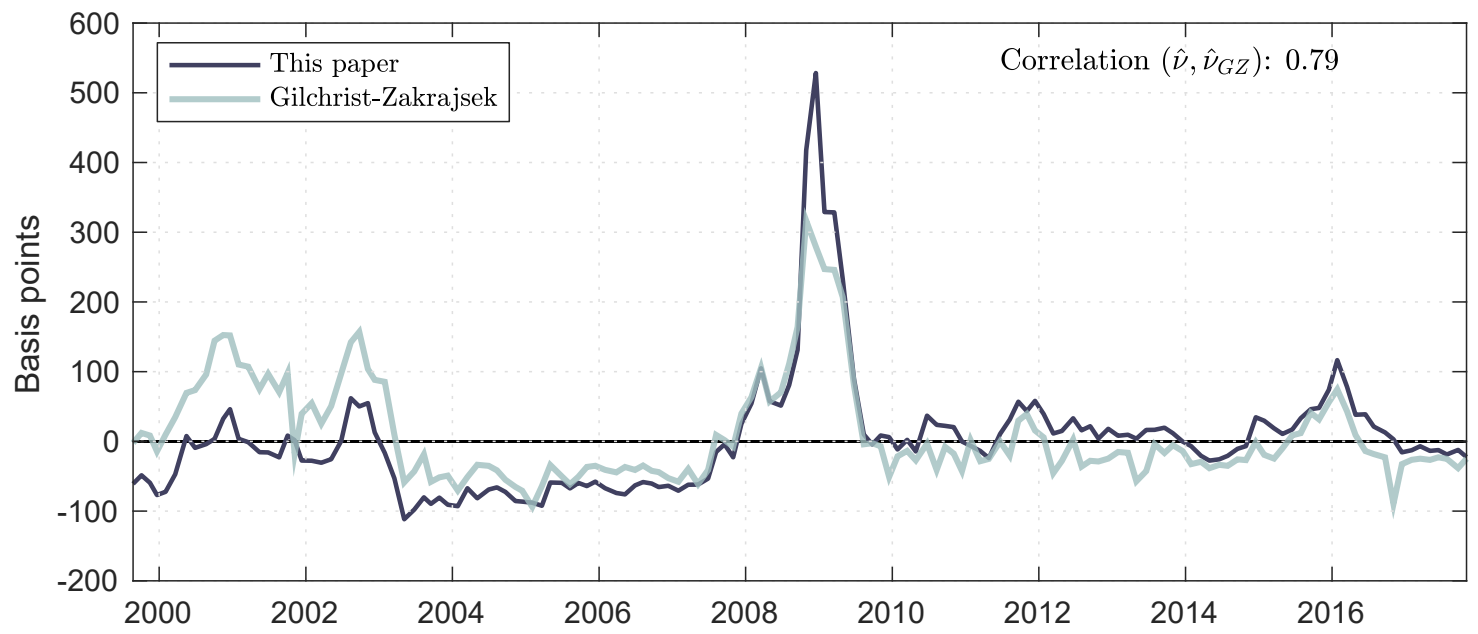

Note. The Figure reports a comparison of the average excess bond premium computed in this paper with the excess bond premium calculated by Gilchrist and Zakrajsek (2012). The correlation over the whole sample period, from August 1999 to November 2017, is 0.77.

from different sources. Moreover, we use credit spreads data bracketing FOMC announcements for the estimation of specification (E.6), while GZ use end of month observations. The high correlation between our EBP series and GZ's original one is reassuring suggesting that the EBP is robust to different specifications, data, and potential time variation in the 
estimated coefficients.

\section{F High Frequency Event Study: Additional results}

In this Section we describe additional results and robustness checks that are complementary to the findings reported in Section 3.

Table F.1 reports an extended version of Table 2. Specifically, while specification (3) is parsimonious and allows us to empirically test for the relative response of high versus low-leverage firms, it is also quite restrictive in that it imposes a linear relation between the sensitivity of credit spreads to monetary policy shocks and leverage. We relax this by splitting our sample of bond observations into quartiles based on where each firm lies in the leverage distribution. We then consider how the response of spreads to monetary policy shocks varies by leverage quartile. That is, we run the following more flexible specification:

$$
\Delta s_{i j, t}=\alpha_{i}+\beta_{1}\left(\epsilon_{t}^{m} \ell_{j, t-1}^{1}\right)+\beta_{2}\left(\epsilon_{t}^{m} \ell_{j, t-1}^{2}\right)+\beta_{3}\left(\epsilon_{t}^{m} \ell_{j, t-1}^{3}\right)+\beta_{4}\left(\epsilon_{t}^{m} \ell_{j, t-1}^{4}\right)+e_{i j, t}
$$

where $\ell_{j}^{k}=1$ when the leverage of firm $j$ falls in the $k^{\text {th }}$ quartile of the leverage distribution (and zero otherwise). Coefficients $\beta_{1}$ to $\beta_{4}$ capture the impact of monetary policy on credit spreads by leverage quartile. The results are reported in column (3) of Table F.1. They show that the response of credit spreads is increasing with the leverage quartiles, from 20 basis points for firms in the first leverage quartile to 40 basis points for firms in the fourth leverage quartile.

Table F.2 reports the same robustness exercises shown in Table 3 in the main body of the paper, but instead of using the high-leverage dummy $\ell_{j, t-1}^{H i g h}$ (which is equal to 1 when the leverage of firm $j$ lies above the median leverage in the distribution), we use the continuous leverage interaction $L_{j, t-1}$.

In order to address the concern that leverage might be correlated with other firm characteristics, in the main text we run a series of 'double-interaction' regressions - see equation (5). Similarly, Table F.3 reports the results from the estimation of equation (5) using the

continuous leverage interaction $L_{j, t-1}$, rather than the high-leverage dummy $\ell_{j, t-1}^{H i g h}$. The results are unchanged.

Tables F.4 and F.5 report the results from an exercise where we consider the interaction between monetary policy surprises and alternative proxies for financial constraints, instead of leverage. Specifically, we consider firm (log) size, sales growth, credit rating, time since IPO, a measure of the firm's distance to default (calculated using the Merton-KMV frame- 
work, detailed in Appendix E), the ratio between total debt and EBITDA, and the measure of a firm's liquid assets used in Jeenas (2018). Table F.4 considers the interaction of monetary policy surprises with high financial constraint dummies, $x_{j, t-1}^{H i g h}$, while F.5 considers continuous measures of financial constraints, $x_{j, t-1}$.

In Table F.6 we report the results from estimating specification (1) after standardizing the fitted spreads $\hat{c s}_{i j, t}$ and the excess bond premium $\hat{\nu}_{i j, t}$, which we label $\widetilde{\Delta \hat{c}}_{i j, t}$ and $\widetilde{\Delta \hat{\nu}}_{i j, t}$. We do this to check that the result in Table 6-that monetary policy transmits to credit spreads mainly via the excess bond premium - does not simply reflect the higher variance of $\hat{\nu}_{i j, t}$ relative to $\hat{c}_{i j, t}$. The results show that the response of $\widetilde{\Delta \hat{\nu}_{i j, t}}$ is still larger than $\widetilde{\Delta \hat{c} s}_{i j, t}$.

Table F.7 reports the results from a simple time series regression of credit spreads (and their decomposition into fitted spreads and excess bond premium) on the monetary policy surprises. We do this by taking an average of the credit spread of all outstanding bonds at each time period $t$, using the amount issued with each bond as a weight.

Table F.8 reports the estimation results from the simple specification (1) for different monetary surprises. The average response of credit spreads to the raw interest rate surprises $\left(s_{t}^{F F 4}\right)$ is estimated at 10 basis points, as shown in column (1). This estimate is almost three times smaller than the credit spread response to monetary surprises $\left(\epsilon^{m}\right)$, reported in column (2). The estimate in column (1) not only is smaller, but also is less statistically significant, with a p-value of 0.08 relative to a p-value of less than 0.01 in our baseline. These differences could reflect the fact that an increase in $s_{t}^{F F 4}$ is, in general, due to a linear combination of two forces that have opposing effects on credit spreads: (i) a monetary policy contraction $\left(\epsilon^{m}\right)$ that acts to increase credit spreads; and (ii) a systematic monetary policy tightening by the central bank to respond to improved demand conditions $\left(\epsilon_{t}^{\text {other }}\right)$, which acts to compress credit spreads (see Jarociński and Karadi, 2020). Consistent with this interpretation, the response of credit spreads to non-monetary news $\left(\epsilon_{t}^{\text {other }}\right)$ is strongly negative at -25 basis points (as shown in column (3) of Table F.8), even though is not statistically significant. 
Table F.1 Heterogeneous Response of Credit Spreads: Alternative Baseline Specifications

\begin{tabular}{|c|c|c|c|c|}
\hline Dep. Variable: $\Delta c s_{i j}$ & (1) & $(2)$ & (3) & (4) \\
\hline & Baseline & $\begin{array}{l}\text { Low/High } \\
\text { Leverage }\end{array}$ & $\begin{array}{c}\text { Leverage } \\
\text { Interaction }\end{array}$ & $\begin{array}{c}\text { Leverage } \\
\text { quartile }\end{array}$ \\
\hline MP surp. $\left(\epsilon^{m}\right)$ & $\begin{array}{c}27.68^{* *} \\
(10.62)\end{array}$ & & $\begin{array}{c}26.84^{* *} \\
(10.56)\end{array}$ & \\
\hline MP surp. $\times$ Lev. $\left(\epsilon^{m} \times L_{j}\right)$ & & & $\begin{array}{l}11.09^{*} \\
(6.61)\end{array}$ & \\
\hline MP surp. $\times$ Lev. Q1 $\left(\epsilon^{m} \times \ell_{j}^{1}\right)$ & & & & $\begin{array}{c}19.73^{* * *} \\
(6.43)\end{array}$ \\
\hline MP surp. $\times$ Lev. Q2 $\left(\epsilon^{m} \times \ell_{j}^{2}\right)$ & & & & $\begin{array}{c}22.60^{* *} \\
(9.03)\end{array}$ \\
\hline MP surp. $\times$ Lev. Q3 $\left(\epsilon^{m} \times \ell_{j}^{3}\right)$ & & & & $\begin{array}{c}24.56^{* *} \\
(9.96)\end{array}$ \\
\hline MP surp. $\times$ Lev. Q4 $\left(\epsilon^{m} \times \ell_{j}^{4}\right)$ & & & & $\begin{array}{c}39.63^{* *} \\
(18.56)\end{array}$ \\
\hline MP surp. $\times$ Low Lev. $\left(\epsilon^{m} \times \ell_{j}^{\text {Low }}\right)$ & & $\begin{array}{c}21.15^{* * *} \\
(7.35)\end{array}$ & & \\
\hline MP surp. $\times$ High Lev. $\left(\epsilon^{m} \times \ell_{j}^{H i g h}\right)$ & & $\begin{array}{c}31.54^{* *} \\
(13.68)\end{array}$ & & \\
\hline Double clustering & Yes & Yes & Yes & Yes \\
\hline Time-sector FE & No & No & No & No \\
\hline R-squared & 0.034 & 0.031 & 0.030 & 0.031 \\
\hline Observations & 285,794 & 279,974 & 285,794 & 279,974 \\
\hline
\end{tabular}

Note. Results from estimating specifications (1), (2), (3), and (F.1), where $\epsilon_{t}^{m}$ is the monetary policy surprise; $\Delta c s_{i t}$ is the change in spreads between the day before the FOMC announcement and five days after the announcement; $\alpha_{i}$ is a bond fixed-effect; $L_{j}$ is the (standardized) leverage of firm $j ; \ell_{j, t-1}^{H i g h}=1$ when firm $j$ leverage lies above the median of the leverage distribution (and zero otherwise), while $\ell_{j, t-1}^{L o w}=1$ when firm $j$ leverage lies below the median of the leverage distribution (and zero otherwise); $\ell_{j, t-1}^{k}=1$ when firm $j$ leverage lies in the $k^{\text {th }}$ quartile of the leverage distribution (and zero otherwise). Standard errors (reported in parentheses) are clustered two-way, at the firm level and time level. Credit spreads are measured in basis points and the size of the surprise is normalized so that it corresponds to a 25 basis points increase in the 1-year T-bill. 
Table F.2 Heterogeneous Response of Credit Spreads: Robustness To Continuous Leverage

\begin{tabular}{lccccc}
\hline Dep. Variable: $\Delta c s_{i j}$ & $(1)$ & $(2)$ & $(3)$ & $(4)$ & $(5)$ \\
\hline & $\begin{array}{c}\text { Time- } \\
\text { sector } \\
\text { FE }\end{array}$ & Controls & $\begin{array}{c}\text { Within } \\
\text { Leverage }\end{array}$ & IV & Pre-crisis \\
& & & & \\
\hline MP surp. $\times$ Lev. $\left(\epsilon^{m} \times L_{j}\right)$ & $13.59^{*}$ & $13.21^{*}$ & & & $17.42^{* * *}$ \\
& $(7.28)$ & $(7.54)$ & & & $(5.08)$ \\
MP surp. $\times$ Lev. $\left(\epsilon^{m} \times \tilde{L}_{j}\right)$ & & & $11.40^{* *}$ & & \\
& & & $(5.46)$ & & \\
1yr Rate x Lev. $\left(\epsilon^{m} \times L_{j}\right)$ & & & & \\
& & & & & \\
& Yes & Yes & Yes & Yes & Yes \\
Double clustering & Yes & Yes & Yes & Yes & Yes \\
Time-sector FE & 0.309 & 0.304 & 0.309 & -0.028 & 0.345 \\
R-squared & 279,603 & 267,306 & 279,603 & 279,603 & 52,056 \\
Observations & & & & & \\
\hline
\end{tabular}

Note. Results from estimating specification (4), namely $\Delta c s_{i j, t}=\alpha_{i}+\beta_{s c t, t}+\gamma\left(\epsilon_{t}^{m} L_{j, t-1}\right)+\delta L_{j, t-1}+e_{i j, t}$ and its variants described in the text, where $\epsilon_{t}^{m}$ is the monetary policy surprise; $\Delta c s_{i t}$ is the change in spreads between the day before the FOMC announcement and five days after the announcement; $L_{j}$ is the (standardized) leverage of firm $j ; \alpha_{i}$ is a bond fixed-effect; $\beta_{s c t, t}$ is a time-sector fixed effect; $\tilde{L}_{j}$ is the within-firm $\left(L_{j, t-1}-\mathbb{E}_{j}\left[L_{j, t-1}\right]\right)$ standardized leverage; 1yr Rate is the 1-year T-bill. Standard errors (reported in parentheses) are clustered two-way, at the firm level and time level. Additional controls include firm ( $\log$ ) size, sales growth, credit rating, and time since IPO. Credit spreads are measured in basis points and the size of the surprise is normalized so that it corresponds to a 25 basis points increase in the 1-year T-bill. 
Table F.3 Heterogeneous Response of Credit Spreads to Monetary Policy: Double Sorting (Continuous)

\begin{tabular}{|c|c|c|c|c|c|c|c|c|}
\hline Dep. Variable: $\Delta c s_{i j}$ & (1) & $(2)$ & $(3)$ & $(4)$ & $(5)$ & $(6)$ & $(7)$ & (8) \\
\hline & Baseline & Size & $\begin{array}{l}\text { Sales } \\
\text { Growth }\end{array}$ & $\begin{array}{l}\text { Credit } \\
\text { Rating }\end{array}$ & $\begin{array}{l}\text { Time } \\
\text { IPO }\end{array}$ & DD & $\begin{array}{l}\text { Debt- } \\
\text { Ebitda }\end{array}$ & $\begin{array}{l}\text { Liquid } \\
\text { Assets }\end{array}$ \\
\hline MP surp. $\times$ Lev. $\left(\epsilon^{m} \times L_{j}\right)$ & $\begin{array}{c}13.43^{*} \\
(7.32)\end{array}$ & $\begin{array}{c}14.26^{*} \\
(7.81)\end{array}$ & $\begin{array}{c}13.54^{*} \\
(7.35)\end{array}$ & $\begin{array}{l}9.79^{*} \\
(5.36)\end{array}$ & $\begin{array}{c}13.23^{*} \\
(7.16)\end{array}$ & $\begin{array}{c}11.83^{*} \\
(7.04)\end{array}$ & $\begin{array}{l}13.83^{*} \\
(7.81)\end{array}$ & $\begin{array}{l}13.46^{*} \\
(7.32)\end{array}$ \\
\hline MP surp. $\times$ Size $\left(\epsilon^{m} \times X_{j}\right)$ & & $\begin{array}{c}2.64 \\
(5.63)\end{array}$ & & & & & & \\
\hline MP surp. $\times$ Sales growth $\left(\epsilon^{m} \times X_{j}\right)$ & & & $\begin{array}{c}1.01 \\
(1.86)\end{array}$ & & & & & \\
\hline MP surp. $\times$ Credit rating $\left(\epsilon^{m} \times X_{j}\right)$ & & & & $\begin{array}{l}-8.52 \\
(7.75)\end{array}$ & & & & \\
\hline MP surp. $\times$ Time IPO $\left(\epsilon^{m} \times X_{j}\right)$ & & & & & $\begin{array}{l}-1.32 \\
(3.51)\end{array}$ & & & \\
\hline MP surp. $\times \mathrm{DD}\left(\epsilon^{m} \times X_{j}\right)$ & & & & & & $\begin{array}{l}-6.92 \\
(5.76)\end{array}$ & & \\
\hline MP surp. $\times$ Debt-Ebitda $\left(\epsilon^{m} \times X_{j}\right)$ & & & & & & & $\begin{array}{c}3.20 \\
(2.89)\end{array}$ & \\
\hline MP surp. $\times$ Liquid Assets $\left(\epsilon^{m} \times X_{j}\right)$ & & & & & & & & $\begin{array}{c}0.86 \\
(1.13)\end{array}$ \\
\hline Double clustering & Yes & Yes & Yes & Yes & Yes & Yes & Yes & Yes \\
\hline Time-sector FE & Yes & Yes & Yes & Yes & Yes & Yes & Yes & Yes \\
\hline R-squared & 0.309 & 0.309 & 0.309 & 0.310 & 0.309 & 0.310 & 0.311 & 0.309 \\
\hline Observations & 279,603 & 279,603 & 279,075 & 277,288 & 279,603 & 277,281 & 251,257 & 279,597 \\
\hline
\end{tabular}

Note. Results from estimating specification (5), namely $\Delta c s_{i j, t}=\alpha_{i}+\beta_{s c t, t}+\gamma\left(\epsilon_{t}^{m} L_{j, t-1}\right)+\delta\left(\epsilon_{t}^{m} X_{j, t-1}\right)+\Gamma W_{j, t-1}+e_{i j, t}$, where $\epsilon_{t}^{m}$ is the monetary policy surprise; $\Delta c s_{i t}$ is the change in spreads between the day before the FOMC announcement and five days after the announcement; $\alpha_{i}$ is a bond fixed-effect; $\beta_{s c t, t}$ is a time-sector fixed effect; $L_{j}$ is the (standardized) leverage of firm $j ; X_{j}$ is a (standardized) generic characteristic of firm $j$, namely size, sales growth, credit rating, time since IPO, distance to default (DD), debt-to-EBITDA ratio, and liquid assets lies above the median of its distribution (and zero otherwise). Standard errors (reported in parentheses) are clustered two-way, at the firm level and time level. Credit spreads are measured in basis points and the size of the surprise is normalized so that it corresponds to a 25 basis points increase in the 1-year T-bill. 
Table F.4 Heterogeneous Response of Credit Spreads: Other Interactions (High/Low Dummy)

\begin{tabular}{|c|c|c|c|c|c|c|c|}
\hline Dep. Variable: $\Delta c s_{i j}$ & (1) & (2) & $(3)$ & $(4)$ & $(5)$ & (6) & (7) \\
\hline & Size & $\begin{array}{l}\text { Sales } \\
\text { Growth }\end{array}$ & $\begin{array}{l}\text { Credit } \\
\text { Rating }\end{array}$ & Time IPO & $\mathrm{DD}$ & $\begin{array}{l}\text { Debt- } \\
\text { Ebitda }\end{array}$ & $\begin{array}{l}\text { Liquid } \\
\text { Assets }\end{array}$ \\
\hline MP surp. $\times$ Size $\left(\epsilon^{m} \times x_{j}^{H i g h}\right)$ & $\begin{array}{l}-3.18 \\
(7.49)\end{array}$ & & & & & & \\
\hline MP surp. $\times$ Sales growth $\left(\epsilon^{m} \times x_{j}^{H i g h}\right)$ & & $\begin{array}{l}-6.35 \\
(6.67)\end{array}$ & & & & & \\
\hline MP surp. $\times$ Credit rating $\left(\epsilon^{m} \times x_{j}^{H i g h}\right)$ & & & $\begin{array}{c}-14.76 \\
(8.99)\end{array}$ & & & & \\
\hline MP surp. $\times$ Time IPO $\left(\epsilon^{m} \times x_{j}^{H i g h}\right)$ & & & & $\begin{array}{l}-3.30 \\
(5.58)\end{array}$ & & & \\
\hline MP surp. $\times$ Time DD $\left(\epsilon^{m} \times x_{j}^{H i g h}\right)$ & & & & & $\begin{array}{l}-7.27 \\
(9.22)\end{array}$ & & \\
\hline MP surp. $\times$ Time Debt-Ebitda $\left(\epsilon^{m} \times x_{j}^{H i g h}\right)$ & & & & & & $\begin{array}{c}22.55^{* *} \\
(10.57)\end{array}$ & \\
\hline MP surp. $\times$ Liquid Assets $\left(\epsilon^{m} \times x_{j}^{\text {High }}\right)$ & & & & & & & $\begin{array}{c}1.24 \\
(3.97)\end{array}$ \\
\hline Double clustering & Yes & Yes & Yes & Yes & Yes & Yes & Yes \\
\hline Time-sector FE & Yes & Yes & Yes & Yes & Yes & Yes & Yes \\
\hline R-squared & 0.320 & 0.320 & 0.321 & 0.320 & 0.321 & 0.310 & 0.320 \\
\hline Observations & 285,272 & 284,732 & 283,076 & 285,332 & 283,069 & 251,257 & 285,262 \\
\hline
\end{tabular}

Note. Results from estimating equation (4), where $\epsilon_{t}^{m}$ is the monetary policy surprise; $\Delta c s_{i t}$ is the change in spreads between the day before the FOMC announcement and five days after the announcement; $\alpha_{i}$ is a bond fixed-effect; $\beta_{s c t, t}$ is a time-sector fixed effect; $x_{j, t-1}^{H i g h}=1$ when a given characteristic $(X)$ of firm $j$, namely size, sales growth, credit rating, time since IPO, distance to default (DD), debt-to-EBITDA ratio, and liquid assets lies above the median of its distribution (and zero otherwise). Standard errors (reported in parenthesis) are clustered at the firm level. Credit spreads are measured in basis points and the size of the surprise is normalized so that it corresponds to a 25 basis points increase in the 1-year T-bill. 
Table F.5 Heterogeneous Response of Credit Spreads: Other Interactions (Continuous)

\begin{tabular}{|c|c|c|c|c|c|c|c|}
\hline Dep. Variable: $\Delta c s_{i j}$ & $(1)$ & $(2)$ & $(3)$ & $(4)$ & $(5)$ & $(6)$ & $(7)$ \\
\hline & Size & $\begin{array}{l}\text { Sales } \\
\text { Growth }\end{array}$ & $\begin{array}{l}\text { Credit } \\
\text { Rating }\end{array}$ & Time IPO & $\mathrm{DD}$ & $\begin{array}{l}\text { Debt- } \\
\text { Ebitda }\end{array}$ & $\begin{array}{l}\text { Liquid } \\
\text { Assets }\end{array}$ \\
\hline MP surp. $\times$ Size $\left(\epsilon^{m} \times X_{j}\right)$ & $\begin{array}{l}-2.00 \\
(5.17)\end{array}$ & & & & & & \\
\hline MP surp. $\times$ Sales growth $\left(\epsilon^{m} \times X_{j}\right)$ & & $\begin{array}{l}-0.25 \\
(2.33)\end{array}$ & & & & & \\
\hline MP surp. $\times$ Credit rating $\left(\epsilon^{m} \times X_{j}\right)$ & & & $\begin{array}{c}-13.80 \\
(8.94)\end{array}$ & & & & \\
\hline MP surp. $\times$ Time IPO $\left(\epsilon^{m} \times X_{j}\right)$ & & & & $\begin{array}{l}-3.64 \\
(4.16)\end{array}$ & & & \\
\hline MP surp. $\times \mathrm{DD}\left(\epsilon^{m} \times X_{j}\right)$ & & & & & $\begin{array}{c}-13.52^{*} \\
(7.40)\end{array}$ & & \\
\hline MP surp. $\times$ Debt-Ebitda $\left(\epsilon^{m} \times X_{j}\right)$ & & & & & & $\begin{array}{c}1.27 \\
(2.24)\end{array}$ & \\
\hline MP surp. $\times$ Liquid Assets $\left(\epsilon^{m} \times X_{j}\right)$ & & & & & & & $\begin{array}{c}0.04 \\
(1.36)\end{array}$ \\
\hline Double clustering & Yes & Yes & Yes & Yes & Yes & Yes & Yes \\
\hline Time-sector FE & Yes & Yes & Yes & Yes & Yes & Yes & Yes \\
\hline R-squared & 0.320 & 0.320 & 0.322 & 0.320 & 0.322 & 0.310 & 0.320 \\
\hline Observations & 285,272 & 284,732 & 283,076 & 285,332 & 283,069 & 251,257 & 285,262 \\
\hline
\end{tabular}

NoтE. Results from estimating equation (4), where $\epsilon_{t}^{m}$ is the monetary policy surprise; $\Delta c s_{i t}$ is the change in spreads between the day before the FOMC announcement and five days after the announcement; $\alpha_{i}$ is a bond fixed-effect; $\beta_{s c t, t}$ is a time-sector fixed effect; $X_{j, t-1}$ is a (standardized) generic characteristic of firm $j$, namely size, sales growth, credit rating, time since IPO, distance to default (DD), debt-to-EBITDA ratio, and liquid assets lies above the median of its distribution (and zero otherwise). Standard errors (reported in parenthesis) are clustered at the firm level. Credit spreads are measured in basis points and the size of the surprise is normalized so that it corresponds to a 25 basis points increase in the 1-year T-bill. 
Table F.6 Expected Default and Excess Bond Premium:

StANDARDized SERIES

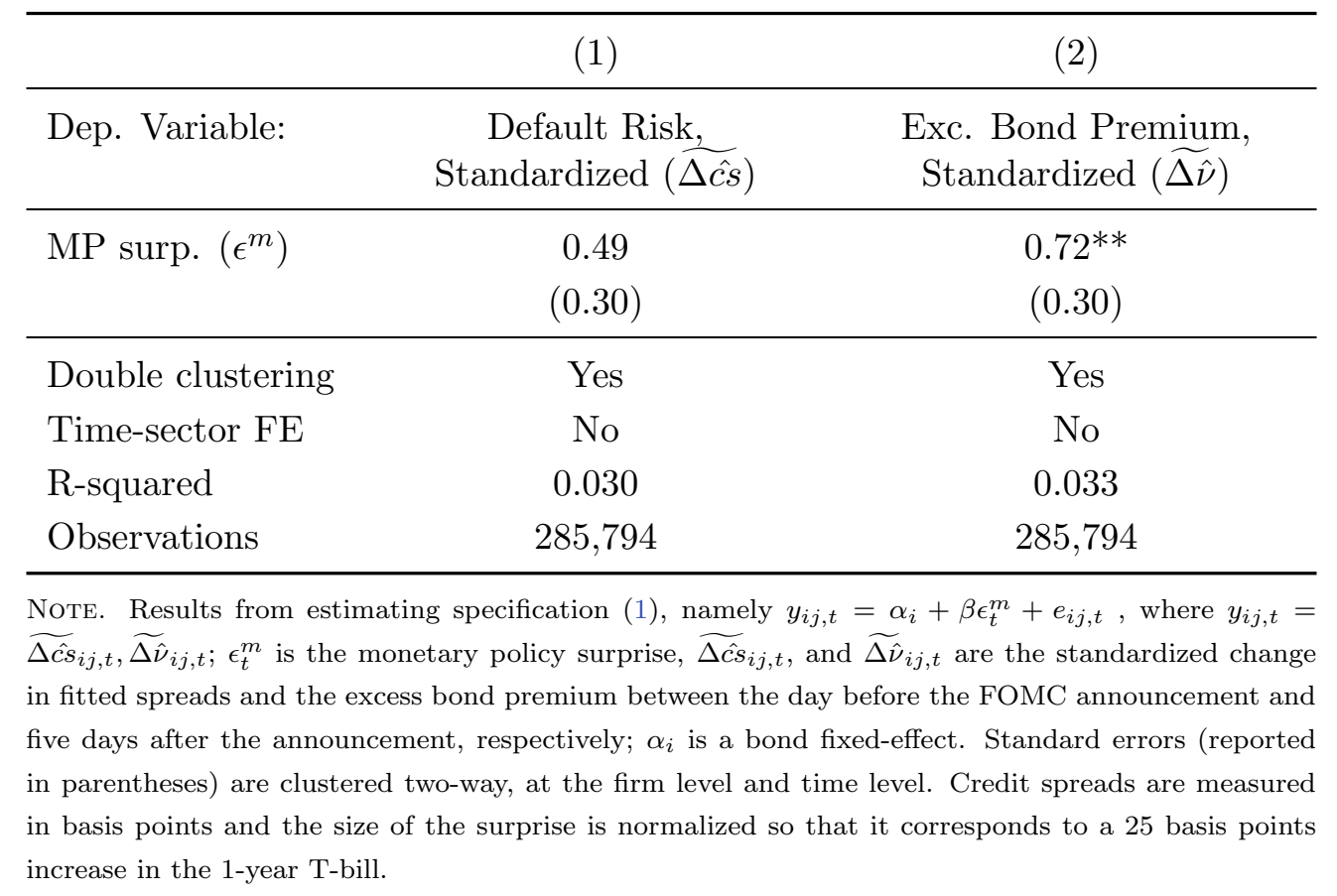

Table F.7 Expected Default and Excess Bond Premium: Time Series

\begin{tabular}{lccc}
\hline Dep. Variable: & $\begin{array}{c}\text { Spread } \\
(\Delta c s)\end{array}$ & $\begin{array}{c}\text { Default Risk } \\
(\Delta \hat{c} s)\end{array}$ & $\begin{array}{c}\text { Exc. Bond Premium } \\
(\Delta \hat{\nu})\end{array}$ \\
\hline MP surp. $\left(\epsilon^{m}\right)$ & $24.17^{* * *}$ & 2.00 & $22.17^{* * *}$ \\
& $(7.12)$ & $(1.43)$ & $(6.59)$ \\
\hline Double clustering & No & No & No \\
Time-sector FE & No & No & No \\
R-squared & 0.070 & 0.013 & 0.068 \\
Observations & 156 & 156 & 156 \\
\hline
\end{tabular}

Note. Results from estimating a simple time series regression of credit spreads (and their decomposition into fitted spreads and excess bond premium) on the monetary policy surprises, namely $y_{t}=\alpha_{i}+\beta \epsilon_{t}^{m}+e_{t}$, where $y_{i t}=\Delta c s_{t}, \Delta \hat{c} s_{t}, \Delta \hat{\nu}_{t} ; \epsilon_{t}^{m}$ is the monetary policy surprise, $\Delta c s_{t}, \Delta \hat{c s}_{t}$, and $\Delta \hat{\nu}_{t}$ are the change in spreads, fitted spreads and the excess bond premium between the day before the FOMC announcement and five days after the announcement, respectively, on average across all outstanding bonds at each time $t$ (using the amount issued with each bond as a weight); $\alpha_{i}$ is a constant. Standard errors are reported in parentheses. Credit spreads are measured in basis points and the size of the surprise is normalized so that it corresponds to a 25 basis points increase in the 1-year T-bill. 
Table F.8 Average Response of Credit Spreads://Monetary Vs. Non-Monetary Surprises

\begin{tabular}{lccc}
\hline Dep. Variable: $\Delta c s_{i j}$ & $(1)$ & $(2)$ & $(3)$ \\
\hline Indep. Variable: & $\begin{array}{r}\text { Interest rate surp. } \\
\left(s^{F F 4}\right)\end{array}$ & $\begin{array}{c}\text { Monetary surp. } \\
\left(\epsilon^{m}\right)\end{array}$ & $\begin{array}{c}\text { Non-monetary } \\
\text { surp. }\left(\epsilon^{\text {other }}\right)\end{array}$ \\
\hline MP surp. $(\epsilon)$ & $10.15^{*}$ & $27.68^{* *}$ & -24.91 \\
& $(5.86)$ & $(10.62)$ & $(16.47)$ \\
\hline Time-Sector FE & No & No & No \\
Double clustering & Yes & Yes & Yes \\
R-squared & 0.034 & 0.030 & 0.033 \\
Observations & 285,794 & 285,794 & 285,794 \\
\hline
\end{tabular}

Note. Results from estimating specification (1), namely $y_{i j, t}=\alpha_{i}+\beta \epsilon_{t}^{m}+e_{i j, t}$, with different high frequency surprises. In column (1) the independent variable is the raw FF4 surprise $\left(s_{t}^{F F 4}\right)$; in column (2) is our baseline monetary surprise $\left(\epsilon_{t}^{m}\right)$; and in column (3) is the non-monetary surprise $\left(\epsilon_{t}^{o t h e r}\right) ; \Delta c s_{i t}$ is the change in spreads between the day before the FOMC announcement and five days after the announcement. Standard errors (reported in parentheses) are clustered two-way, at the firm level and time level. Credit spreads are measured in basis points and the size of the surprise is normalized so that it corresponds to a 25 basis points increase in the 1-year T-bill. The asterisks denote statistical significance $\left(* * *\right.$ for $p<0.01,{ }^{* *}$ for $p<0.05,{ }^{*}$ for $\left.p<0.1\right)$. 


\section{G Local Projections: Additional results}

In this Section we report additional exercises that show the robustness of our main analysis using local projections and allow us to compare our findings to those of recent studies in the literature.

First, we compare our results on debt and investment to Cloyne et al. (2018), Jeenas (2018), and Ottonello and Winberry (2020) by estimating our specification on pre-crisis data. Relative to these studies, our sample of firms is smaller (as we keep only firms for which we can match credit spread data) and the series of monetary surprises is different. Figure G.1 reports the relative impulse responses based on specification (6) for total debt (Panel (A)) and investment (Panel (B)). As in our full sample results, the impulse responses in Figure G.1 show that high-leverage firms contract their debt and investment by more than low-leverage firms. Again, as in our baseline, the relative response on debt is more precisely estimated than the relative response of investment.

Second, as discussed in the main text, Ottonello and Winberry (2020) argue that it is important to use within-firm variation in leverage - rather than the firm's leverage in the previous quarter - as an interaction variable, to control for permanent differences in firm leverage. We therefore estimate specification (6) for debt and investment using a dummy variable that is based on within-firm variation in leverage, namely $\mathcal{L}_{j, t-1}=L_{j, t-1}-\mathbb{E}_{j}\left[L_{j, t-1}\right]$, as an interaction variable. Figure G.2 shows that our results are not materially affected by the definition of the interaction variable. 


\section{Figure G.1 Heterogeneous Response of Debt and Investment: Pre-CRISIS SAMPle}

(A) Total debt

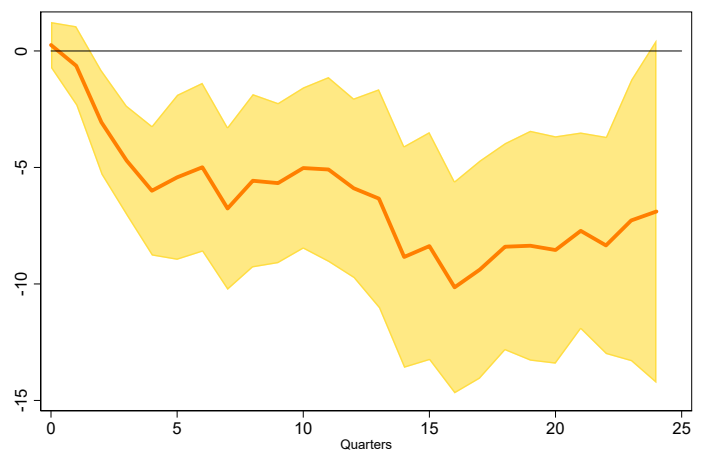

(B) Investment

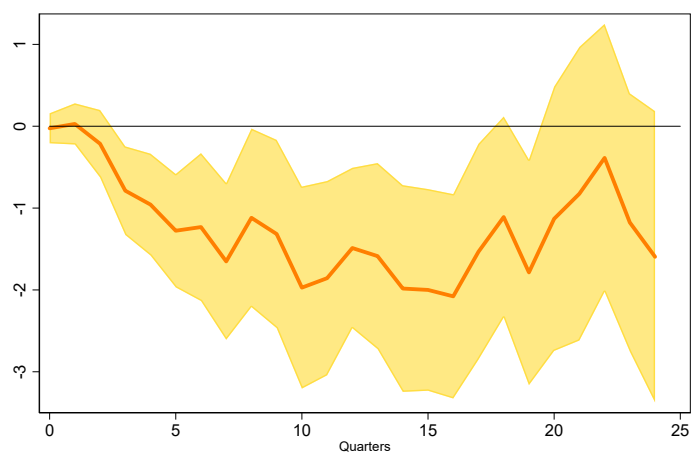

Note. Relative impulse response of total debt and investment with data up to 2007:Q4. The impulse responses $\left(\gamma^{h}\right)$ are estimated with the local projection specification in (6), namely $y_{j, t+h}-y_{j, t-1}=\alpha_{j}^{h}+\beta_{s c t, t}+\gamma^{h} \epsilon_{\tau}^{m} \ell_{j, t-1}^{H i g h}+\sum_{p=1}^{P} \Gamma_{p} W_{j, t-p}+e_{j, t+h}$, where $h=0,1,2, \ldots, 24 ; j ; \epsilon_{\tau}^{m}$ is the monetary policy surprise; $\alpha_{i}$ is a bond fixed-effect; $\beta_{s c t, t}$ is a time-sector fixed effect; $\ell_{j, t-1}^{H i g h}=1$ when firm $j$ leverage lies above the median of the leverage distribution (and zero otherwise); the vector $W_{j, t}$ includes the following firm-level controls, namely leverage, size, real sales growth and current assets share. The shaded areas display 90 percent confidence intervals based on two-way clustered (quarter and firm) standard errors.

\section{Figure G.2 Heterogeneous Response of Debt and Investment: Pre-Crisis Sample \& Within-Firm Leverage}

(A) Total debt

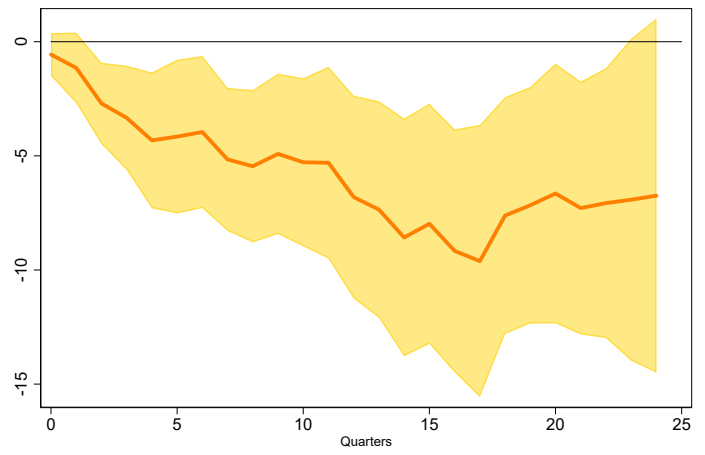

(B) Investment

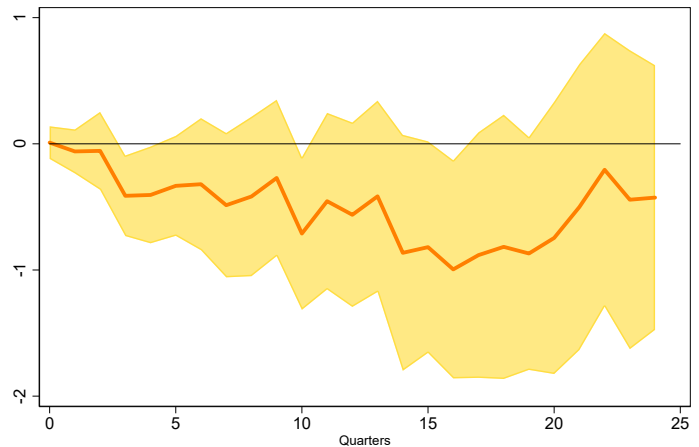

Note. Relative impulse response of total debt and investment with data up to 2007:Q4. The impulse responses $\left(\gamma^{h}\right)$ are estimated with the local projection specification in (6), namely $y_{j, t+h}-y_{j, t-1}=\alpha_{j}^{h}+\beta_{s c t, t}+\gamma^{h}\left(\epsilon_{\tau}^{m} \mathcal{L}_{j, t-1}\right)+\sum_{p=1}^{P} \Gamma_{p} W_{j, t-p}+e_{j, t+h}$, where $h=0,1,2, \ldots, 24 ; j ; \epsilon_{\tau}^{m}$ is the monetary policy surprise; $\alpha_{i}$ is a bond fixed-effect; $\beta_{s c t, t}$ is a time-sector fixed effect; $\mathcal{L}_{j, t-1} 1$ is defined by $L_{j, t-1}-\mathbb{E}_{j}\left[L_{j, t-1}\right]$; the vector $W_{j, t}$ includes the following firm-level controls, namely leverage, size, real sales growth and current assets share. The shaded areas display 90 percent confidence intervals based on two-way clustered (quarter and firm) standard errors. 


\section{References}

Bahaj, S., A. Foulis, G. Pinter, And P. Surico (2018): "Employment and the Collateral Channel of Monetary Policy," Discussion Papers 1832, Centre for Macroeconomics (CFM).

Barakchian, S. M. And C. Crowe (2013): "Monetary Policy Matters: Evidence from New Shocks Data," Journal of Monetary Economics, 60, 950-966.

Bauer, M. D. and E. T. Swanson (2020): “The Fed's Response to Economic News Explains the \&quot;Fed Information Effect\&quot;", NBER Working Papers 27013, National Bureau of Economic Research, Inc.

Bernanke, B. And M. Gertler (1989): "Agency Costs, Net Worth, and Business Fluctuations," American Economic Review, 79, 14-31.

Bernanke, B. S. And A. S. Blinder (1992): "The Federal Funds Rate and the Channels of Monetary Transmission," American Economic Review, 82, 901-921.

Bernanke, B. S. and M. Gertler (1995): "Inside the Black Box: The Credit Channel of Monetary Policy Transmission," Journal of Economic Perspectives, 9, 27-48.

Bernanke, B. S., M. Gertler, and S. Gilchrist (1999): "The Financial Accelerator in a Quantitative Business Cycle Framework," in Handbook of Macroeconomics, ed. by J. B. Taylor and M. Woodford, Elsevier, vol. 1, chap. 21, 1341-1393.

Bharath, S. T. And T. Shumway (2008): "Forecasting Default with the Merton Distance to Default Model," Review of Financial Studies, 21, 1339-1369.

Caldara, D. And E. Herbst (2019): "Monetary Policy, Real Activity, and Credit Spreads: Evidence from Bayesian Proxy SVARs," American Economic Journal: Macroeconomics, 11, 157-92.

Chudik, A. And G. Georgiadis (2019): "Estimation of Impulse Response Functions When Shocks are Observed at a Higher Frequency than Outcome Variables," Working Paper Series 2307, European Central Bank.

Cloyne, J., C. Ferreira, M. Froemel, and P. Surico (2018): "Monetary Policy, Corporate Finance and Investment," NBER Working Papers 25366, National Bureau of Economic Research, Inc.

Crouzet, N. and N. R. Mehrotra (2020): "Small and Large Firms Over the Business Cycle," forthcoming in American Economic Review.

Drechsel, T. (2018): "Earnings-Based Borrowing Constraints and Macroeconomic Fluctuations," Unpublished manuscript.

Duffee, G. R. (1998): "The Relation Between Treasury Yields and Corporate Bond Yield Spreads," Journal of Finance, 53, 2225-2241.

Farre-Mensa, J. And A. Luungqvist (2016): "Do Measures of Financial Constraints Measure Financial Constraints?" Review of Financial Studies, 29, 271-308.

Gazzani, A. G. And A. Vicondoa (2019): "Proxy-SVAR as a Bridge for Identification with Higher Frequency Data," 2019 Meeting Papers 855, Society for Economic Dynamics.

Gertler, M. And S. Gilchrist (1994): "Monetary Policy, Business Cycles, and the Behavior of Small Manufacturing Firms," The Quarterly Journal of Economics, 109, 309-340. 
Gertler, M. And P. Karadi (2011): "A Model of Unconventional Monetary Policy," Journal of Monetary Economics, 58, 17-34.

(2015): "Monetary Policy Surprises, Credit Costs, and Economic Activity," American Economic Journal: Macroeconomics, 7, 44-76.

Gertler, M. and N. Kiyotaki (2010): "Financial Intermediation and Credit Policy in Business Cycle Analysis," in Handbook of Monetary Economics, ed. by B. M. Friedman and M. Woodford, Elsevier, vol. 3 of Handbook of Monetary Economics, chap. 11, 547-599.

Gilchrist, S., B. Wei, V. Yue, And E. Zakrajsek (2020): "The Fed Takes on Corporate Credit Risk: An Analysis of the Efficacy of the SMCCF," CEPR Discussion Papers 15258, C.E.P.R. Discussion Papers.

Gilchrist, S., V. Yankov, and E. Zakrajsek (2009): "Credit Market Shocks and Economic Fluctuations: Evidence from Corporate Bond and Stock Markets," Journal of Monetary Economics, 56, 471-493.

Gilchrist, S. And E. Zakrajsek (2012): "Credit Spreads and Business Cycle Fluctuations," American Economic Review, 102, 1692-1720.

Greenwald, D. (2019): "Firm Debt Covenants and the Macroeconomy: The Interest Coverage Channel," 2019 Meeting Papers 520, Society for Economic Dynamics.

Gurkaynak, R. S., G. Karasoy Can, and S. S. Lee (2019): "Stock Market's Assessment of Monetary Policy Transmission: The Cash Flow Effect," CEPR Discussion Papers 14017, C.E.P.R. Discussion Papers.

Gürkaynak, R. S., B. Sack, And E. Swanson (2005): "Do Actions Speak Louder Than Words? The Response of Asset Prices to Monetary Policy Actions and Statements," International Journal of Central Banking, 1.

Hadlock, C. J. AND J. R. Pierce (2010): "New Evidence on Measuring Financial Constraints: Moving Beyond the KZ Index," Review of Financial Studies, 23, 1909-1940.

Ippolito, F., A. K. Ozdagli, And A. Perez-Orive (2018): "The Transmission of Monetary Policy through Bank Lending: The Floating Rate Channel," Journal of Monetary Economics, 95, 49-71.

Jarociński, M. And P. Karadi (2020): "Deconstructing Monetary Policy Surprises-The Role of Information Shocks," American Economic Journal: Macroeconomics, 12, 1-43.

Jeenas, P. (2018): "Monetary Policy Shocks, Financial Structure, and Firm Activity: A Panel Approach," Unpublished manuscript.

JordA, O. (2005): "Estimation and Inference of Impulse Responses by Local Projections," American Economic Review, 95, 161-182.

Kalemli-Ozcan, S., L. Laeven, and D. Moreno (2018): "Debt Overhang, Rollover Risk, and Corporate Investment: Evidence from the European Crisis," NBER Working Papers 24555, National Bureau of Economic Research, Inc.

Kashyap, A. K., O. A. Lamont, and J. C. Stein (1994): "Credit Conditions and the Cyclical Behavior of Inventories," The Quarterly Journal of Economics, 109, 565-592.

Kashyap, A. K. And J. C. Stein (1995): "The Impact of Monetary Policy on Bank Balance Sheets," Carnegie-Rochester Conference Series on Public Policy, 42, 151-195.

(2000): "What Do a Million Observations on Banks Say about the Transmission of Monetary Policy?" American Economic Review, 90, 407-428. 
Kuttner, K. (2001): "Monetary Policy Surprises and Interest Rates: Evidence from the Fed Funds Futures Market," Journal of Monetary Economics, 47, 523-544.

Lakdawala, A. And T. Moreland (2019): "Monetary Policy and Firm Heterogeneity: The Role of Leverage Since the Financial Crisis," Unpublished manuscript.

Levin, A. T., F. M. Natalucci, and E. Zakrajsek (2004): "The Magnitude and Cyclical Behavior of Financial Market Frictions," Finance and Economics Discussion Series 2004-70, Board of Governors of the Federal Reserve System (U.S.).

Lian, C. AND Y. MA (2019): “Anatomy of Corporate Borrowing Constraints," Unpublished manuscript.

Lunsford, K. G. (2018): "Understanding the Aspects of Federal Reserve Forward Guidance," Working Papers (Old Series) 1815, Federal Reserve Bank of Cleveland.

Melosi, L. (2017): "Signalling Effects of Monetary Policy," Review of Economic Studies, 84, 853-884.

Miranda-Agrippino, S. And G. Ricco (2020): "The Transmission of Monetary Policy Shocks," forthcoming in American Economic Journal: Macroeconomics.

Nakamura, E. And J. Steinsson (2018): "High Frequency Identification of Monetary Non-Neutrality: The Information Effect," Quarterly Journal of Economics, 133, 1283-1330.

Ottonello, P. And T. Winberry (2020): "Financial Heterogeneity and the Investment Channel of Monetary Policy," forthcoming in Econometrica.

Ozdagli, A. And M. Weber (2017): "Monetary Policy through Production Networks: Evidence from the Stock Market," Working Paper 23424, National Bureau of Economic Research.

Ozdagli, A. K. (2018): "Financial Frictions and the Stock Price Reaction to Monetary Policy," Review of Financial Studies, 31, 3895-3936.

Ramey, V. (2016): Macroeconomic Shocks and Their Propagation, Elsevier, vol. 2 of Handbook of Macroeconomics, chap. 0, 71-162.

Swanson, E. T. (2017): "Measuring the Effects of Federal Reserve Forward Guidance and Asset Purchases on Financial Markets," NBER Working Papers 23311, National Bureau of Economic Research, Inc. 